Corinne Sanchez

E. Dellong

J. Guerre

Frédéric Loppe

Dominique Moulis

\title{
Un établissement littoral antique, l'île Saint-Martin à Gruissan
}

\author{
(Aude) \\ In: Revue archéologique de Narbonnaise, Tome 33, 2000. pp. 309-349.
}

\section{Résumé}

Le site archéologique de l'île Saint-Martin, sur la commune de Gruissan, est considéré comme l'emplacement probable d'une installation portuaire antique. En 1999, une demande de fouille programmée avait pour objectif de reprendre le dossier : seules la chronologie et quelques structures étaient connues grâce à l'article de M. Guy (Guy 1955) et à deux sondages réalisés en 1988 et 19902. Les fouilles récentes du site de l'île Saint-Martin-le-Bas permettent d'aborder plusieurs aspects de l'histoire régionale comme le rôle de ces habitats littoraux. La présence d'un aménagement en grand appareil rend d'autant plus complexe l'interprétation des vestiges. La fouille d'un établissement rural proche de Narbonne datant de la première déduction (en - 118) et occupé jusqu'au Vle s. de notre ère, est essentielle pour la connaissance des habitats ruraux en Narbonnais.

\section{Abstract}

The archaelogical site of Saint-Martin, Gruissan, is suggested to be the emplacement of an ancient harbour. In 1999, a research excavation licence was asked in order to restudy the file: only the chronology and a few structures were known published by Mr. Guy (Guy, 1955) and live exploratory digs made in 1988 and 1990. The recent archaeological excavation of the island of SaintMartin-le-Bas allows us to deal with many aspects of the history of this area as well as the meaning of those shore settlements. The interpretation of the remains (building with large courses of stones) is very complicated. The excavation of a rural settement next to Narbo dating back from the first deductio (118 B.C.) and occupied until the 6th century A.D. is very important for the knowledge of rural settlements in Narbo area.

Citer ce document / Cite this document :

Sanchez Corinne, Dellong E., Guerre J., Loppe Frédéric, Moulis Dominique. Un établissement littoral antique, l'île Saint-Martin à Gruissan (Aude). In: Revue archéologique de Narbonnaise, Tome 33, 2000. pp. 309-349.

doi : $10.3406 /$ ran.2000.1570

http://www.persee.fr/web/revues/home/prescript/article/ran_0557-7705_2000_num_33_1_1570 


\title{
UN ÉTABLISSEMENT LITTORAL ANTIQUE, LÎLEE SAINT-MARTIN À GRUISSAN (AUDE)
}

\author{
C. SANCHEZ, E. DELLONG, J. GUERRE, F. LOPPE et D. MOULIS*
}

Résumé - Le site archéologique de lìle Saint-Martin, sur la commune de Gruissan, est considéré comme l'emplacement probable d'une installation portuaire antique. En 1999, une demande de fouille programmée avait pour objectif de reprendre le dossier : seules la chronologie et quelques structures étaient connues grâce à l'article de M. Guy (Guy 1955) et à deux sondages réalisés en 1988 et 19902. Les fouilles récentes du site de l'âle Saint-Martin-le-Bas permettent d'aborder plusieurs aspects de l'bistoire régionale comme le rôle de ces babitats littoraux. La présence d'un aménagement en grand appareil rend d'autant plus complexe l'interprétation des vestiges. La fouille d'un établissement rural proche de Narbonne datant de la première déduction (en - 118) et occupé jusqu'au VI s. de notre ère, est essentielle pour la connaissance des habitats ruraux en Narbonnais.

Mots clés : Île Saint-Martin (Gruissan); port; habitats ruraux; région de Narbonne; IIe s. avant notre ère-VI $s$.

Abstract - The archaelogical site of Saint-Martin, Gruissan, is suggested to be the emplacement of an ancient harbour. In 1999, a research excavation licence was asked in order to restudy the file: only the chronology and a few structures were known published by Mr. Guy (Guy, 1955) and live exploratory digs made in 1988 and 1990. The recent archaeological excavation of the island of Saint-Martin-le-Bas allows us to deal with many aspects of the history of this area as well as the meaning of those shore settlements. The interpretation of the remains (building with large courses of stones) is very complicated. The excavation of a rural settement next to Narbo dating back from the first deductio $\left(118\right.$ B.C.) and occupied until the $\sigma^{\text {h }}$ century A.D. is very important for the knowledge of rural settlements in Narbo area.

Keywords: Île Saint-Martin (Gruissan); harbour; rural settlement; $2^{\text {nd }}$ century B.C.-G $\sigma^{\text {th }}$ century A.D.

* C. Sanchez, doctorante à l'Université Lyon II, technicien patrimoine, association Connaître Narbonne ;

E. Dellong, doctorant à l'Université Toulouse Le Mirail ;

J. Guerre, étudiante à l'université Montpellier III, Service archéologique de Castillon-du-Gard ;

F. Loppe, animateur patrimoine, Amicale laïque de Carcassonne, étudiant en DEA à l'Université d'Aix en Provence ;

D. Moulis, attaché de conservation, ville de Narbonne.

(1) La fouille 1999 a été effectuée à la demande du groupe archéologique local (Groupe de Recherches archéologiques subaquatiques gruissanais). Nous tenons à remercier la municipalité de Gruissan pour son soutien logistique ainsi que les autres partenaires et l'équipe de fouille. Notre équipe ne pouvant intervenir sur le site, il était nécessaire de publier les premiers résultats.

(2) Fouilles réalisées par D. Paya en 1988 et Ch. Graulle en 1990 à la demande du GRASG.

\section{LE SITE DE L'ILE SAINT-MARTIN}

\section{ENTRE TERRE ET MER : SITUATION GEOGRAPHIQUE ET ENVIRONNEMENTALE DU SITE DE SAINT-MARTIN}

L'île Saint-Martin occupe une superficie de $7,5 \mathrm{~km}^{2}$ environ. Elle regarde au nord vers l'étang de Gruissan, à l'est vers les salins littoraux et la mer, au sud et à l'ouest vers l'étang de l'Ayrolle qui, avec l'étang de Bages-Sigean, garde le souvenir de l'antique golfe narbonnais. La ville de Narbonne se trouve à $12 \mathrm{~km}$ au nord-ouest, à vol d'oiseau. Lîle Saint-Martin dont l'altitude maximale est de $72 \mathrm{~m}$ constitue le prolongement et la terminaison sud du massif de la Clape. Elle se caractérise par deux grands ensembles 


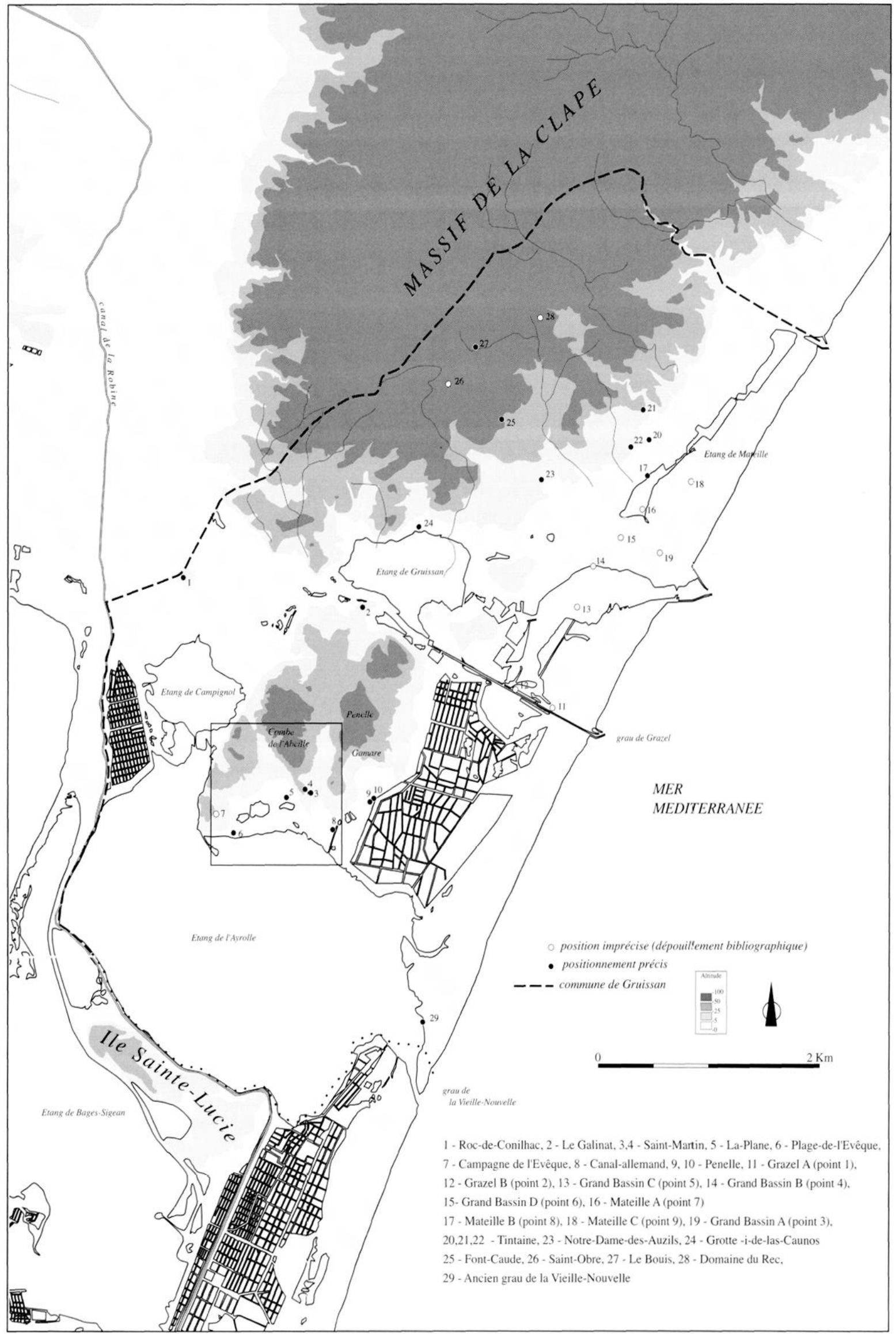

Fig. 1. Carte du littoral narbonnais, DAO E. Dellong. 


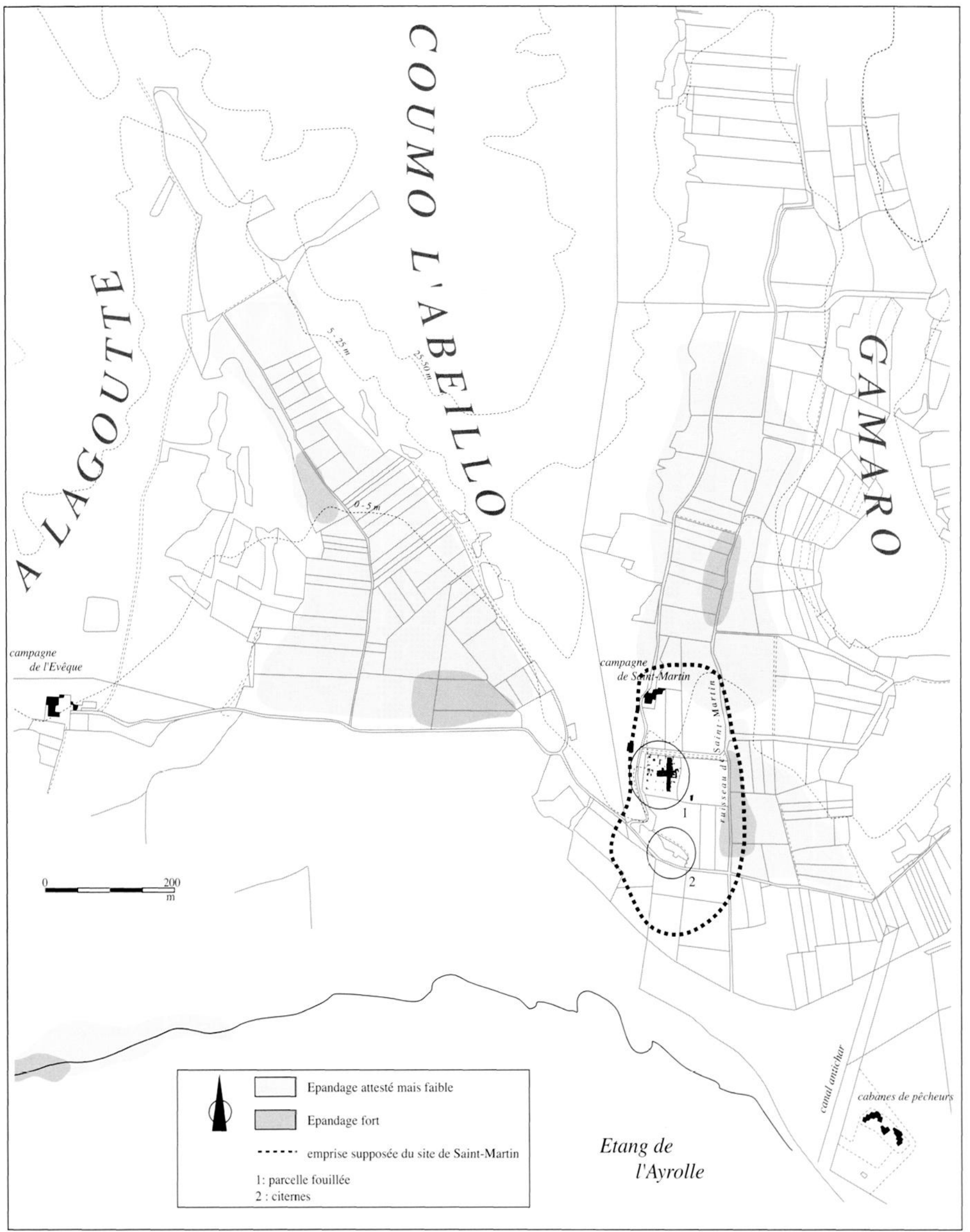

Fig. 2. La zone sud de l'île Saint-Martin, DAO E. Dellong. 
topographiques (fig. 1 et 2). À l'ouest, un affleurement rocheux, avec les massifs du Pujol, de Saint-Martin et la barre de l'Évêque, oscille du nord au sud entre 20 et $70 \mathrm{~m}$ d'altitude. L'autre relief, les Penelles, forme la limite orientale de l'île. Entre ces deux ensembles, une dépression alluviale, empruntée par le ruisseau de Saint-Martin, débouche sur une vastc criquc, en partic colmatćc, baignćc par l'ćtang de l'Ayrolle. Tournée vers le grau de la Vieille Nouvelle, bien exposée, elle a été longtemps considérée comme l'emplacement d'une probable installation portuaire antique (Guy 1955). C'est à la jonction de la combe et de la crique qu'il domine, face à l'étang, sur une pente d'orientation nord-ouest/sud-est que se trouve plus précisément le site de Saint-Martin, sujet de cet article.

Les sites littoraux de la lagune narbonnaise (fig. 3) ont souvent suscité l'intérêt des chercheurs au cours de leurs diverses tentatives de restitution du système portuaire antique de la Citć. La publication des recherches cffcctućcs sur les épaves mises au jour dans le secteur de l'étang de Mateille, à $6 \mathrm{~km}$ au nord-est de l'île, avait permis une première synthèse des différentes hypothèses (Solier et al., 1981). Le site de Saint-Martin-le-Bas, auquel se réferent Y. Solier et ses collaborateurs, est alors considéré comme une composante du port de Narbonne.

La proposition reste toujours d'actualité : s'agit-il d'un site en relation avec le système portuaire narbonnais, d'un habitat littoral ou d'un établissement lié à l'exploitation des ressources maritimes? Bien que ne révélant pas de façon catégorique la véritable vocation du site de Saint-Martin, la campagne de fouille 1999 apporte de nouveaux éléments de réflexion.

\section{HISTORIQUE DES RECHERCHES SUR LE SITE}

La connaissance des potentialités archéologiques de l'île Saint-Martin n'est guère récente puisque dès 1911, $\mathrm{H}$. Rouzaud signale des découvertes ${ }^{3}$ localisées aux environs du domaine de l'Évêque. Mais le tènement sur lequel

(3) (PV du BCAN 04-05-1908, p. LVI) : “ M. Rouzaud dépose au nom de M.U. Labeur, de Gruissan, un pied de vase gallo-romain en bronze, trouvé dans l'île de Saint-Martin, où se trouve la propriété de M. Labeur dite Lévêque. Ce griffon ailé porte encore, au dos et à la naissance des ailes, les traces de la soudure à l'étain qui fixait ce pied à la panse du vase. Celui-ci devait avoir 3 ou 4 pieds semblables. Sur l'emplacement de la propriété de l'Évêque, où l'on rencontre des poreries gallo-romaines, des médailles romaines et divers objets des premiers siècles de notre ère, devait se trouver quelque villa gallo-romaine, comme il y en avait tant aux environs de Narbonne ". se trouve le site n'est véritablement pris en compte qu'au lendemain de la Seconde Guerre Mondiale.

Ce regain d'intérêt pour cette zone de l'île est dû, en grande partie, à la publication de l'article de M. Guy consacré aux ports de Narbonne ${ }^{4}$. Reprenant les données de H. Rouzaud (Rouzaud 1915) qui le premier avait émis l'hypothèse de la division du port de Narbonne en avant-ports situés dans la lagune, M. Guy fait le point sur les témoignages archéologiques (fig. 4). Ce secteur, considéré comme indispensable à la compréhension de l'organisation portuaire de Narbonne, fut alors interprété comme un possible avant-port de Narbonne (Guy 1955, 237). L'utilisation complémentaire de la photointerprétation et de la prospection archéologique a permis de faire un certain nombre d'observations sur les traces repérées dans les parcelles avoisinant le site (fig. 4). M. Guy décrit ainsi, au nord de la fouille, un mur « en petit appareil, tout près de la maison actuelle (maison de Saint-Martin) d'une quarantaine de mètres de long, avec des dérivations perpendiculaires " et ajoute " un peu partout traînent des débris de pavement en arêtes de poisson " (Guy 1955). II est fort probable que le site s'étende vers le nord, sur le domaine actuel de Saint-Martin, non accessible car appartenant à une propriété privée. En effet, un sol en opus spicatum est encore visible en bordure du chemin, contre la limite de propriété.

L'extension du site vers le ruisseau de Saint-Martin est confirmée par l'observation, sur photographie aérienne, de structures de type circulaire " Les alignements de cercles grisâtres notés dans la vigne au sud-est de la maison de Saint-Martin correspondaient sur le terrain à des amas d'ordures (silos, fonds de cabanes) avec de la céramique des $\left.\right|^{e r}-\|\left.\right|^{e}$ s. ap. J.-C. " (Guy 1955). On y recense actuellement en surface de nombreux fragments de céramiques et de dolia mais aussi des

(4) (Guy, 1955) Ses recherches ont pu être orientées par les propos de J. Pauc qui cite en particulier un procès-verbal de visite canonique fait en 1404, par Jean Coursier, vicaire de l'archevêque de Narbonne, aux églises du Narbonnais (cité par Mgr Griffe, Les Anciens Pays de l'Aude). D'après ce texte, existait hors le lieu de Gruissan une église dédiée à Saint-Martin " qu'autrefois avais été l'église paroissielle, estant lors ruinée à cause des guerres ", (d'après Pauc, 1985, p. 155). "Il faut donc placer cette église paroissielle dans le territoire qui a précédé son nom, c'est-à-dire SaintMartin-le-Bas, dans l'ancienne île qui porte aussi ce nom. Un mur de soutènement, en dessous de la ferme Saint-Martin, contient une partie du mur de cette ancienne église. (...) l'église paroissiale de Saint-Martin de Gruissan avait une antiquité certaine. Son emplacement est de plus situé dans le voisinage d'une habitation romaine dont les murs sont encore visibles, le Château Vieux. (...) des labours, lors de plantation de vignes, ont remonté des dalles et des ossements à proximité. Église et cimetière étaient presque toujours liés à cette époque ; nous aurions donc la cerritude que l'église paroissiale était bien située dans ce lieu..." 


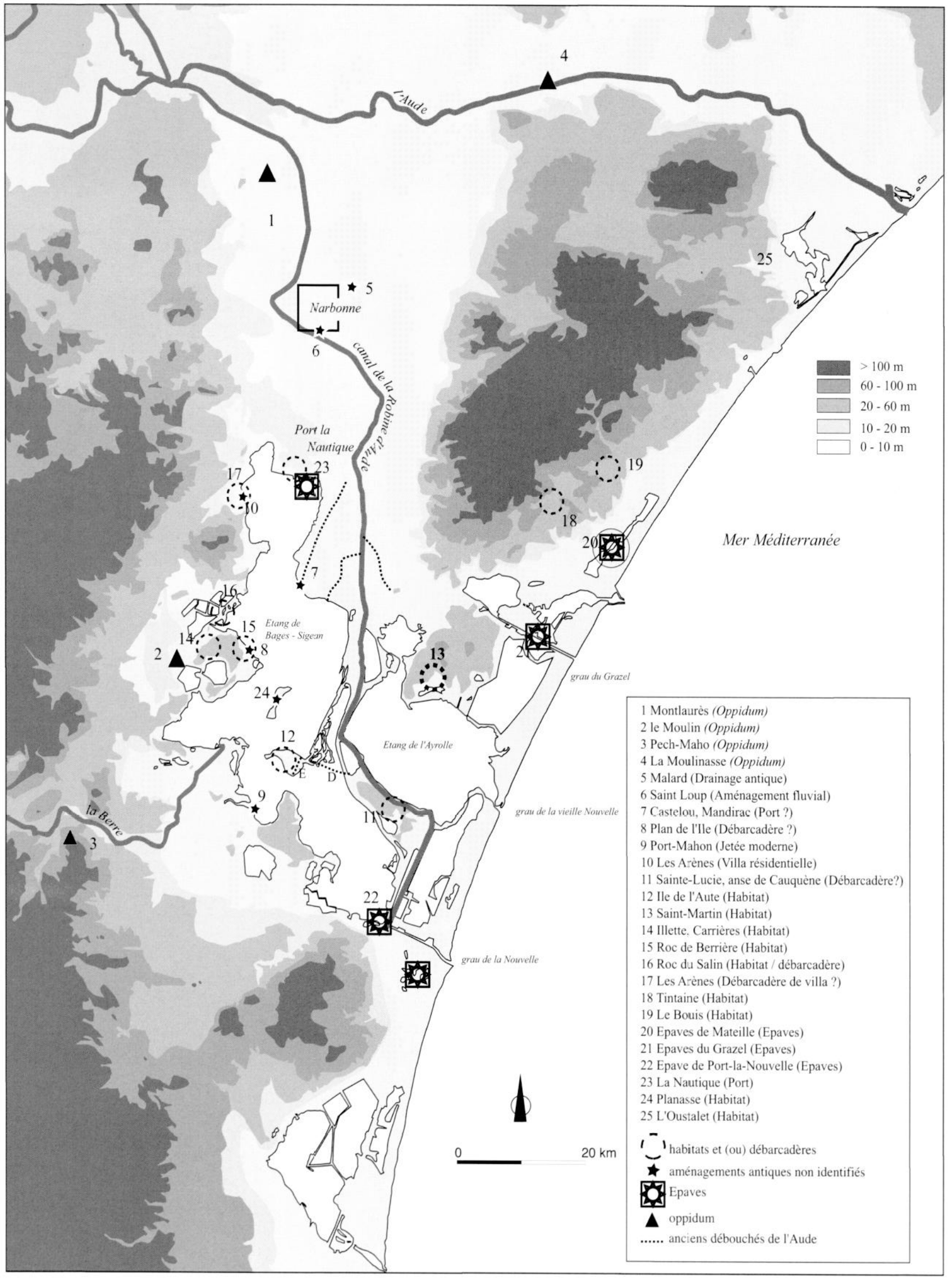

Fig. 3. Le littoral narbonnais et les principaux sites antiques, DAO E. Dellong. 


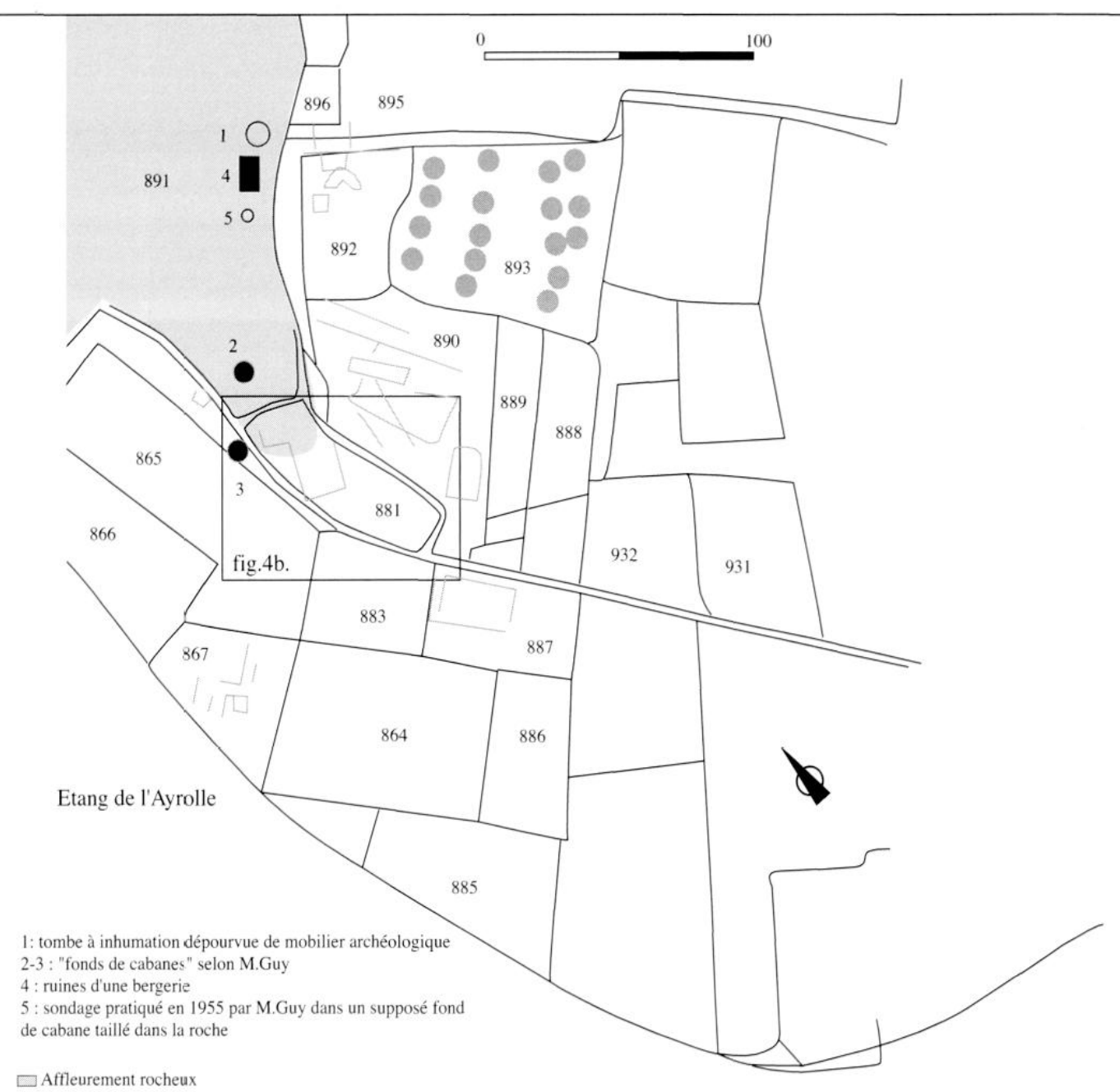

4A.

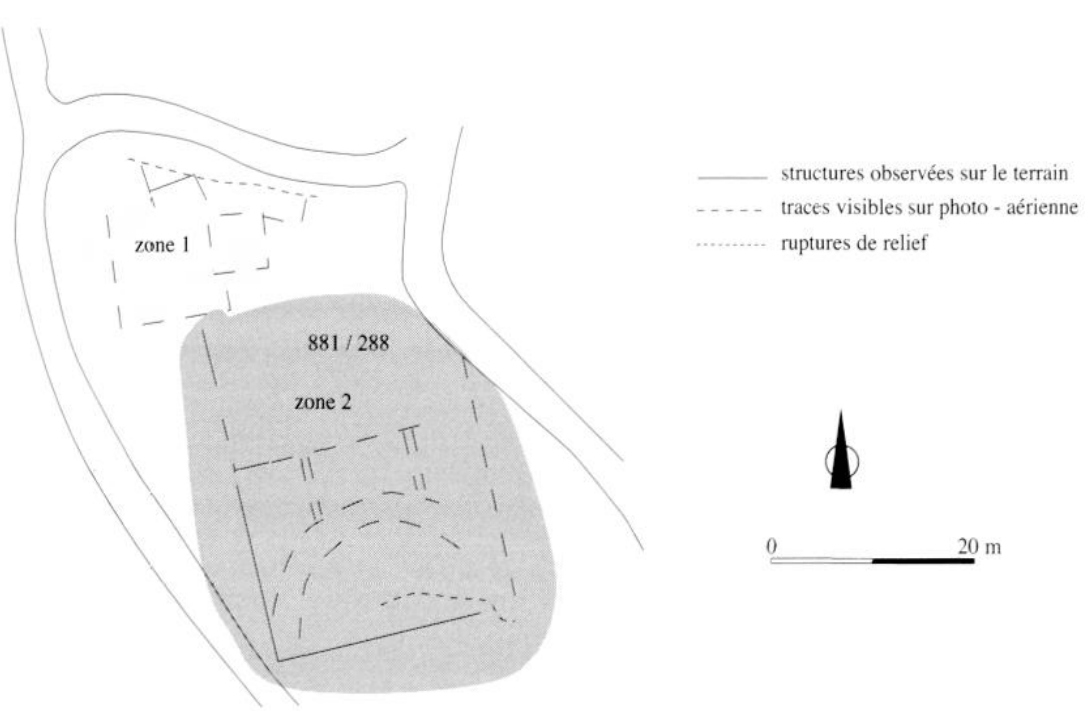

$4 \mathrm{~B}$.

Fig. 4. Plan des vestiges selon Guy 1955, DAO E. Dellong.

4A. Structures fossiles observées en photographie aérienne par M. Guy.

4B. Détails des structures fossiles observées sur le tènement du Vieux Château. 
tuiles surcuites, ainsi qu'un fragment de paroi de four dans l'angle nord-est de la parcelle. À l'ouest du site, une tombe aurait été mise au jour.

Au sud de la parcelle fouillée se trouve, pour reprendre les propos de M. Guy, une « éminence terrestre » dénommée par les habitants le « Vieux Châteaus " : " À $100 \mathrm{~m}$ plus au sud, une petite éminence porte des ruines appelées localement le Vieux Château. Les ruines comprennent un grand bâtiment de $35 \mathrm{~m} \times 20 \mathrm{~m}$ orienté nord-ouest/sud-est. Les murs sont construits en blocage et recouverts de brique pilée. Divers murs divisent le bâtiment et, quoique tout soit recouvert de décombres, on voit bien leurs traces sur la photo aérienne. » (Guy 1955). À une quarantaine de mètres, vers le sud du site, deux bassins sont effectivement toujours visibles ${ }^{6}$, la route actuelle (chemin rural $n^{\circ} 436$ ) ayant coupé l'un d'entre eux. Ce dernier, mesurant environ $10 \mathrm{~m} \times 3 \mathrm{~m}$, possède un radier de fondation très épais ${ }^{7}$. Seul un côté a été conservé pour le second bassin. Dans leur continuité, le mur orienté nordouest/sud-est est encore bien visible ainsi qu'un aménagement de la roche. D'ailleurs, à l'extrémité nord de ces vestiges, M. Guy aurait observé, creusés dans des affleurements rocheux, ce qu'il qualifie de " fonds de cabanes ».

La majeure partie du site se développe donc immédiatement au sud du domaine actuel de Saint-Martin, avec extension probable vers le ruisseau. Séparées de cet ensemble d'une quarantaine de mètres environ, les bassins ont été construits sur une butte toute proche des rives de l'étang de l'Ayrolle. Le lien entre ces structures tout comme leur chronologie restent à établir. En effet, à la lecture des observations faites par M. Guy sur la parcelle séparant les deux ensembles, on aurait pu croire à une forte densité de vestiges. Cependant, suite à un entretien avec le propriétaire, qui signalait la présence de " dalles de couvertures de tombes", des sondages mécaniques jusqu'au substrat nature ${ }^{8}$ y ont été effectués de manière systématique par le groupe de recherches gruissanais et n'ont révélé aucun artefact.

M. Guy signalait aussi des aspects inédits qu'il convenait d'approfondir : il s'agit dans les parcelles en contrebas du domaine

(5) " le village actuel (de Gruissan) n'a livré aucune trace d'une présence romaine, en revanche, l'île Saint-Martin comporte plusieurs vestiges de constructions importantes comme celui du Château Vieux " (Pauc, 1985, p. 141).

(6) L'ensemble des vestiges des parcelles D4-881et 882 correspond aux descriptions du tènement du Vieux Château faites par M. Guy (Guy 1955).

(7) Cf. plan des bassins fig. 33.

(8) Un substrat naturel composé de galets similaires à ceux constituant la plage actuelle ? (fig. 4 et 5), de restes de fondations 9 , ainsi que des vestiges " de maison rasée ${ }^{10}$.

C'est en 1986 que des travaux agricoles mettent à nouveau au jour sur la parcelle D4-892 de nombreux artefacts. Un échange de parcelles est alors réalisé entre le propriétaire et la municipalité.

A la demande du groupe archéologique local, deux campagnes de sondages ont été entreprises ${ }^{11}$. En 1988, ces investigations ont lieu uniquement dans la partie orientale du site, sur une surface approximative de $50 \mathrm{~m}^{2}$, et permettent le dégagement d'une pièce constituée de murs relativement bien appareillés mais qui suggèrent un certain nombre de reprises. Une chronologie relative est établie, soulignant que le mur occidental, plus récent, supportait une canalisation de tegulae.

En 1990, la poursuite de ce sondage permet d'atteindre le niveau de fondation des murs de cette pièce, tandis qu'un sol en terre apparaît au sud. Des sondages ponctuels sont effectués pour mieux saisir l'emprise de ces structures et, au cours d'un d'entre eux (fig. 6), des blocs en grand appareil sont mis en évidence. Cette découverte témoigne ainsi de l'existence d'un édifice important qui, à l'évidence, constitue un point fort dans la compréhension de la morphologie et de la fonction du site. Le mobilier prélevé au cours de ces deux interventions permit d'avoir une première approche de la chronologie, comprise entre le $\mathrm{I}^{\text {er }} \mathrm{s}$. av. notre ère et le $\mathrm{V}^{\mathrm{e}} \mathrm{s}$. de notre ère

En 1999, les possibilités d'intervention sur Saint-Martin dépendaient de l'accès aux terrains. En effet, seule la partie fouillée ${ }^{12}$ constitue une " réserve " archéologique tandis que les autres parcelles appartiennent à des particuliers.

\section{LA CAMPAGNE DE FOUILLE 1999}

Cette année de fouille programmée devait permettre d'établir un état de la documentation existante et de réévaluer

(9) “ ̀̀ $200 \mathrm{~m}$ à l'est des ruines du Vieux Château, reste d'une maison où l'on a trouvé de la céramique rouge très tardive et des débris d'amphores. Elle a été découverte par des tranchées de fortifications allemandes. " (Guy 1955).

(10) " au nord de l'actuelle maison de Saint-Martin les vestiges se font plus rares. Mais jusqu'à $200 \mathrm{~m}$ environ où l'on voit dans une petite combe des vestiges de maisons rasées, on trouve de nombreux débris de meules et de tuile. " (Guy 1955, p. 228).

(11) Voir note 3.

(12) Le terrain clôturé représente une superficie de $3300 \mathrm{~m}^{2}$ pour une stratigraphie pouvant atteindre $1,70 \mathrm{~m}$ d'épaisseur. 


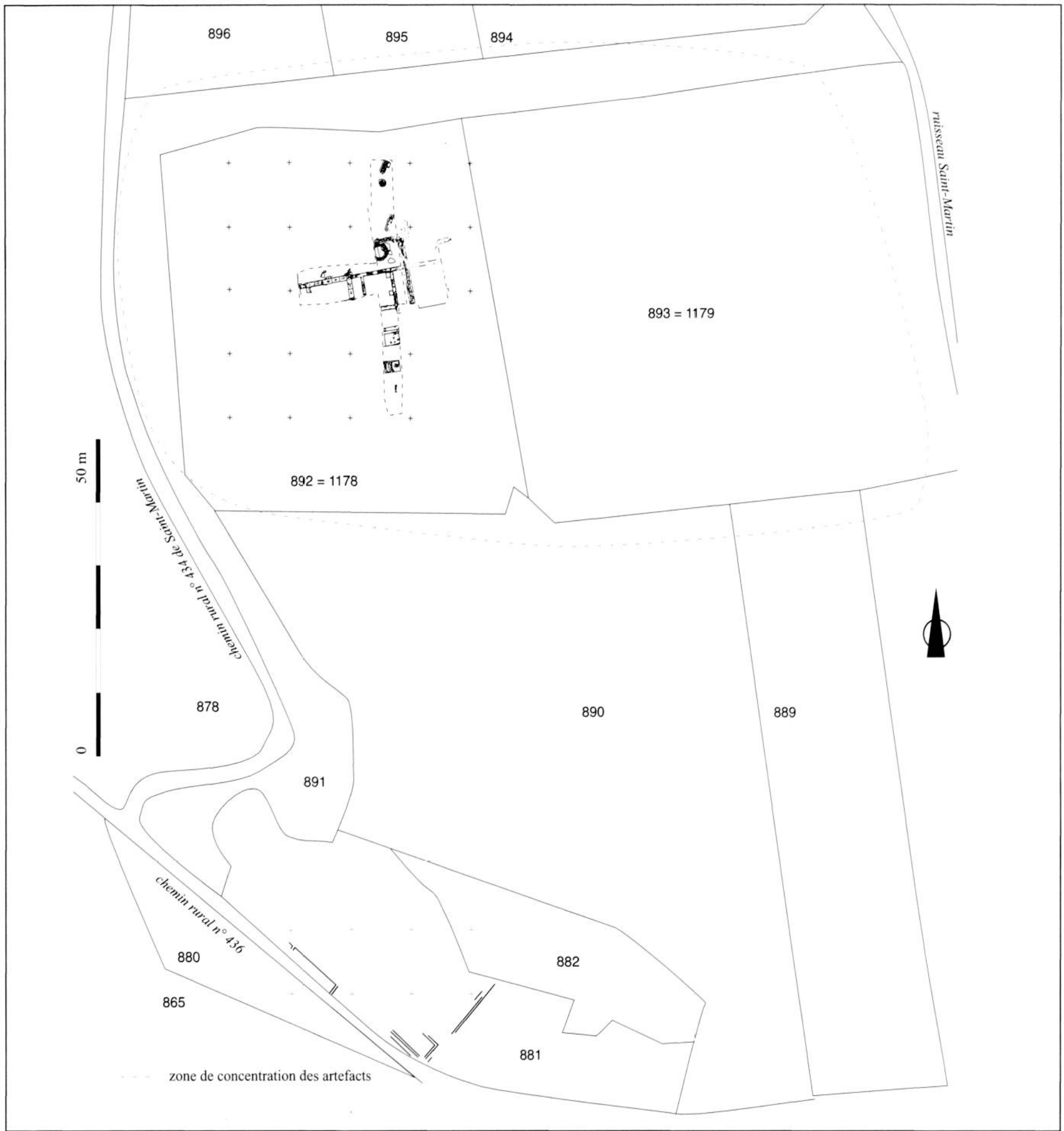

Fig. 5. Localisation cadastrale du site, $D A O E$. Dellong, $C$. Sanchez.

les potentialités archéologiques du site. Le relevé des bassins ou citernes visibles a pu être réalisé sur la parcelle 881 (cf. fig. 33).

La reprise de sondages existants sur la parcelle 892 (fig. 6 et 7) s'est concrétisée par le nettoyage de l'ancien sondage 1, afin de redresser la coupe de la berme sud et d'effectuer quelques observations. L'élargissement du sondage 2 (voir plan général pour l'état au moment de l'intervention) a apporté des résultats importants pour la compréhension du site. Une tranchée nord/sud et la jonction entre les sondages 1 et 2 devaient à la fois les intégrer et 


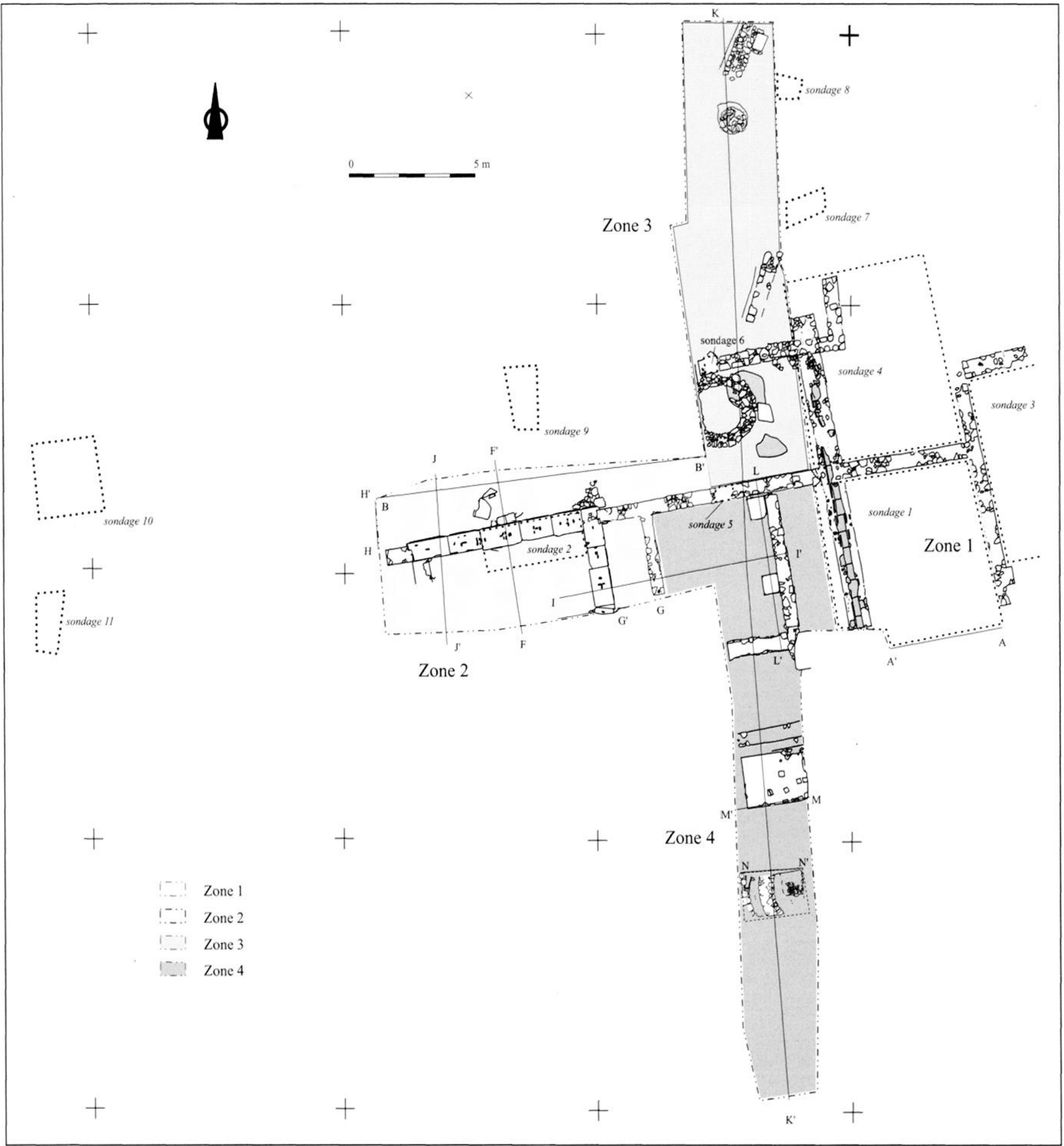

Fig. 6. Plan général des vestiges, localisation des coupes présentées et des sondages GRASG, DAO E. Dellong, C. Sanchez.

permettre d'avoir une nouvelle approche de l'organisation du site.

Les principaux résultats de la campagne 1999 ont permis la mise en évidence d'un ensemble de structures bâties dont la fonction reste à préciser et qui prennent appui sur une construction en grand appareil, d'un hypocauste, d'une démolition exceptionnellement bien conservée d'un mur à pans de bois de la fin de l'Antiquité, enfin, des traces d'une réoccupation médiévale. La rareté des niveaux de circulation en relation avec ces murs rend d'autant plus nécessaires les descriptions afin de proposer une chronologie relative. 


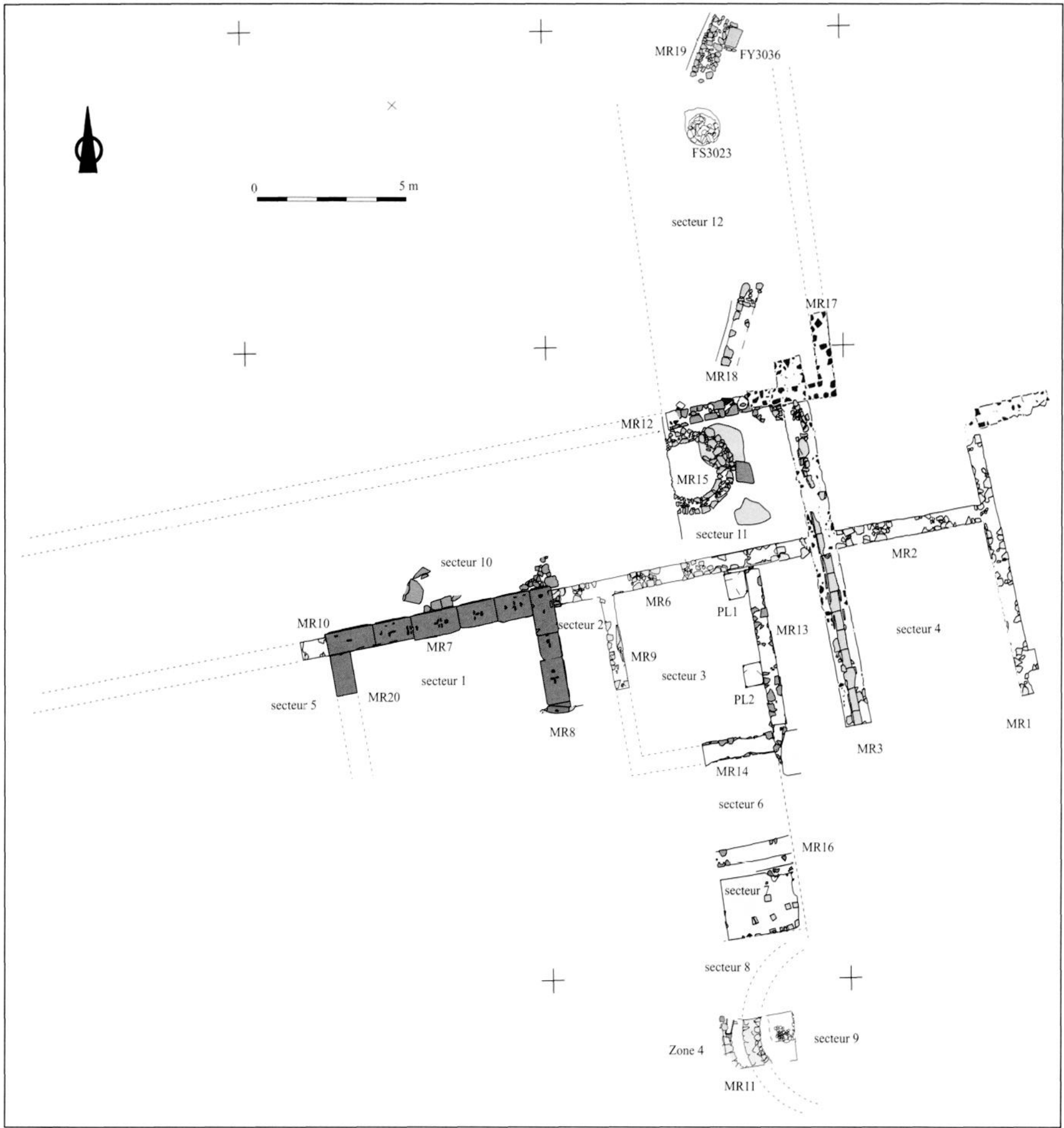

Fig. 7. Plan général des vestiges et numérotation des secteurs, DAO E. Dellong, C. Sanchez.

\section{UN AMENAGEMENT EN GRAND APPAREIL ${ }^{13}$}

La zone 2 se définit par un aménagement de trois murs en grand appareil (MR 7, 8, et 20) constituant un côté d'une structure non définie (fig. 7). À ce dispositif sont accolés

(13) Nous tenons à remercier J.-C. Bessac pour les informations aimablement communiquées lors d'une visite sur le site. d'autres murs bâtis en petit appareil régulier (MR 6, 9, et 10) qui délimitent des espaces respectant la même orientation nord/sud. Au nord, le mur en grand appareil (MR 7) est prolongé, à l'est et à l'ouest, par les murs 6 et 10 , alors qu'à l'est, le mur 9 est parallèle au mur en grand appareil (MR 8) dont il n'est séparé que par un espace étroit (secteur 2). En 1990, le dégagement du mur 7 a provoqué la 
destruction des couches stratigraphiques situées à l'ouest, nous privant des relations entre ce mur et les niveaux archéologiques qui apparaissent seulement dans la berme.

\section{Contexte stratigraphique}

Composées d'éclats de roche, les US 2027 et 2023 (fig. 8) correspondent vraisemblablement aux rejets de taille provenant de la mise en place de cet aménagement. L'US 2027 (fig. 9, $10)$, au nord du mur 7 , se caractérise par sa structure qui présente une grande quantité de fragments de roche calcaire. Au sud du mur 7, c'est-à-dire à l'intérieur de la structure en grand appareil, ce niveau de calcaire " décomposé » se retrouve sous une épaisse couche de démolition (2028, fig. 11 et 12) dont le comblement est constitué par une forte concentration de mortier de chaux, de mortier hydraulique (fragments de bourrelet d'étanchéité), de blocs parfois importants, ainsi que de fragments de tegulae et d'imbrices. Le niveau à l'intérieur de la construction (2028) n'a été observé que sur un espace trop restreint pour livrer une datation sûre. En effet, seuls ont été identifiés des fragments d'amphores de Bétique ou de Tarraconaise prises dans le mortier ainsi que des fragments de tegulae. On peut cependant penser, au vu de sa situation à l'intérieur de l'aménagement en grand appareil, sous le niveau de la première assise, qu'il correspond à un comblement antérieur à la mise en place d'un sol.

Le matériel provenant de l'US 2027 comporte essentiellement des fragments d'amphores italiques, bétiques et tarraconaises, ainsi que des sigillées italiques et des campaniennes nous situant dans la seconde moitié du ${ }^{\text {er }} s$. av. notre ère. Afin d'obtenir une première approche des niveaux au contact du mur 7 , seule une fenêtre de $1,10 \mathrm{~m} \mathrm{x} 1 \mathrm{~m}$ a été ouverte à l'ouest de la zone 2 (fig. 8,13 ). Il semblerait que des sols (2032 et 2030) séparés par un remblai argileux (2031) se succèdent. Cette fenêtre a permis de connaître l'épaisseur de l'US 2029 (environ 0,50 m), composée d'argile mêlée à de la cendre qui pourrait aussi constituer un remblai dont la partie supérieure a servi de sol. Elle contient comme éléments datables : un fragment de campanienne $B$, un bord de présigillée, des fragments d'amphores italiques, bétiques et tarraconnaises. Ces témoins situeraient donc l'occupation vers le milieu du I Ir $s$. av. notre ère

\section{Quelques dimensions}

Les murs 7, 8, 20 (fig. 14 à 17) semblent faire partie des soubassements d'une construction homogène (secteur 1) encore en grande partie enfouie au sud, sous le sol actuel.
En élévation, il n'en subsiste qu'une seule assise en grand appareil, faite de blocs de longueurs variables, soigneusement taillés dans un calcaire coquillier à grains fins.

- Le mur 7 est le seul qui ait été dégagé dans son entier. II mesure 7,62 $\mathrm{m}$ de long et se compose de cinq parpaings reposant sur leur long côté le plus large (panneresses) plus un autre vu dans son épaisseur et appartenant au mur en retour d'angle. D'est en ouest les 5 blocs ont les dimensions suivantes:

Bloc $1:(L \times \mid \times H): 1,17 \mathrm{~m} \times 0,82 \mathrm{~m} \times 0,43 \mathrm{~m}$

Bloc $2: 1,28 \mathrm{~m} \times 0,76 \mathrm{~m} \times 0,41 \mathrm{~m}$

Bloc $3: 1,56 \mathrm{~m} \times 0,80 \mathrm{~m} \times 0,42 \mathrm{~m}$

Bloc $4: 1,28 \mathrm{~m} \times 0,78 \mathrm{~m} \times 0,35 \mathrm{~m}$

Bloc $5: 1,59 \mathrm{~m} \times 0,71 \mathrm{~m} \times 0,42 \mathrm{~m}$

- Mur 8 : trois parpaings et le départ d'un quatrième, malheureusement délité, ont été dégagés. Du sud vers le nord, leurs dimensions sont les suivantes:

Bloc $6:(L \times \mid \times H): 1,43 \mathrm{~m} \times 0,77 \mathrm{~m} \times 0,39 \mathrm{~m}$

Bloc $7: 0,78 \mathrm{~m} \times 0,71 \mathrm{~m} \times 0,46 \mathrm{~m}$

Bloc $8: 1,46 \mathrm{~m} \times 0,75 \mathrm{~m} \times 0,50 \mathrm{~m}$

- Mur 20 : Le premier parpaing et l'amorce du second ont pu être observés. Ce mur a été à peine dégagé parce qu'il se trouve au seul endroit non perturbé du secteur 1 , susceptible de nous apporter des éclaircissements sur les derniers réaménagements dont il a pu faire l'objet. La mise au jour d'un niveau d'adobes, posé directement sur le lit d'attente de l'assise en grand appareil, plaide en faveur d'un changement radical d'affectation de cette structure.

Bloc $9:(L \times \mid \times H): 1,45 m \times 0,73 m \times ?$

À la lecture de ces chiffres, on constate, à l'inverse des longueurs quelque peu disparates des pierres, que leur épaisseur et leur hauteur s'approchent d'un module commun.

\section{Description des vestiges en place}

Les trois murs en retour d'angle ( $M R 8,7$ et 20), réduits à une assise unique, sont fondés sur un radier artificiel épais de $0,60 \mathrm{~m}$, composé de moellons en calcaire, bruts de carrière ou à peine équarris, liés par un mortier de chaux contenant quelques inclusions de coquillages. Cette fondation soutient des parpaings de hauteurs légèrement différentes, de telle manière que leur lit d'attente soit rigoureusement au même niveau. Cette première assise devait, par conséquent, et d'autres indices nous le prouvent, accueillir au moins une assise supplémentaire qui a complètement 


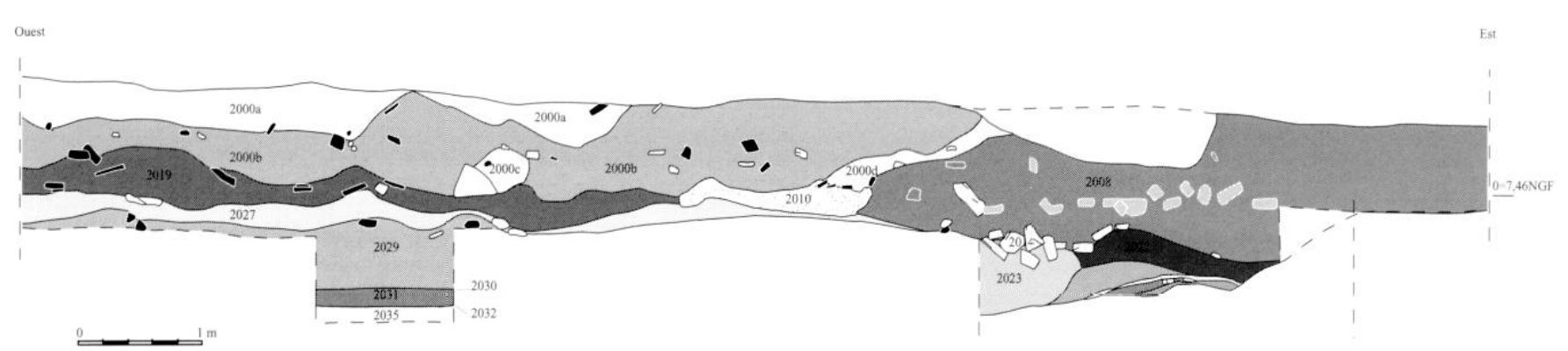

Fig. 8. Coupe nord zone 2, secteur $10\left(B^{\prime}\right), D A O$ E. Dellong, C. Sanchez.

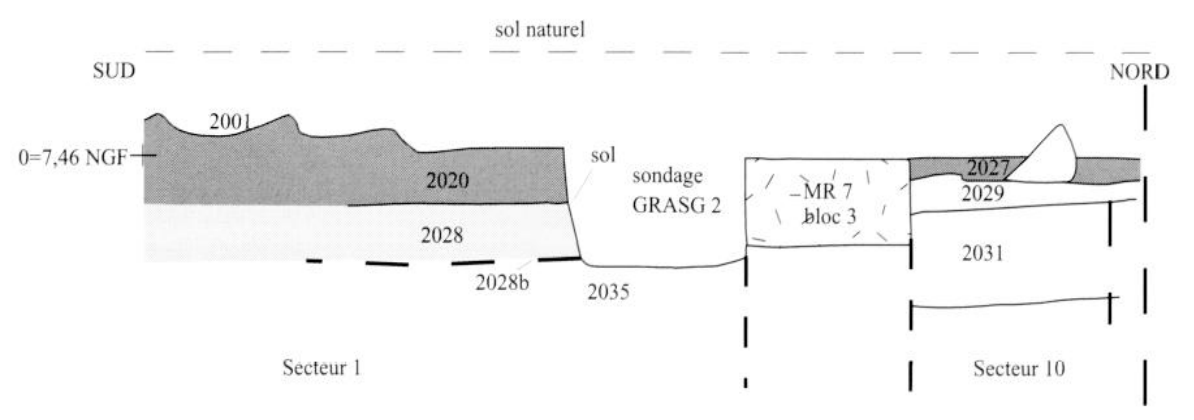

Fig. 9. Coupe zone 2, secteurs 1 et $10\left(F^{\prime}\right), D A O$ E. Dellong, C. Sanchez.

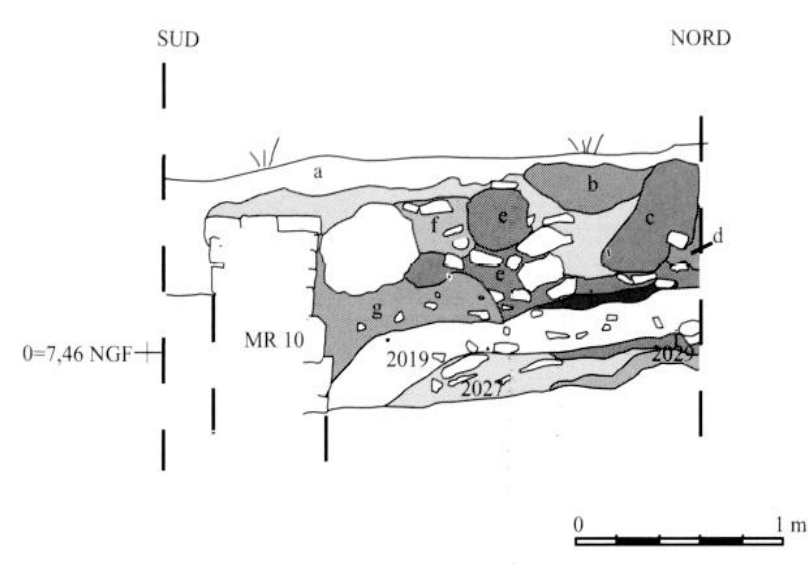

Fig. 10. Coupe sud zone 2, secteur 10(HH'),

$D A O$ E. Dellong, C. Sanchez.

disparu. Il en subsiste sans doute les trois fragments déplacés, visibles au nord du mur 7 , et il est possible que le pilier PL2 du secteur 3 représente le réemploi d'un de ces parpaings originels.

La seule assise subsistante est constituée d'un alignement de blocs disposés dans le sens de la longueur et occupant toute l'épaisseur du mur.

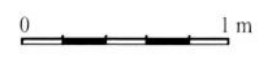

Chaque pierre a donc ses deux parements visibles sur l'une et l'autre face du mur, ce qui en fait des parpaings.

Leur face de parement possède un bossage rustique aux bordures très irrégulières, d'épaisseur variable $(1$ à $4 \mathrm{~cm})$, avec en surface de larges sillons obliques produits par une smille, une broche ou un poinçon (tranchant de 8-9 cm). Ces bossages représentent en réalité l'état à peine travaillé du bloc issu de la carrière. Ils sont matérialisés par la présence périphérique d'une ciselure d'encadrement d'une largeur pouvant atteindre $14 \mathrm{~cm}$, réalisée à l'aide de ciseaux plus fins ; elle est destinée à affiner les arêtes des blocs et à parfaire ainsi leur positionnement frontal.

- Les faces de parement ne jouaient à l'évidence aucun rôle décoratif et cette première assise devait être cachée à la vue, enterrée directement sous le niveau de circulation, ou bien affleurante. Les faces arrières sont tout juste dégrossies et n'offrent entre elles aucune régularité linéaire. Cette absence de ravalement indique que les murs en grand appareil devaient soutenir, à l'intérieur, un remblai les dissimulant à la vue.

- Les lits d'attente sont parfaitement ravalés au ciseau ou à la gradine et offrent une surface plane et horizontale. Un soin identique a dû être apporté aux faces de joint, si l'on considère la précision de la juxtaposition des blocs entre eux. 


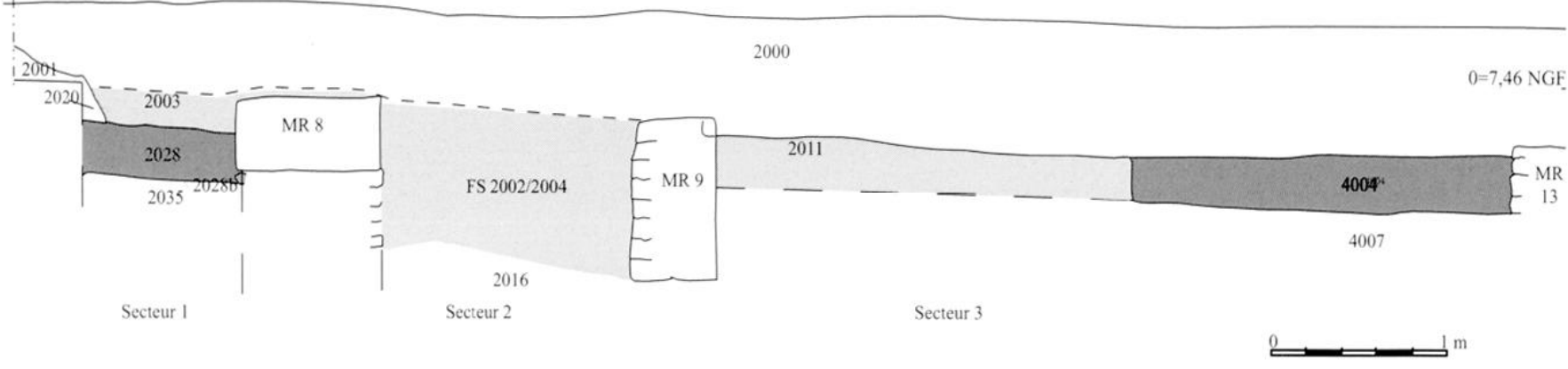

Fig. 11. Coupe zones 2/4, secteurs 1 à $3\left(I I^{\prime}\right)$, DAO E. Dellong, C. Sanchez.

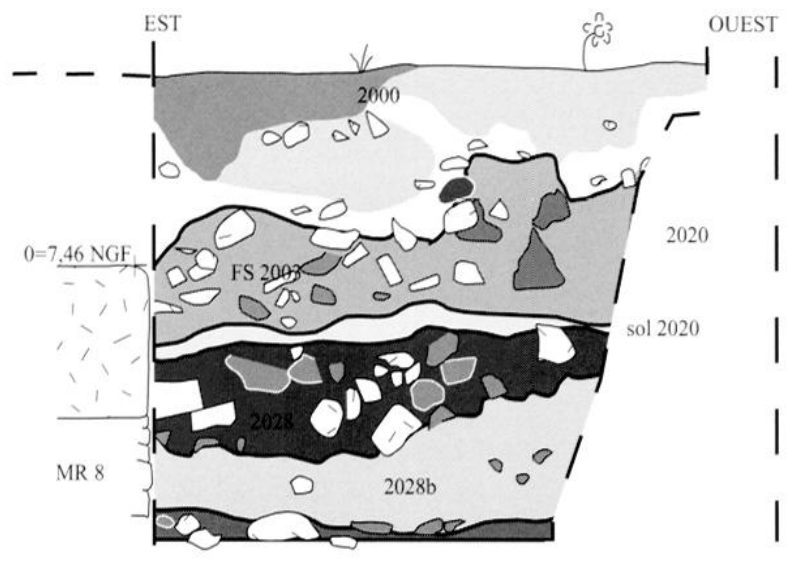

Fig. 12. Coupe zone 2, berme sud zone 2(GG'), secteurl, $D A O E$. Dellong, C. Sanchez.

- Plusieurs traces intéressantes sont visibles à la surface des lits d'attente : de fines incisions perpendiculaires aux parements des murs et régulièrement espacées, de la longueur d'un parpaing, sont des repères en vue du positionnement définitif des blocs alternés de l'assise supérieure. D'autres sillons, parallèles, cette fois-ci, à la face de parement et distants de l'arête d'une dizaine de centimètres semblent apporter la preuve que les parpaings de l'assise supérieure étaient disposés en retrait et qu'ils étaient donc de moindre épaisseur. Cette assise en retrait pouvait être la première, affleurant à la surface du sol de circulation antique.

Deux sortes de cavités sont réparties sur les lits d'attente : en premier lieu, des encoches de faible profondeur de forme demi-ovale, allant le plus souvent par paire ; elles recevaient l'extrémité des barres de fer, à l'aide desquelles on faisait pivoter les blocs de l'assise supérieure jusqu'à leur emplacement définitif, matérialisé par les incisions signalées ci-dessus. II est d'ailleurs à remarquer que ces encoches se trouvent au voisinage des incisions et montrent clairement l'ordre de pose des blocs, des extrémités vers le centre des murs. En second lieu, au centre de chaque parpaing, une encoche rectangulaire aux parois verticales, profonde de quelques centimètres, permettait assurément le levage des blocs, à l'aide de pinces spéciales connues sous le nom de louves auto-serrantes.

En revanche, on remarque l'absence totale de toute trace de liaison des blocs entre eux, par le moyen de crampons ou de doubles-queues d'aronde. Les parpaings sont simplement et soigneusement juxtaposés à joints vifs.

Toutes ces traces de mises en œuvre offrent des pistes de datation. En effet, les incisions de repérage, encoches, cavités verticales et centrales de levage, sont bien attestées dans le monde romain, en particulier à l'époque augustéenne. À Rome, la base du temple de Mars Ultor ou divers vestiges du Forum d'Auguste, comme la base de l'arc de Drusus, les montrent, employées tour à tour et de la même façon. Les blocs de parement du pont de Nona sur la via Praenestina conservent des bossages rustiques bruts de carrière et des traces de doubles-encoches pour l'ajustement (Lugli 1957). Ces indices, associés au contexte stratigraphique, désigneraient plutôt une période de construction située dans la deuxième moitié du I $^{\text {er }} s$. av. notre ère.

En résumé nous sommes certains que cet aménagement en grand appareil possédait au moins trois côtés (seul le côté nord long de 7,60 m étant entièrement dégagé), qu'il avait au moins deux assises en grand appareil et qu'il contenait, à l'intérieur, un remblai ou un terrassement dont la hauteur ne nous est pas connue.

De plus, les murs 6 et 10, en petit appareil d'assez bonne facture, le prolongent et l'encadrent symétriquement tout en respectant et développant son orientation. Ils 


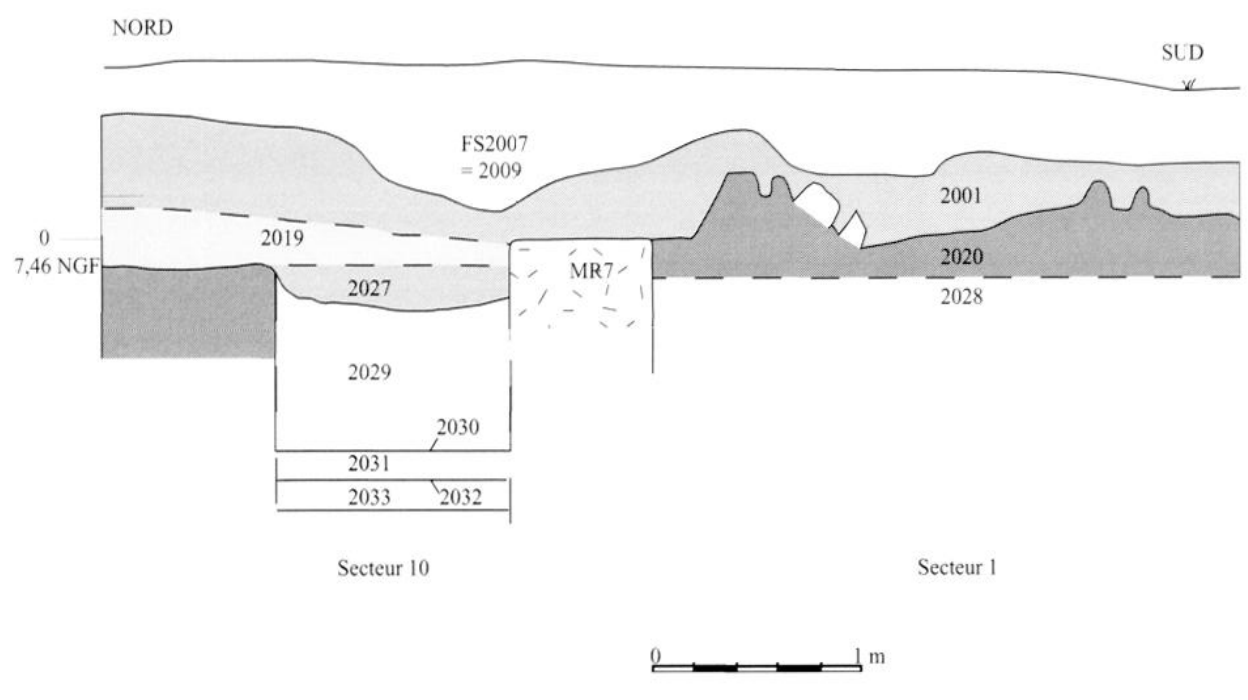

Fig. 13. Coupe zone 2 secteurs 1 et $10(\mathrm{JJ})$,

$D A O E$. Dellong, C. Sanchez.

s'appuient et empiètent légèrement (d'une dizaine de centimètres) sur les murs 8 et 20 , ce qui prouve l'antériorité de l'aménagement en grand appareil. Cela démontre, une fois de plus, l'existence d'une assise supérieure au-dessus de celle qui demeure aujourd'hui.

Ces constatations nous amènent à penser que les structures en grand appareil auraient pu constituer une terrasse, un podium, pour une construction d'une certaine importance, valorisée par sa position surélevée, face à l'étang de l'Ayrolle, le long d'un axe de symétrie nord/sud et au cœur d'un dispositif architectural plus vaste.

Cette proposition doit être rapprochée des conditions habituelles qui commandent le recours au grand appareil. Dans les provinces de l'Occident romain, à cause de la technicité qu'il exige et des difficultés de sa mise en œuvre, on le réserve à des entreprises d'envergure intéressant l'architecture publique monumentale ou l'architecture privée à but honorifique ou funéraire. Dans la région narbonnaise, les quelques exemples connus de l'utilisation du grand appareil, appartiennent à ces catégories de monuments :

- chaînages verticaux, avec des pierres de module proche de celle de Saint-Martin et présentant parfois un bossage semblable dans les galeries souterraines de l'horreum de Narbonne ; différents indices font remonter leur construction aux années 30 avant notre ère (Solier 1973);

- aménagement portuaire récemment découvert à Port-laNautique (Falguera 1999);

- grand appareil de marbre entrant dans la construction du temple capitolin (Perret 1956) ;
- éléments d'enclos funéraires ou de mausolées conservés au musée lapidaire de Narbonne...

On le voit, tous ces ensembles appartiennent au milieu urbain et Saint-Martin reste, à ce titre, une exception. Même le complexe imposant de Fount de Rome, près de l'Oustalet sur la commune de Fleury d'Aude, ne possède pas de dispositif en grand appareil (Fabre 1967)

\section{Les niveaux de démolition}

A l'extérieur de la construction en grand appareil (fig. 8 et 10), d'importants fragments de blocs posés sur le niveau de circulation témoignent d'une phase d'abandon et de récupération difficile à dater car proche de la surface et donc perturbée par les labours. L'US 2019 ressemble par sa composition au niveau sur lequel elle repose (2027) ; elle est cependant bien moins compacte, avec de très nombreux fragments d'éclats de calcaire jaune. Nous ne pouvons, pour l'instant, avancer de datation pour cette couche qui correspond à la phase de démolition de la construction (antiquité tardive ?).

L'US 2008 est un niveau au contact du mur 7. Cette US, composée d'inclusions d'argile de couleurs différentes, est assez compacte. Des fragments d'adobes sont déterminables. Nous serions donc en présence d'une phase de démolition qui se retrouve sur l'ensemble de la zone 3 et une partie des zones 2 et 4. Malgré un nombre de tessons relativement réduit, on peut supposer que la datation de cette US se situe à la fin du jer $\mathrm{s}$. av. notre ère ou au début du jer siècle de notre ère. L'absence de sigillées sud-gauloises laisse penser que cette destruction se situe entre les années - 10/+30. La présence de sigillées italiques, de campanienne $B$, de sombrero de copa et d'amphores 


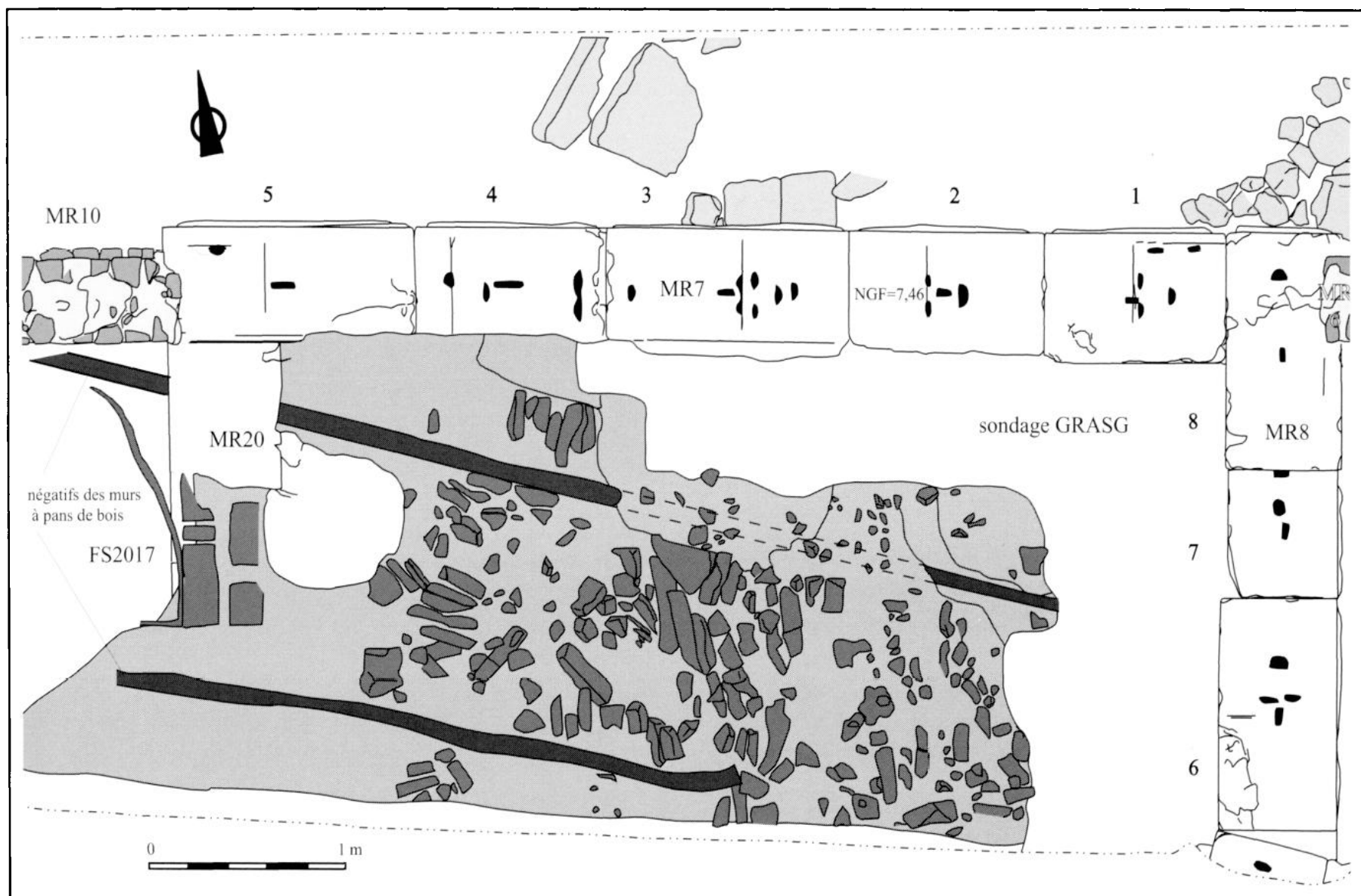

Fig. 14. Relevé en plan du mur en grand appareil et de la démolition du mur à pans de bois, DAO E. Dellong, C. Sanchez.

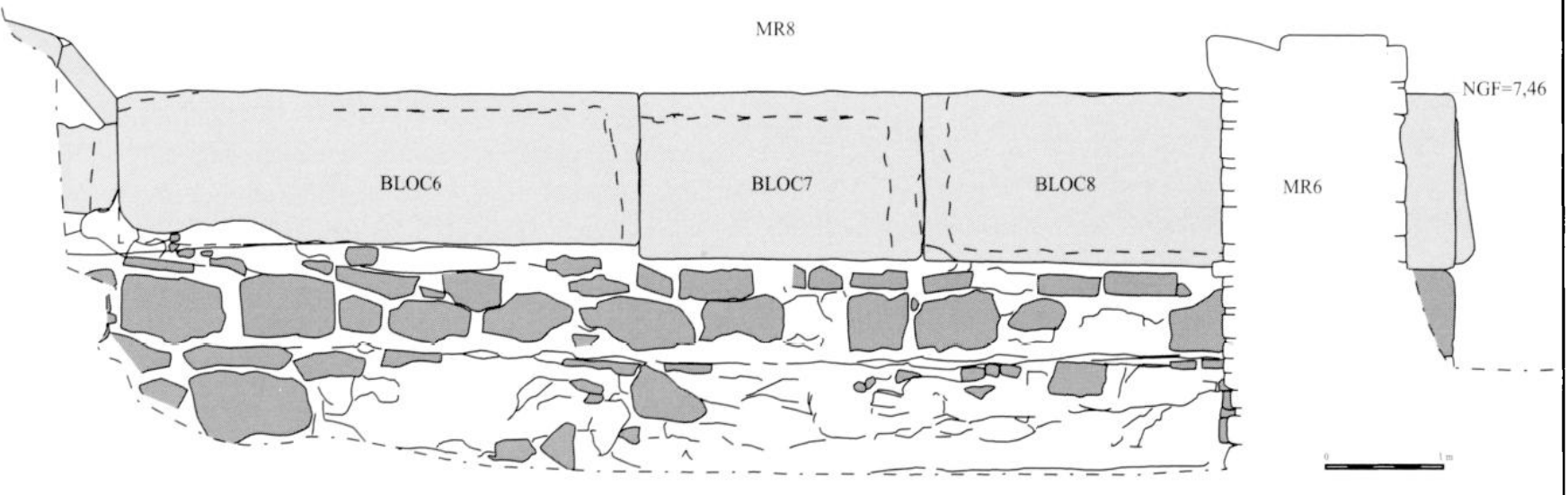

Fig. 15. Relevé du parement est du mur 8, DAO E. Dellong, C. Sanchez. 
italiques indique la période de mise en place des bâtiments. Un fragment d'amphore italique a conservé une marque peinte où I'on peut encore observer un $A$ et quatre barres parallèles pouvant correspondre à une mention de contenance.

II semblerait donc qu'une phase de démolition de ces structures encore mal définies ait lieu peu de temps après la construction en grand appareil. Au vu du matériel, les niveaux de destruction (2008) datés de la période augustéenne peuvent appartenir à un abandon qui précède la mise en place des " annexes".

En résumé, des niveaux de fondation ont été retrouvés (2027 pour l'extérieur et 2035 pour l'intérieur), pour la construction en grand appareil au cours de la seconde moitié du $\mathrm{I}^{\text {er }} \mathrm{s}$. av. notre ère. Autour du changement d'ère, des structures en matériaux légers qui lui étaient accolées sont abandonnées (2008). C'est vraisemblablement à cette période que sont construites les " annexes " en dur qui prennent appui contre l'assise en grand appareil (MR 1, 6, 9 et 10).

La construction est épierrée jusqu'à sa première assise de fondation à un moment indéterminé. Après une période d'abandon, des aménagements en matériaux légers vont alors prendre place sur les fondations de l'ancienne construction.

\section{DES AMÉNAGEMENTS PÉRIPHÉRIQUES}

Murs en moellons bien équarris venant s'appuyer contre la structure en grand appareil : MR 6 et 10

C'est contre l'angle nord-ouest de cette construction qu'est venu se plaquer postérieurement le mur 10 qui s'appuie sur le tableau supérieur du bloc 5 , sur une largeur de $0,10 \mathrm{~m}$. D'une hauteur moyenne conservée de $0,80 \mathrm{~m}$ pour une épaisseur de $0,52 \mathrm{~m}$, le mur 10 est grossièrement orienté ouest/est, dans le prolongement du mur 7. Le parement nord possède à sa base une petite semelle (ou solin de fondation) de $0,40 \mathrm{~m}$ de haut (trois assises) composée de blocs de calcaire jaune ou coquillier ( $L \times H$ moy. : 0,22 $\mathrm{m} \times 0,18 \mathrm{~m}$ ) dont l'arase supérieure forme un léger ressaut de $5 \mathrm{~cm}$. Ces éléments sont liés par un mortier coquillier à forte granulométrie. Cette semelle ne semble pourtant pas constituer à proprement parler la fondation du mur qui doit encore se trouver plus bas, sous le remblai non dégagé par le sondage. Au-dessus, la partie haute du mur se compose de moellons calcaires équarris et bien assisés ( $\mathrm{L} \times \mathrm{H}$ moy. : $0,25 \mathrm{~m} \times 0,15 \mathrm{~m}$ ) solidarisés par un mortier plein sur joints (joints gras : épaisseur 2 à $3 \mathrm{~cm}$ ).

Le parement sud du mur 10 est encore en grande partie sous le remblai puisqu'il émerge à peine de $0,60 \mathrm{~m}$ à l'heure actuelle : il se compose de moellons en calcaire jaune ( $\mathrm{L} \times \mathrm{H}$ moy. : 0,22 m $x 0,09 \mathrm{~m}$ ), très bien appareillés. Ils sont liés par un mortier coquillier (à la granulométrie plus faible que celle de la base du parement nord) qui emplit pleinement les joints moyens (ép. : 1 à $2 \mathrm{~cm}$ ).

Le mur 6 (fig. 18) s'appuie pour sa part contre l'angle nordest de la construction en grand appareil en débordant sur le tableau supérieur du bloc 8 de $0,12 \mathrm{~m}$. D'une épaisseur de $0,53 \mathrm{~m}$, ce mur est également situé dans l'axe du mur 7 dont il respecte l'orientation ouest/est (longueur dégagée : $8 \mathrm{~m}$ ). Cette maçonnerie est conservée sur une hauteur moyenne de $0,60 \mathrm{~m}$, sauf à l'ouest, au niveau du secteur 2 , où le sondage pratiqué plus profondément a mis en évidence un solin de fondation de $0,60 \mathrm{~m}$ de haut composé de moellons de calcaire jaune diversement façonnés et irrégulièrement assisés, liés par un mortier coquillier fortement dosé. Au niveau du secteur 3, son parement sud est composé d'une semelle de 3 assises dont l'arase supérieure forme un ressaut de $3 \mathrm{~cm}$ : celle-ci est bâtie en moellons de calcaire jaune bien équarris et bien assisés ( $\mathrm{L} \times \mathrm{H}$ moy. : $0,20 \mathrm{~m} \times 0,06 \mathrm{~m}$ ) tout comme la partie supérieure du mur, également conservée sur 3 assises ( $L \times \mathrm{H}$ moy. des moellons : $0,24 \mathrm{~m} \times 0,08 \mathrm{~m}$ ) liés par un mortier de chaux emplissant pleinement les joints. Ces derniers présentent la particularité d'être assez réguliers, les joints montants faisant environ $2 \mathrm{~cm}$ d'épaisseur contre $4 \mathrm{~cm}$ pour les joints de lit. Le parement nord montre également un appareil régulier de moellons calcaires bien équarris et bien assisés ( $L \times H$ moy. : 0,20 $\mathrm{m} \times 0,06 \mathrm{~m}$ ).

Contemporain du mur 6, le mur 9 (orientation nord/sud, longueur dégagée : $3,20 \mathrm{~m}$ ) est harpé avec lui en formant un angle droit délimitant un espace de surface réduite $(1,50 \mathrm{~m}$ de large). Le sondage du secteur 2 montre que sa hauteur conservée atteint $1,03 \mathrm{~m}$, sa base $(H: 0,60 \mathrm{~m})$ étant une semelle de fondation en moellons de calcaire jaune assez bien équarris ( $L$ x H moy. : 0,25 $\mathrm{m} \times 0,10 \mathrm{~m}$ ) liés par un mortier blanc à forte granulométrie. Au-dessus, le mur proprement dit se compose de moellons de calcaire jaune assez bien équarris et assisés ( $\mathrm{L} \times \mathrm{H}$ moy. : 0,20 $\mathrm{m} \times 0,17 \mathrm{~m}$ ) liés par un mortier de chaux.

\section{La zone 1}

\section{Analyse stratigraphique de la zone I (fg. 19)}

La zone 1 englobe le premier sondage commencé en 1988 et achevé en 1990, délimité par les murs $1,2 \mathrm{a}, 2 \mathrm{~b}$ et 3 . Les murs 3 et 13 n'étant pas liés au mur $2 / 6$, il semblerait quà l'origine, la pièce s'étendait jusqu'au mur 9. Au sud, la limite de la pièce (secteur 4) n'ayant pas été trouvée, seule 


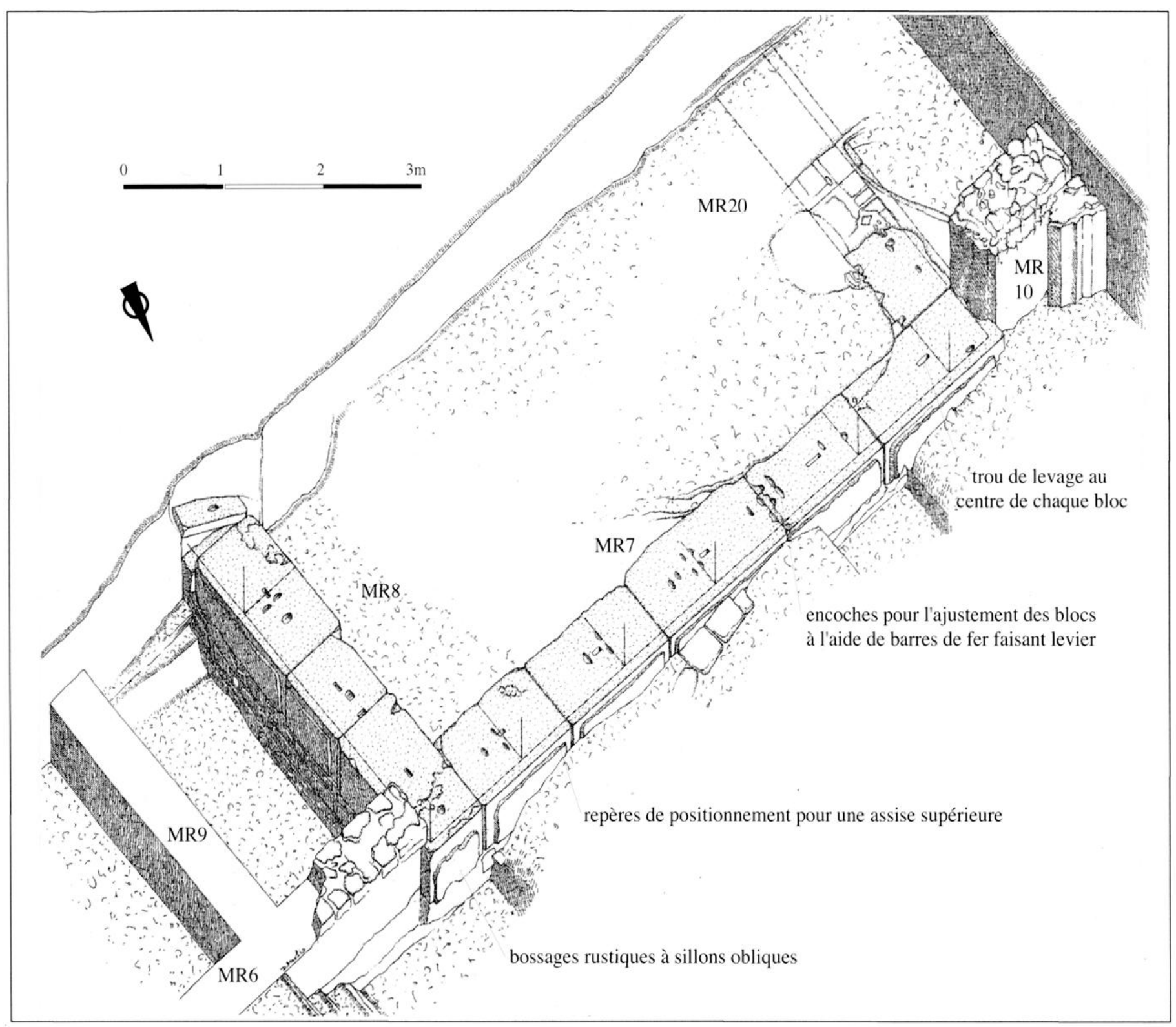

Fig. 16. Vue axonométrique de l'aménagement en grand appareil, dessin D. Moulis.

la coupe stratigraphique d'une partie du sondage a pu être établie (fig. 19). Sur presque $0,50 \mathrm{~m}$ d'épaisseur, les labours (US 1004 à 1011) sont venus perturber les niveaux archéologiques (la couche de terre végétale qui scelle la coupe s'épaissit vers l'ouest).

La reprise de cette coupe a permis de mettre en évidence la tranchée de fondation 1030 du mur 1 ainsi qu'un niveau de sol composé de mortier de chaux, constitué de nombreuses inclusions de petites coques (1028-1029); seul ce niveau se trouve sous le mur 3 .

Le niveau horizontal (US 1027) qui repose sur ces sols est difficile à interpréter et peut être interprété comme un niveau de démolition daté de la seconde moitié du ler $s$. av. notre ère.
Pour les US 1018a 1018 b, 1018c, 1021, 1022, 1023, 1024, 1025, 1026, les inclusions de tegulae, de mortier et d'argile, témoignent d'un niveau de démolition. Le pendage ouest/est de ces US, venant s'appuyer contre le mur 3 , laisse supposer un comblement postérieur à l'aménagement de ce mur portant une canalisation, mais il reste à déterminer si ce dernier constitue une adduction d'eau venant alimenter des thermes supposés dans les secteurs 8 et 9 . Les sigillées claire C, B luisante ainsi que les amphores africaines datent cette séquence de l'Antiquité tardive.

Les couches compactes qui se situent sous la couche 1003 appartiennent donc à des niveaux de comblement successifs, riches en matériaux de construction et qui présentent une 


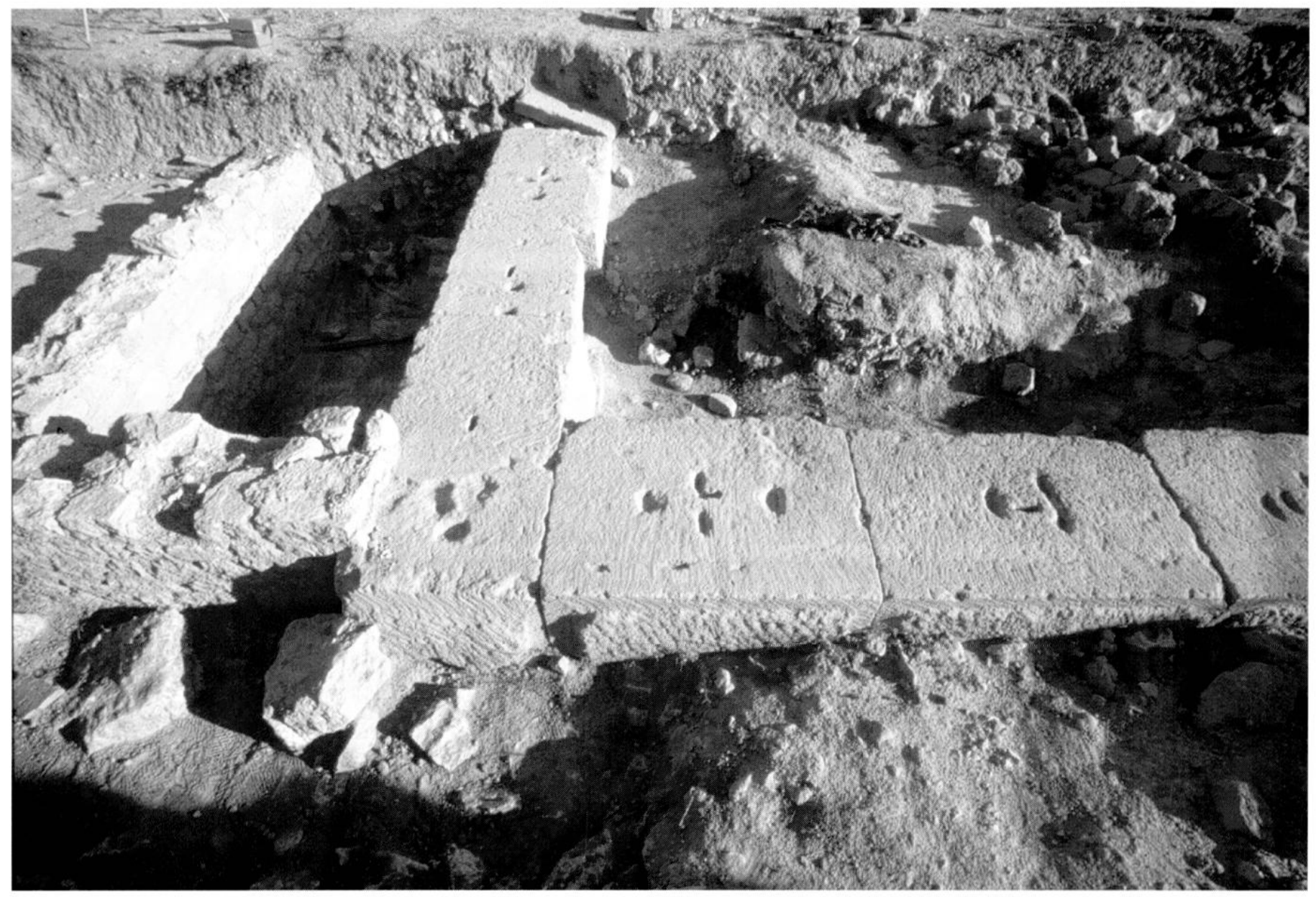

Fig. 17. Grand appareil, photo D. Moulis.

pente du mur 3 vers le mur 1. Par l'abondance des fragments de coquillages et des céramiques culinaires qui la caractérisent, I'US 1003 témoigne de la présence d'un dépotoir scellé par un niveau de démolition (1017). Un bord de céramique commune réductrice à bandeau permet de la dater du V $\mathbf{l}^{\mathbf{e}} \mathrm{s}$. de notre ère.

On peut donc résumer l'interprétation de cette coupe en soulignant la mise en place, dans la seconde moitié du $I^{\text {er }} \mathbf{s}$. av. notre ère, des murs $1,2 a$ et $2 b$ (fig. 20) et des sols 1028/1029. Des niveaux de remblais ou de démolition durant les III $-\mathrm{V}^{\mathrm{e}}$ siècles ap. notre ère et une phase de dépotoir durant le $\mathrm{VI}^{\mathrm{e}} \mathrm{s}$. de notre ère viennent sceller cette séquence. Les datations, rendues difficiles par la nature même de l'intervention qui n'a pas permis de récupérer un matériel abondant, restent à confirmer.

\section{Description des murs de la zone 1}

Le mur 1, orienté plein nord, est conservé sur une hauteur moyenne de $1,20 \mathrm{~m}$. Son parement ouest étant actuellement seul visible, il s'avère impossible de connaître son épaisseur. Dans sa partie nord, cette maçonnerie est dotée d'une semelle de fondation ( $L \times H$ : env. $3,40 \mathrm{~m} \times 0,60 \mathrm{~m}^{14}$ ) dont l'arase supérieure montre un ressaut pouvant atteindre une largeur de $0,14 \mathrm{~m}$. Cette fondation, qui affecte un pendage nord/sud, se compose de moellons en calcaire jaune ou en calcaire coquillier moyennement bien équarris et assisés. Ces éléments sont séparés par des joints gras de 2 à $5 \mathrm{~cm}$ d'épaisseur bourrés d'un mortier coquillier, riche en chaux, très bien dosé. Cette semelle n'a pas de base visible puisque cette dernière semble encore enterrée sous le remblai.

La partie supérieure du mur est bâtie dans un appareil différent puisqu'elle se compose de moellons de calcaire jaune très bien équarris et bien assisés ( $\mathrm{L} \times \mathrm{H}$ moy. : $0,20 \mathrm{~m} \times 0,14 \mathrm{~m}$ ), liés par un mortier de même nature qui emplit des joints maigres (l'épaisseur variant entre 1 et $2 \mathrm{~cm}$ ). Cette maçonnerie présente à son tour dans sa partie supérieure un ressaut d'une largeur de $5 \mathrm{~cm}$ dominé par une seconde "surélévation " d'environ 3 assises de haut $(0,24 \mathrm{~m})$, composée de moellons de calcaire coquillier ( $L \times H$ moy. : 0,24 $\mathrm{m} \times 0,07 \mathrm{~m}$ ) liés par un mortier de

(14) Cette " fondation " peut atteindre $1 \mathrm{~m}$ d'après le sondage effectué en 1990 (cf. rapport GRASG 1990, doc. 2). 


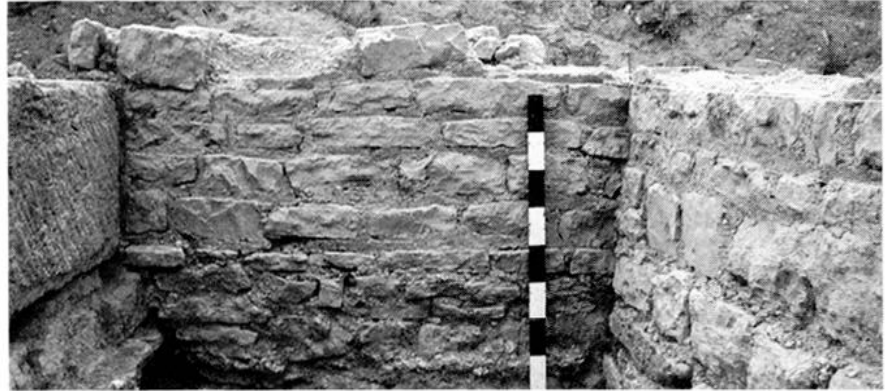

Fig. 18. Mur 6, à gauche mur 8 et à droite mur 9, photo E. Dellong.

chaux emplissant des joints de 1 à $2 \mathrm{~cm}$ d'épaisseur. Malgré ces différences minimes d'appareil, il est probable que le mur 1 fut bâti d'un seul jet et que ces perturbations correspondent à des adaptations à des éléments extérieurs dont nous ne savons rien à l'heure actuelle (irrégularité du substrat ?).

Ce mur 1 est lié au nord avec un mur $\mathbf{2 a}$ (fig. 20) qui présente une nette reprise de construction (MR 2b). Le mur 2 (ouest/est) est doté d'un solin de fondation de $0,60 \mathrm{~m}$ de haut bâti en moellons de calcaire gris bruts de carrière $(L: 0,10$ à $0,35 \mathrm{~m} ; \mathrm{H}: 0,12 \mathrm{à} 0,17 \mathrm{~m}$ ), irrégulièrement assisés, et liés par un mortier coquillier à forte granulométrie. Cette fondation possède à son extrémité supérieure un ressaut de $7 \mathrm{~cm}$ et vient se plaquer sans liaison contre le mur 1. Elle s'appuie par ailleurs sur un radier au mortier de chaux qui fut répandu sur le sol afin de constituer une assise stable pour l'établissement de la fondation.

Le mur 1 est lié avec l'élévation du mur $2 a$ au moyen de deux moellons harpés en boutisse séparés d'une assise. Le mur $2 a$ est bâti en moellons de calcaire jaune très bien équarris et assisés ( $L: 0,14$ à $0,35 \mathrm{~m} ; \mathrm{H}: 0,06$ à $0,10 \mathrm{~m}$ ), liés par un mortier de chaux coquillier emplissant des joints d'une épaisseur de $2 \mathrm{~cm}$. Ce mur 2a est conservé sur une longueur de $1,65 \mathrm{~m}$ et une hauteur de $1,30 \mathrm{~m}$, fondation comprise. Par la suite, il semble que ce mur $2 a$ ait été détruit, un mur $\mathbf{2 b}$ venant prendre le relais à l'ouest sur l'arrachement : cette nouvelle maçonnerie se présente sous la forme d'une construction en moellons de calcaire jaune moyennement bien équarris et assisés $(L: 0,18$ à $0,45 \mathrm{~m} ; \mathrm{H}: 0,04$ à $0,30 \mathrm{~m}$ ) liés par un mortier coquillier à forte granulométrie. Cette construction s'enfonce à l'ouest dans la berme mais il n'est pas impossible de penser qu'elle corresponde au mur 6 ou soit dans son alignement direct (orientation similaire).

On remarquera en outre l'utilisation de moellons de calcaire gris et froid (durs à la taille et explosant par éclats lors de l'impact de l'outil) pour les fondations, le mur 2a possédant pour son élévation des moellons de calcaire jaune plus faciles à tailler, grâce à leurs propriétés physiques.
Orienté nord/sud, le mur 3 est conservé sur une hauteur moyenne de $0,85 \mathrm{~m}$. II vient se plaquer sans liaison contre le mur $2 b$ et possède une facture très médiocre qui semble induite par l'emploi d'éléments de récupération : on remarque ainsi des éléments de calcaire gris ou jaune, bruts de carrière bien équarris, assez irrégulièrement assisés selon un léger pendage nord/sud. Ces éléments sont liés par un mortier de chaux coquillier, les joints étant parfois assez beurrés.

Leurs dimensions sont également assez variables $(L: 0,10$ à $0,54 \mathrm{~m} ; \mathrm{H}: 0,16$ à $0,30 \mathrm{~m}$ ) et on notera même la réutilisation en parement d'un élément lithique en calcaire coquillier qui pourrait s'apparenter à un fragment de colonne : ce demicylindre (diam. : 0,42 $\mathrm{m}$ ) semble posséder une épaisseur minimale de $0,20 \mathrm{~m}$ et ne paraît pas présenter d'axe central.

On remarquera en outre que les deux assises supérieures de cette maçonnerie sont d'une facture plus soignée puisqu'elles sont bâties en moellons de calcaire jaune bien équarris et bien assisés ( $\mathrm{L} \times \mathrm{H}$ moy. : 0,20 $\mathrm{m} \times 0,07 \mathrm{~m}$ ), séparés par des joints de $2 \mathrm{~cm}$ de large. Ces maigres vestiges constitueraient l'élévation du mur proprement dite, soutenant la canalisation, alors que la maçonnerie située en-dessous correspond probablement à la fondation.

\section{Secteur 3 (fig. 21)}

Le secteur 3 forme une pièce limitée par les murs 6, 9, 13 et 14 .

La fouille du secteur 3 permet de retrouver la même séquence que dans les zones 2 et 3 . En effet, l'US 4009 correspond au sondage sous le sol 4008 et à la première phase connue du site. Un niveau de sol très jaune (4008), contenant des tessons et des pierres posés à plat, est inégalement conservé et affiche une pente ouest/est.

L'US 4007 est une couche d'argile homogène d'environ $30 \mathrm{~cm}$ d'épaisseur de couleur jaune orange ou gris, avec beaucoup d'inclusions de pierres, parfois de gros blocs, mêlés à l'argile dure.

On retrouve donc, une première séquence représentée par I'US 4009 (remblai ?), un sol 4008, un niveau de destruction 4007. L'US 4004 est de composition très différente : elle est constituée de poches d'argile contenant des fragments de tegulae et de gravier. Sa composition hétérogène démontre un niveau fortement perturbé.

Les deux blocs qui se trouvent dans la pièce 3 (PLl et 2) proviennent vraisemblablement de l'aménagement en grand appareil voisin. Ils attestent donc une phase durant 


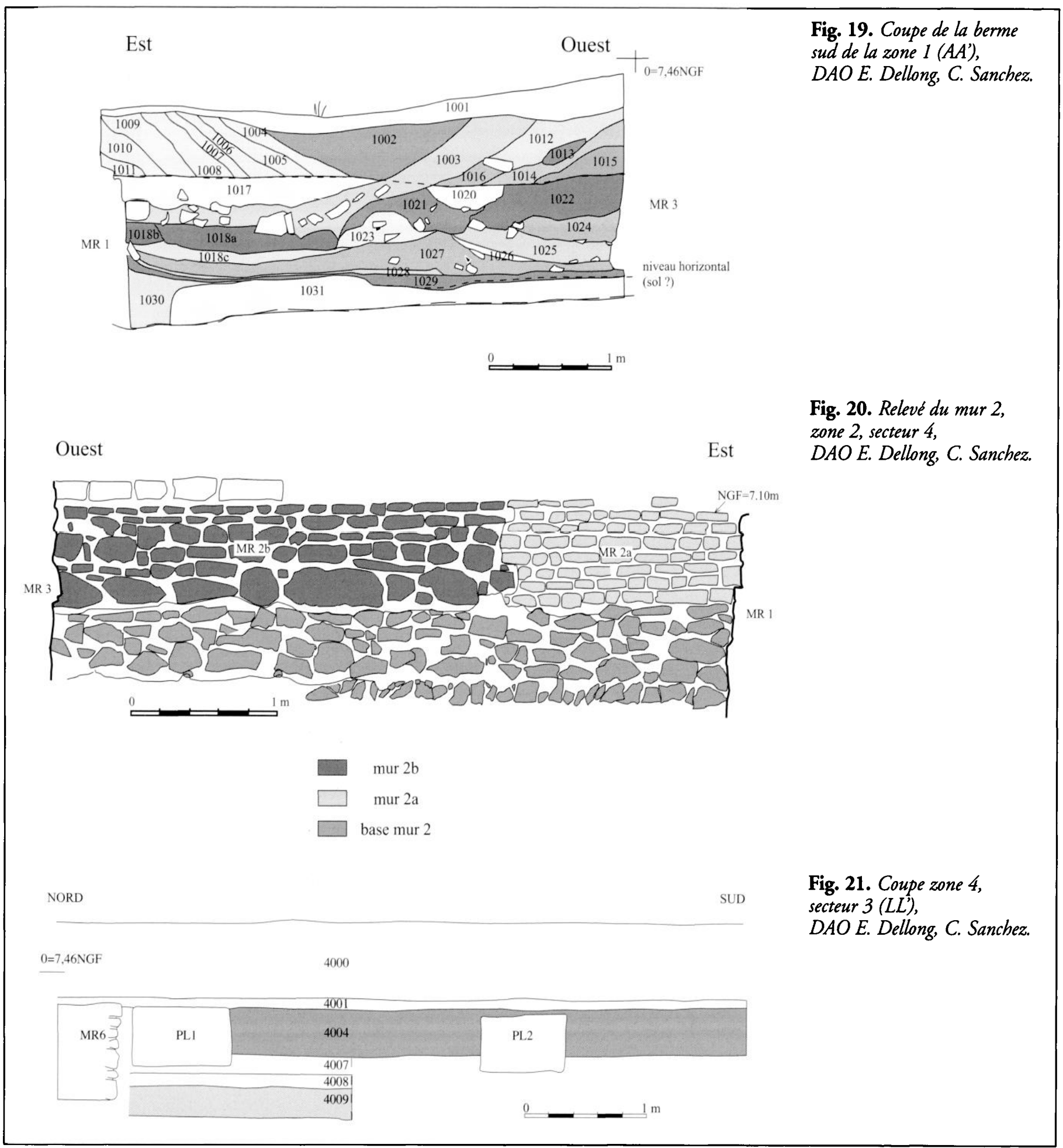

laquelle la construction est démantelée, mais où les " annexes " semblent encore en fonction. L'interprétation de ces deux blocs n'est pas encore établie. En effet ils ne sont pas en position centrale dans la pièce ; sont-ils vraiment en relation avec cette dernière?

De toute évidence cette phase qui semble remodeler la structure du site nous échappe mais il serait tentant de la rattacher à l'Antiquité tardive, au moment de la reconstruction en matériaux légers sur l'édifice.

Pour le mur 13, seul le parement ouest est visible à l'heure actuelle. D'une hauteur encore visible de $0,60 \mathrm{~m}$ pour une épaisseur de $0,52 \mathrm{~m}$, cette maçonnerie est orientée plein nord. Sa base, sur environ $0,25 \mathrm{~m}$ de haut, est préservée sur deux à trois assises en moellons calcaires bien équarris ou très bien 


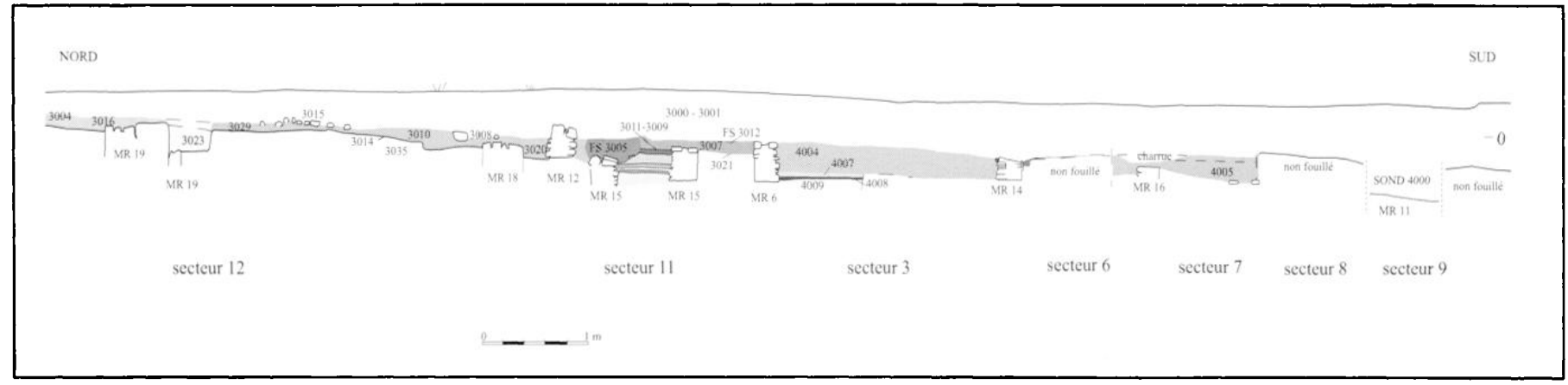

Fig. 22. Coupe nordlsud des zones 3 et $4\left(K K^{\prime}\right), D A O E$. Dellong, C. Sanchez.

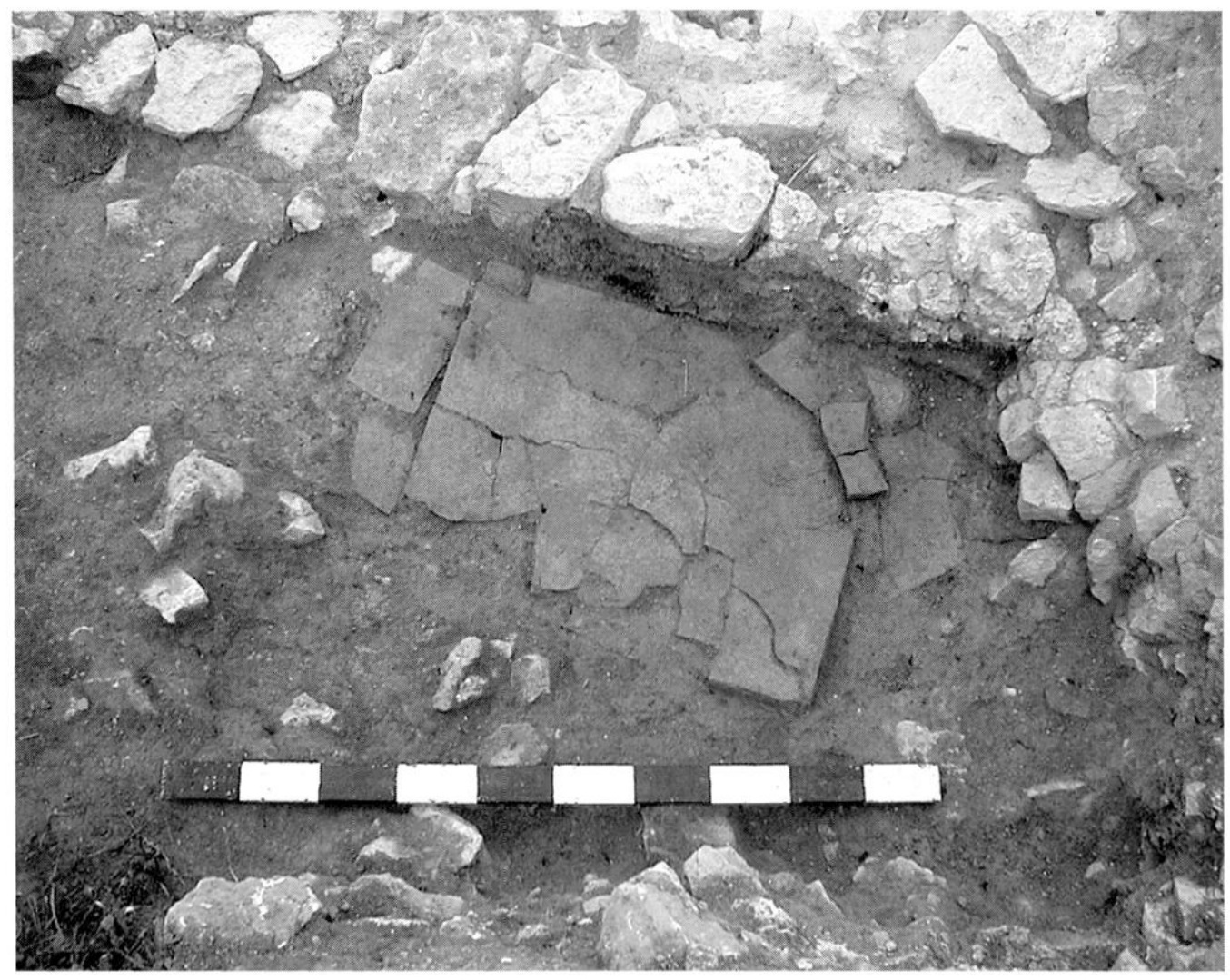

Fig. 23. Foyer 3036,

photo E. Dellong.

équarris ( $\mathrm{L} \times \mathrm{H}$ moy. : 0,20 $\mathrm{m} \times 0,09 \mathrm{~m}$ ), liés par un mortier de chaux emplissant pleinement les joints (épaisseur des joints montants : $0,5 \mathrm{~cm}$; épaisseur des joints de lit : $2 \mathrm{~cm}$ ). Au-dessus de cette base, sur $0,30 \mathrm{~m}$ de haut (hauteur actuelle conservée), le mur montre un appareil totalement différent, composé de moellons calcaires grossièrement équarris et assisés ( $\mathrm{L} \times \mathrm{H}$ moy. : 0,25 $\mathrm{m} \times 0,10 \mathrm{~m}$ ) ; les plus longs, séparés par des joints gras au mortier de chaux (épaisseur : 2 à $2,5 \mathrm{~cm}$ ) atteignent une longueur de $0,43 \mathrm{~m}$.

Ce mur 13 (longueur : $6,30 \mathrm{~m}$ ) est plaqué sans liaison contre le mur 6 et deux piliers 1 et 2 sont venus s'appuyer contre lui : Le pilier $1(\mathrm{~L} \times \mid \times \mathrm{H}: 0,82 \mathrm{~m} \times 0,65 \mathrm{~m} \times 0,52 \mathrm{~m})$ est un gros bloc en pierre de taille qui s'appuie sur un radier de terre (épaisseur : $8 \mathrm{~cm}$ ) posé sur le sol d'occupation du secteur 3 (4008).
Ce bloc utilisé en réemploi pourrait provenir de l'élévation de l'aménagement en grand appareil et montre une brisure sur sa face est, cassure qui fut bourrée de terre et de cailloutis pour pouvoir maintenir une horizontalité adéquate au niveau de la face supérieure.

Le pilier $2(\mathrm{~L} \times \mid \times \mathrm{H}: 0,78 \mathrm{~m} \times 0,63 \mathrm{~m} \times 0,46 \mathrm{~m})$ fut brisé sur son tableau supérieur par un charruage profond. Son tableau ouest montre trois cupules oblongues (la plus importante mesure : $L \times H \times P: 10 \mathrm{~cm} \times 4 \mathrm{~cm} \times 3 \mathrm{~cm}$ ) qui sont probablement des trous de calage, preuve que ce bloc fut lui aussi utilisé en réemploi et qu'il provenait peut-être à l'origine de l'élévation de la construction (secteur 1). Les tableaux ouest et nord présentent apparemment encore des traces de taille (layage ou dégrossissage au pic de carrier ?) et ce bloc est posé 
sur une petite semelle de terre de $0,10 \mathrm{~m}$ d'épaisseur établie sur le sol d'occupation.

Le secteur 3 semble fermé au sud par le mur 14 (longueur dégagée : $2,90 \mathrm{~m}$ ) venu s'appuyer postérieurement contre le parement ouest du mur 13. D'une hauteur visible de $0,40 \mathrm{~m}$ pour une épaisseur de $0,62 \mathrm{~m}$, ce mur orienté ouest/est (et donc parallèle au mur 6) est bâti en moellons de calcaire jaune assez bien équarris ( $\mathrm{L} \times \mathrm{H}$ moy. : 0,22 $\mathrm{m} \times 0,17 \mathrm{~m}$ ) dont la face de parement est bien dressée. Cet appareil assez régulièrement assisé semble être en léger pendage ouest/est. Les moellons sont séparés par des joints de 0,5 à $3 \mathrm{~cm}$ emplis d'un mortier de chaux coquillier fortement dosé.

\section{Zone 3 (fig. 22)}

La zone 3 qui se singularise par la rareté des vestiges construits est limitée au sud par le mur 6 ; elle correspond à la partie nord de la tranchée nord/sud qui s'arrête non loin de la limite de la parcelle. Il existe deux secteurs : le secteur 11 , entre les murs 6 et 12, et le secteur 12, du nord du mur 12 à l'extrémité de la tranchée.

\section{Une première phase d'occupation}

Sous les sols (3009, 3011, 3014, 3015, 3021, 3029), plusieurs murs $(18,19$ et 15$)$ ont pu être mis en évidence. La structure circulaire (MR 15) a été fouillée sur une profondeur de $0,50 \mathrm{~m}$, mais son comblement n'a pas permis d'identification. Il a été également possible d'appréhender les niveaux au contact du mur 18. Le sol 3014 est composé de mortier de chaux avec des inclusions de coquilles de cardium. La plupart des céramiques (sigillée italique, présigillée, parois fines) datent l'abandon de ces structures et la mise en place des sols de la fin du jer $s$. av. notre ère

Situé à l'extrémité nord de la tranchée, le mur 19 est, pour l'instant, le plus dégagé de la zone 3 . On note la présence dans le parement de fragments d'amphores italiques. La tranchée de fondation est bien visible (3026) avec son comblement de cailloutis. La fosse 3023 permet de suivre ce mur et d'appréhender sa hauteur conservée sur $75 \mathrm{~cm}$. Contre le parement est, une tegula posée à plat porte des traces de feu. La partie du parement conservé au-dessus de la tuile est recouverte par de l'argile rubéfiée; nous sommes donc en présence d'un foyer construit (FY 3036, fig. 23).

Les deux murs arasés (mur 18, longueur dégagée : $2,20 \mathrm{~m}$ et mur 19, longueur dégagée : $2,15 \mathrm{~m}$ ), séparés de quelques mètres $(3,40 \mathrm{~m})$, présentent des orientations similaires (légèrement nord-est/sud-ouest), perpendiculaires au sens de la pente naturelle. Le mur 19 présente une épaisseur de $0,57 \mathrm{~m}$ pour une hauteur conservée visible de $0,08 \mathrm{~m}$ et, pour autant que l'on puisse en juger, se compose de moellons en calcaire jaune moyennement bien équarris, solidarisés par un liant de mortier de chaux et d'argile. Plus au sud, le mur 18 est, à I'heure actuelle, à peine visible sous une croûte de mortier de chaux incluant de petits moellons calcaires, qui l'a presque entièrement recouvert ( $H$ conservée visible : 0,25 m).

Cependant on distingue encore 3 moellons grossièrement équarris ( $\mathrm{L} \times \mathrm{H}$ moy. : $0,25 \mathrm{~m} \times 0,07 \mathrm{~m}$ ) dont la face de parement est assez bien dressée et qui paraissent être liés à la chaux et à l'argile.

La structure semi-circulaire (mur 15, diamètre $2,80 \mathrm{~m}$ ) est constituée de matériaux apparemment liés à l'argile. D'une épaisseur de $0,60 \mathrm{~m}$, ces moellons calcaires sont bruts de carrière ou à peine équarris, leur face de parement étant peu ou pas dressée. La partie méridionale de ce mur paraît mieux bâtie ; elle fut prise ultérieurement dans une croûte de chaux qui l'a recouverte : ses moellons de calcaire jaune sont bien équarris ( $\mathrm{L} \times \mathrm{H}$ moy. : $0,30 \mathrm{~m} \times 0,08 \mathrm{~m}$ ) et bien assisés, leur face de parement étant bien dressée. Ils sont à une hauteur supérieure par rapport aux moellons de la partie nord du mur laquelle pourrait constituer la fondation proprement dite. Le liant de cette maçonnerie n'est pas clairement identifiable à I'heure actuelle.

\section{Une restructuration}

Les niveaux de sol qui se retrouvent sur l'ensemble de la zone 3 se présentent différemment selon les secteurs : dans le secteur 11 (entre MR 6 et 12), le sol 3021 est une structure très compacte, composée de mortier mêlé à la terre. Il est perturbé par la fosse 3012. Vers le nord, ce sol de mortier (3011 et 3009) a une structure moins compacte, de couleur jaune vif. Au nord du mur 12, le sol (3029 et 3014) correspond à un niveau de mortier très compact et homogène, bourré de coquilles de cardium.

Ce mur 12 orienté est/ouest, de $0,58 \mathrm{~m}$ d'épaisseur (haut. moy. conservée visible : entre 0,60 et $0,80 \mathrm{~m}$, longueur dégagée : $3,8 \mathrm{~m}$ ) semble parallèle aux murs 6 et 2 . II paraît être bâti sur un petit solin de fondation de $0,25 \mathrm{~m}$ de haut composé de blocs en calcaire jaune bruts de carrière ou assez mal équarris liés à l'argile : sur cette semelle, une mince couche de mortier établie horizontalement a servi à asseoir de gros blocs calcaires très moyennement équarris $(L: 0,37$ à $0,53 \mathrm{~m} ; \mathrm{H}: 0,28$ à $0,35 \mathrm{~m}$ ), dont la face de parement est cependant très bien dressée. Ces blocs sont liés par un mortier de chaux assez peu dosé ainsi que par un liant à l'argile. 


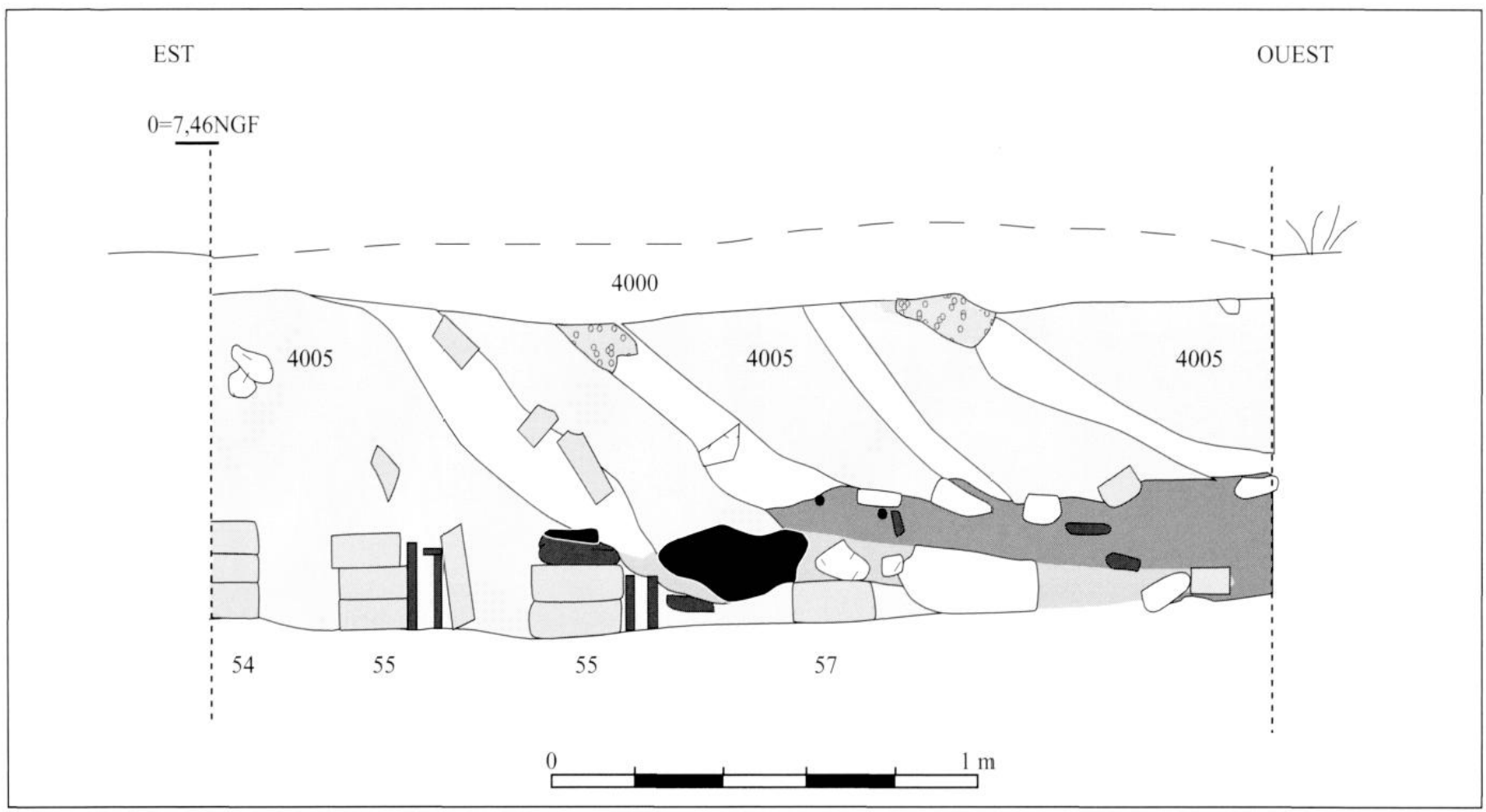

Fig. 24. Coupe de l'hypocauste, zone 4, secteur $7\left(M M^{\prime}\right), D A O$ E. Dellong, C. Sanchez.

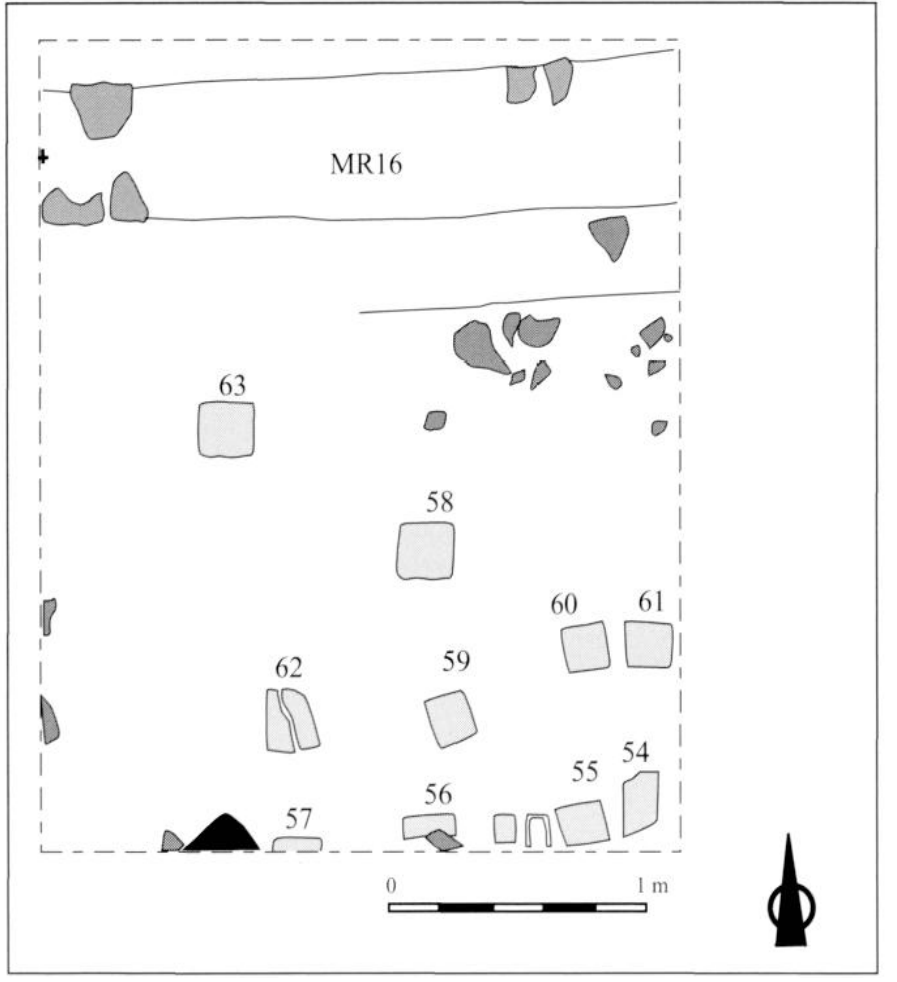

Fig. 25. Relevé en plan de l'hypocauste secteur 7 , $D A O E$. Dellong, C. Sanchez.

Le mur 17 (orienté nord/sud), à peine visible à l'heure actuelle, s'appuie sans liaison contre le parement sud du mur 12 : ses moellons calcaires assez bien équarris ( $\mathrm{L} \times \mathrm{H}: 0,20 \mathrm{~m} \times 0,14 \mathrm{~m})$ émergent d'une assise seulement.

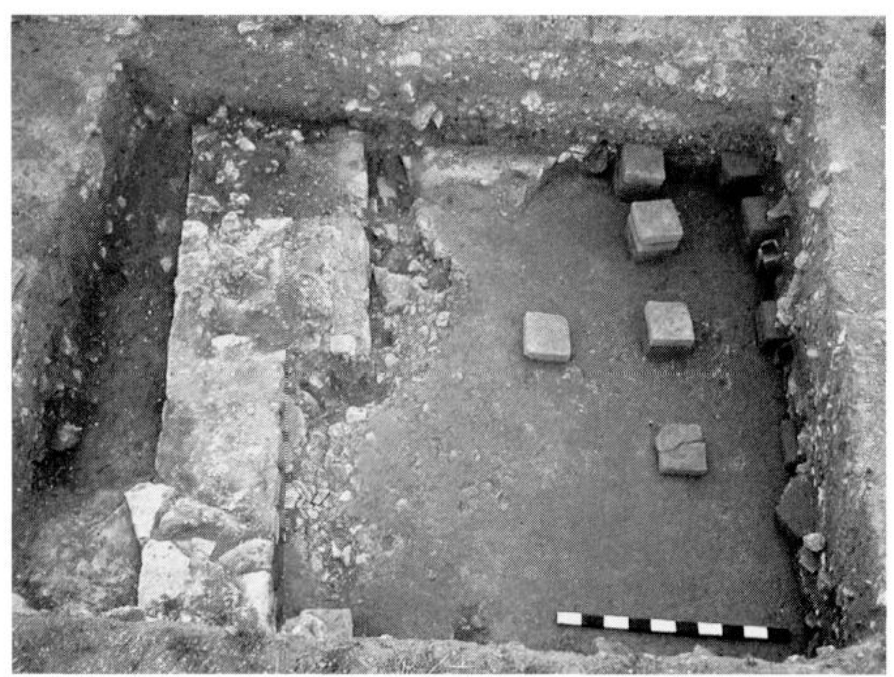

Fig. 26. Hypocauste, photo E. Dellong.

Les sols décrits précédemment sont scellés par un niveau de destruction de $0,25 \mathrm{~m}$ environ (US $3007=3010=3015$ ), qui comporte des inclusions différentes selon les secteurs. Entre les murs 6 et 12, il s'agit essentiellement de fragments de briques crues (3007). Dans le secteur 12, l'US 3010 correspond au même niveau de démolition mais est constituée par des concentrations de blocs. Il en est de même pour 3015 qui se caractérise par une forte concentration de pierres et d'éléments de démolition (nombreux fragments de tegulae). Les niveaux du Haut-Empire ne sont 


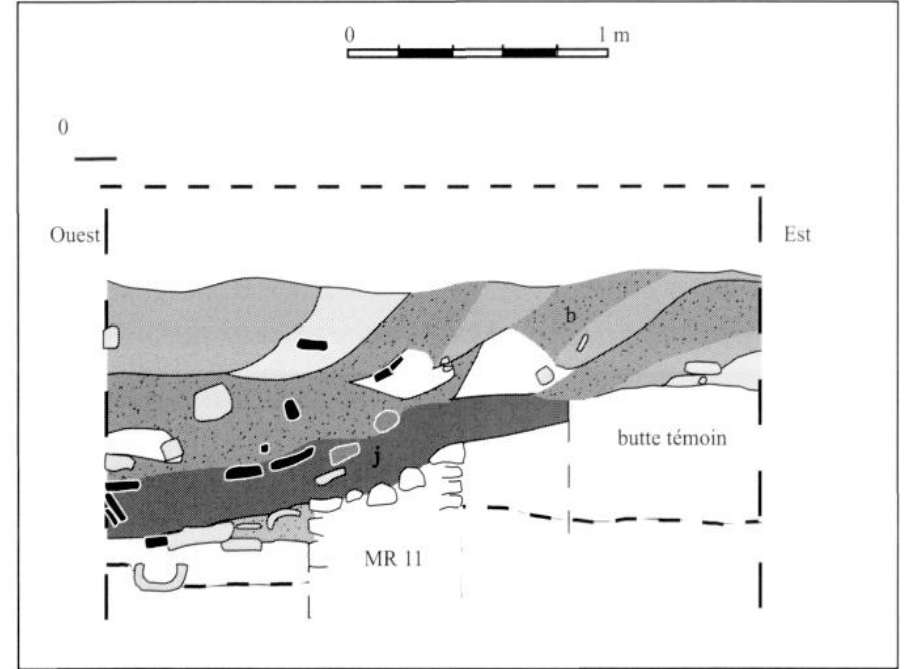

Fig. 27. Coupe nord sondage $4000\left(N^{\prime}\right)$, $D A O$ E. Dellong, C. Sanchez.

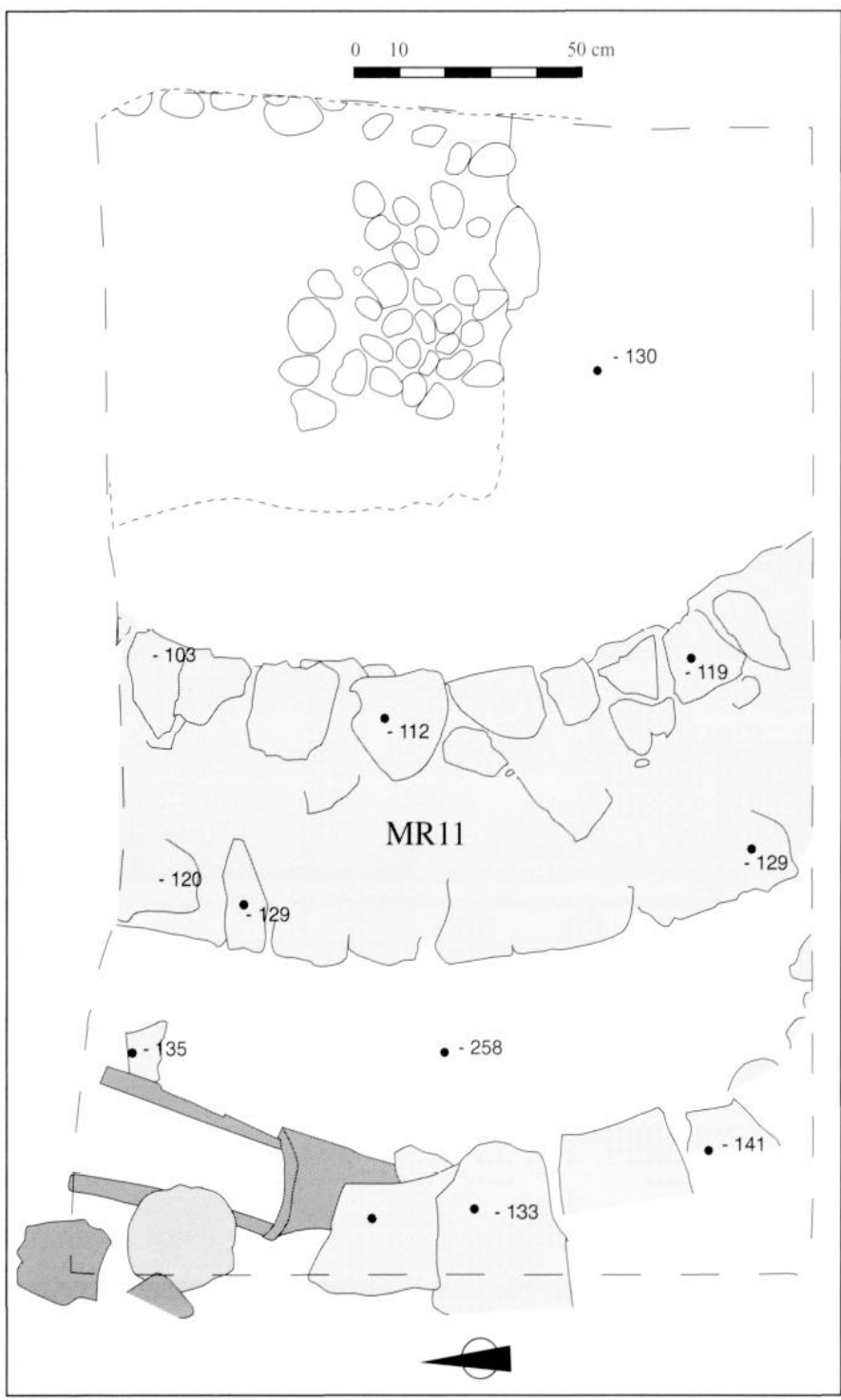

Fig. 28. Relevé en plan du sondage 4000 , $D A O E$. Dellong, C. Sanchez. pas conservés dans la zone 3. Seule la fosse 3023 (fig. 22) qui ne contient que peu d'artefacts témoigne de cette période : elle est essentiellement comblée par des pierres de $0,20 \mathrm{~m}$ de long en moyenne. Un mortier ou un pilon en pierre a également été mis au jour.

\section{DES THERMES?}

\section{Un hypocauste : le secteur 7 (fig. 24 à 26)}

Un décapage régulier a permis de mettre en évidence un niveau de destruction perturbé par les labours et composé d'une terre argilo-sableuse très orangée (US 4005, fig. 24). De nombreux fragments de tubulures et de pilettes s'y retrouvent mêlés, attestant la présence d'un système de chauffage. La base d'un dispositif d'hypocauste a effectivement été retrouvée et on observe une meilleure conservation des vestiges dans le secteur sud, moins touché par les labours. Sur les dix pilettes conservées ( ${ }^{\circ} 54$ à 63, fig. 25), neuf se trouvent dans l'angle sud-est du sondage ${ }^{15}$.

En ce qui concerne les datations, le niveau 4005 contient de nombreux fragments de céramiques résiduelles, les tessons de claire B et d'amphores africaines étant les éléments de datation les plus récents. L'hypocauste semble donc abandonné durant l'Antiquité tardive.

Quelques observations sur les matériaux de construction en terre cuite ont étẻ faites par G. Fédière. Les Tubuli d'hypocauste sont du type à ouverture triangulaire sur chaque petit côté.

Le mur 16 délimite l'hypocauste au nord. Cette maçonnerie (longueur dégagée : $2,80 \mathrm{~m}$ ), dont on ne perçoit à l'heure actuelle que l'arase, semble posséder une épaisseur de $0,55 \mathrm{~m}$ et se compose de moellons calcaires assez bien équarris $(L: 0,20$ à $0,30 \mathrm{~m}$ ) liés au mortier de chaux.

Un mur à abside : le secteur 9 (fig. 27, 28)

Le secteur 9 a fait l'objet d'un sondage (appelé sondage 4000) de $1,70 \mathrm{~m}$ de large sur $2,60 \mathrm{~m}$ de long. À la jonction des secteurs 8 et 9 jusqu'à l'extrémité sud de la tranchée 1 , de très nombreuses moules concassées laissent supposer la présence d'une importante zone de rejets dont l'épaisseur restait à éva-

(15) Plus on se rapproche de cet angle, plus la hauteur de pilettes augmente puisque l'on retrouve jusqu'à trois briques superposées. La bande de $1 \mathrm{~m}$ de large laissée entre les secteurs 8 et 9 a permis d'avoir une berme témoin mais elle devra être fouillée afin d'établir les relations entre les secteurs 7 et 9. En effet, la coupe nord du secteur 9 et la coupe sud du secteur 7 ne présentent pas la même séquence stratigraphique. Il est fort probable que cette différence soit due à la présence d'un mur fermant l'hypocauste. 

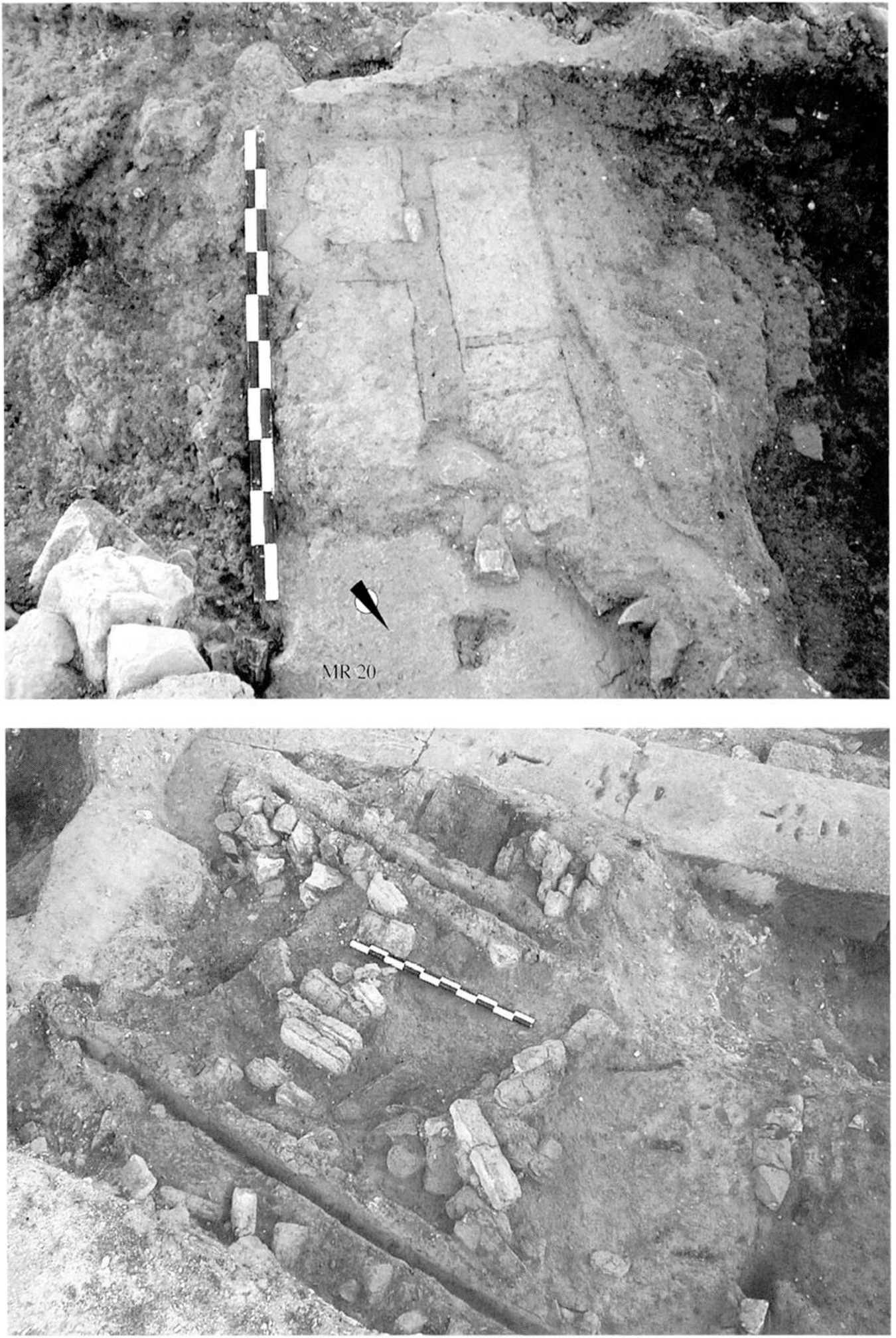

Fig. 29. Adobes en place sur le mur 20,

photo E. Dellong.
Fig. 30. Partie ouest de l'effondrement du mur à pans de bois, photo E. Dellong. luer. Il est pour l'instant difficile de faire le lien entre ce sondage et les observations faites dans les autres secteurs ; d'abord, par manque de repères communs (la stratigraphie est totalement différente) mais surtout par la rareté du matériel découvert, ce qui nous prive d'indices chronologiques.
Les labours ont parfois atteint $0,70 \mathrm{~m}$ de profondeur. Ils ont entamé le niveau de coquillages, composé quasi exclusivement de moules, sur une épaisseur de $0,40 \mathrm{~m}$. A l'angle nordest du sondage, un niveau de galets $(-0,83 \mathrm{~m}$ du niveau 0$)$ est difficile à interpréter : foyer ? 
Un mur courbe (MR 11) apparaît à - $1 \mathrm{~m}$ du niveau 0 . Une canalisation, faite d'imbrices recouvertes de petites dalles calcaires, le suit à l'extérieur (fig. 32). Émergeant de $0,25 \mathrm{~m}$ et lié à la terre, le mur 11, encore en grande partie enfoui, est un mur semi-circulaire regardant à l'ouest. D'une épaisseur de $0,60 \mathrm{~m}$, il est bâti en moellons calcaires moyennement bien équarris et de petit calibre ( $\mathrm{L} \times \mathrm{H}$ moy. : 0,20 $\mathrm{m} \times 0,15 \mathrm{~m}$ ), dont la face de parement est bien dressée. L'appareil semble moyennement régulier mais de meilleure qualité sur le parement ouest, le blocage étant quant à lui composé d'éclats calcaires bruts de carrière.

Jonction entre les secteurs 7 (hypocauste) et 9 (abside) : le secteur 8

Sur le plan, la restitution de la courbe de "l'abside ", tend à rejoindre l'hypocauste. En effet, à l'angle sud-est du secteur 8, les pilettes sont plus rapprochées, suggérant peut-être la proximité de l'angle d'une pièce. Cette hypothèse sera à vérifier lors d'une prochaine campagne de fouilles. La corrélation entre l'abside et une pièce chaude est caractéristique des parties thermales, la présence de nombreux fragments de mortier de tuileau tendant à valider cette hypothèse.

\section{DES AMENAGEMENTS DE TERRE ET DE BOIS}

(fig. 14, 29, 30)

Au-dessus de la première assise en grand appareil du mur 20, quelques adobes sont encore en place (fig. 29). Leur disposition correspond aux prescriptions de Vitruve, II, 3 (Chazelles 1997, p. 68, fig. 61), avec un agencement de briques entières et de demi-briques. Cet aménagement n'a pu être observé que sur une petite surface. On note que ces briques sont disposées avec un retrait de $10 \mathrm{~cm}$ sur le mur 20 (fig. 14 et 29). Se pose le problème du recouvrement des briques crues du mur 20 par la destruction du mur à pans de bois 2020 .

Dans le secteur limité à l'ouest par le mur 8 et au sud par le mur 10, un niveau d'adobes brûlées (fig. 14,30) peut être observé. Ce dernier (2001/2020) n'est pas conservé dans son intégralité, la fosse médiévale (FS 2003) et des creusements à l'ouest du sondage venant perturber sa lecture. Le relevé montre que l'effondrement s'est opéré dans le sens ouest-est.

Deux modules ressortent clairement, l'un d'une largeur de $14 \mathrm{~cm}$ en moyenne, le second de $21 \mathrm{~cm}$ environ. Les épaisseurs varient entre 5,5 et $9 \mathrm{~cm}$ mais la dimension la plus courante avoisine les $7 \mathrm{~cm}$. En ce qui concerne les pro- blèmes de métrologie, C.-A. de Chazelles (Chazelles 1997, p. 65) souligne " avec quelle prudence il faut accueillir les données transmises par les auteurs latins ». Constatons seulement que les mesures prises sur les adobes découvertes à Saint-Martin représentent 1 pied romain pour la longueur, 1 demi pied pour la largeur et 1 tiers de pied pour l'épaisseur. Les comparaisons avec l'Espagne (De Chazelles 1997, p. 65 d'après Bonet et Guérin 1989, p.128) font apparaître deux modules: l'un de $40 \mathrm{~cm} \times 30 \mathrm{~cm} \times 10 \mathrm{~cm}$ pour le rezde-chaussée et l'autre de $40 \mathrm{~cm} \times 17 \mathrm{~cm} \times 10 \mathrm{~cm}$ pour les parois des étages, ces dernières dimensions se rapprochant de celles observées à Saint-Martin.

Deux saignées parallèles (fig. 30) de $8 \mathrm{~cm}$ de large et de profondeurs inégales, sont distantes de $1,40 \mathrm{~m}$ : elles correspondent au négatif du pan de bois de $6,60 \mathrm{~m}$ de long au maximum. Vers l'ouest, des éléments en fer peuvent appartenir à un système d'accrochage (fig. 31). Ces aménagements en terre et bois de l'Antiquité tardive et du haut Moyen Âge sont attestés, en particulier dans la Vallée du Rhône. Il faut rester prudent en ce qui concerne les datations car nous sommes à peine à $20 \mathrm{~cm}$ du sol actuel et des intrusions ont pu avoir lieu. Le dépotoir 2017, daté de l'Antiquité tardive et recouvert par ce niveau de destruction, apporte un élément de datation plus fiable. La date de destruction de ces structures serait le $\mathrm{V}^{e} s$. de notre ère compte tenu de la présence de sigillée claire africaine $D$ (forme Hayes 87A) dans ce dépotoir.

L'état de conservation du mur à pans de bois, malgré sa destruction, apporte des données importantes et inédites concernant les méthodes de construction en vigueur dans le Narbonnais durant l'Antiquité tardive. Dans la ville de Narbonne, les fouilles du Clos de la Lombarde ont bien montré l'utilisation continue de la brique crue.

\section{Des Fosses de L'ANTIQUITÉ TARDIVE OU DU MOYEN ÂGE}

\section{Des fosses de l'Antiquité tardive ou du haut Moyen Âge}

Plusieurs fosses ont été repérées ; elles se distinguent par leur couleur foncée due à la présence de cendres, et par de nombreux coquillages et céramiques provenant vraisemblablement de déchets culinaires. Ces fosses attestent un moment où ce secteur du site est utilisé comme zone de rejets domestiques.

Située au sud du mur 10, une fosse (2017) est comblée par des objets souvent bien conservés, mêlés à de la cendre. De nombreuses pierres sont également présentes. Le comblement 


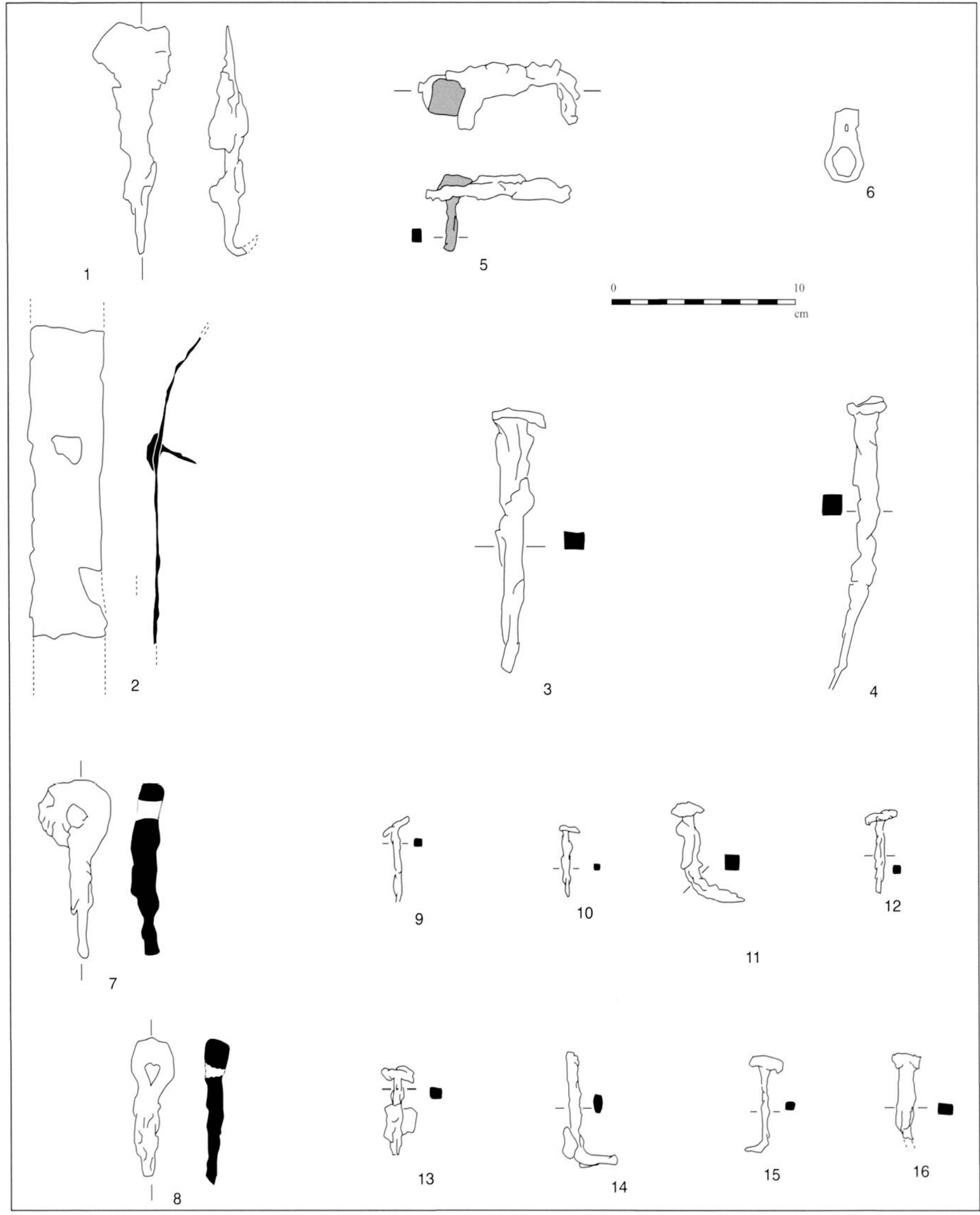

Fig. 31. Objets métalliques de l'US 2020. 1-Crochet en fer dépourvu de boucle de suspension; 2 - Tôle de fer avec repli et clou de fixation ; $3,4,9,10,11,12,13,15,16$ - clous en fer ; 6-tige de bronze plate terminée par un anneau aplati; 7-8-crochet;5-valet d'établi en fer. DAO E. Dellong. 
permet d'interpréter cette fosse comme un dépotoir datant de l'Antiquité tardive (présence de céramique luisante et de claire D), contemporain de l'abandon du site.

L'US 2009 (fig. 13) est un niveau cendreux, argileux, avec de nombreuses coquilles de moules et quelques adobes très fragmentées. Les tessons présents permettent de dater son comblement du $V^{e}-V^{e} \mathbf{s}$. de notre ère.

\section{Une fosse du Moyen Âge}

L'observation du comblement des US 2002, 2003 et 2004 montre qu'elles appartiennent à une seule fosse. Entre les murs 8 et 9 , elle atteint environ $1 \mathrm{~m}$ de profondeur. Aucune différence de comblement ne signale plusieurs phases de remplissage. Le comblement, homogène, présente la même structure (terre cendreuse, meuble, avec de nombreux éléments de faune en particulier des moules). On peut aussi noter un nombre important de chevilles osseuses. La plupart des ossements découverts (étude définitive à réaliser) correspondraient à des bovidés ou des équidés. Au fond de la fosse 2004, une patte d'équidé en connexion a été prélevée. La présence de bords de céramiques à bec ponté des $X^{e}-X^{e}$ siècles (fig. 32) permet de proposer une première datation. Le résiduel est très important, avec une forte représentation des éléments de l'Antiquité tardive.

Une couche brune (2016) a été atteinte, mais pour des raisons de sécurité, il a été choisi de ne pas pousser les investigations plus en profondeur. Cette fosse médiévale a permis de mettre au jour et de relever une partie des murs 6,8 et 9 déjà décrits.

\section{Un silo du Moyen Âge ?}

Après décapage de la couche de terre arable, la fosse 3005 se distinguait du niveau argileux environnant par sa couleur noire et de nombreux fragments de coquillages, en particulier des moules. La fouille a montré un comblement composé de nombreux blocs de moyennes dimensions mêlés à des rejets culinaires caractérisés par une terre cendreuse et de nombreux artefacts. Parmi ceux-ci, on remarque l'importance de la céramique réductrice, pour la plupart des fragments appartenant aux mêmes vases. Cette céramique permet de proposer une datation du comblement, qui semble rapide, durant le haut Moyen Âge. La présence de fragments de moules en grande quantité, d'écailles de poissons ainsi que d'un os de raie montre une consommation assez variée des ressources de l'étang.
LES BASSINS/CITERNES, PARCELLES D4-881/882 (fig. 33)

Deux "bassins " perpendiculaires l'un à l'autre se trouvent à proximité de la fouille sur le flanc sud d'une petite colline, ultime ressaut rocheux avant l'étang dont ils épousent la topographie.

Avec l'accord du propriétaire, il a été possible de désherber et de dégager partiellement les pans de murs qui étaient visibles. Plusieurs observations ont ainsi pu être faites.

\section{Description des vestiges}

Le bassin 1 n'apparaît que par un seul pan de mur, dont une partie est encore enfouie. Nous ne possédons que peu de renseignements à son sujet. Le mur, bétonné (le béton se compose de sable, de chaux et d'éclats de pierres calcaires), d'environ $7,70 \mathrm{~m}$ de long pour une épaisseur de $0,30 \mathrm{~m}$, est orienté sud-est. Dans la partie sud, un retour de mur a été repéré. Cependant, la largeur du bassin reste, pour l'instant, inconnue. Sa partie interne comporte un enduit hydraulique (béton de tuileau) d'environ 3 à $5 \mathrm{~cm}$ d'épaisseur. Le mur bétonné s'appuie sur un second, construit en pierres calcaires liées au mortier. De longueur indéterminée, son épaisseur est de 0,60 m. Cette seconde construction devait servir à renforcer le bassin.

Le bassin 2 apporte un peu plus de renseignements. Certes, il est encore partiellement enfoui ou abîmé dans sa partie sud mais trois côtés sont visibles. Les murs bétonnés sont orientés sud-ouest et mesurent environ $7,20 \mathrm{~m}$ de long sur 3,60 $\mathrm{m}$ de large (hors œuvre) pour une épaisseur d'environ $0,40 \mathrm{~m}$. Un enduit hydraulique d'environ 3 à $5 \mathrm{~cm}$ recouvre les parois internes. La destruction partielle d'un coin du bassin, suite à l'aménagement du chemin communal, permet de décrire sa base : la chape est faite d'éclats de tuiles mêlés à de la chaux et repose sur un radier de blocs calcaires posés en épi. Pour rendre le bassin plus étanche, un boudin en quart de cercle semble avoir été disposé sur chaque arête (le boudin d'étanchéité n'a pu être dégagé que d'un seul côté). Ce bassin est entouré et renforcé par un second mur, fait de pierres calcaires liées au mortier, d'environ 0,60 m d'épaisseur. La coupe du bassin permet également de déterminer en partie la profondeur des murs (environ $1 \mathrm{~m}$ pour chaque mur).

En raison de leur capacité (environ $18 \mathrm{~m}^{3}$ ) et de la présence d'enduit hydraulique, l'hypothèse la plus probable est qu'il s'agit de citernes d'eau douce. 


\begin{tabular}{lll}
\hline \hline & & 1 \\
1 & & 1 \\
0 & \\
\hline & & \\
& & \\
& & \\
\hline
\end{tabular}




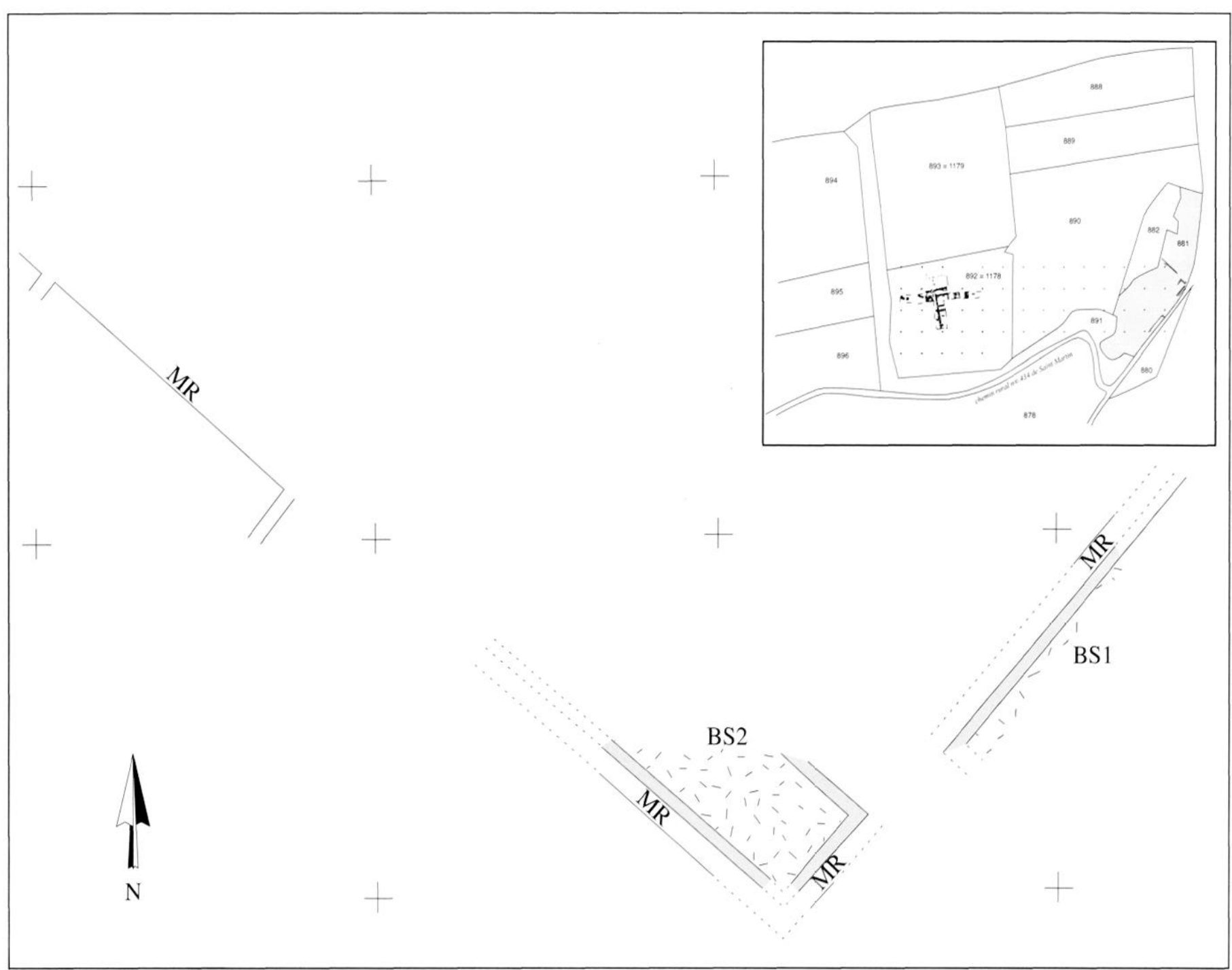

Fig. 33. Plan des bassins, DAO E. Dellong, C. Sanchez.

\section{Technique de construction}

Différents auteurs antiques décrivent les techniques de construction des citernes :

Selon Vitruve (Vitruve, VIII, chap. VI, 14) ${ }^{16}$ : « il faudra que les provisions d'eau venue des toits... soient recueillies dans des ouvrages maçonnés à la manière de Signia. [...] il faut, tout d'abord, avoir du sable très pur et très rude, puis fragmenter dans la pierre des éclats qui ne pèsent pas plus d'une livre, et faire le mortier en ajoutant la chaux la plus fusante possible dans la proportion de 5 parts de sable pour 2 de chaux. Avec des pilons de bois armés de fer, on damera ce mortier dans la tranchée jusqu'au niveau de hauteur prévu. »

(16) Vitruve, De l'Architecture, Livre VII, édition et traduction de L. Callebat, Paris 1973.
Pline l'Ancien (XXXVI, 173) ${ }^{17}$ reprend les recommandations de Vitruve : " Les citernes doivent être construites avec 5 parties de sable pur et granuleux, 2 de chaux la plus vive et avec des fragments de silex ne dépassant pas le poids d'une livre ; ainsi fait, il faut en marteler également le fond et les parois avec des pilons ferrés. "

Enfin Palladius explique (Palladius, I, XVII) ${ }^{18}$ :

« Faite de murs en maçonnerie de Signia, la citerne aura les dimensions qui vous plairont et conviendront à vos moyens, mais sera plus longue que large. Son sol, consolidé par une bonne épaisseur de béton, avec un emplacement ménagé

(17) Pline l'Ancien, Histoire Naturelle, Livre XXXVI, Traduit par R. Bloch, 1981, Paris.

(18) Palladius, Traité d'Agriculture, Livres I et II, Traduit par R. Martin, 1976, Paris. 
pour l'écoulement de l'eau, sera rendu bien lisse grâce au ciment de brique qui le recouvrira. [...] On appliquera également sur les parois un revêtement semblable, et enfin, lorsque le tout sera complètement sec et depuis longtemps, la citerne pourra donner accueil à l'eau. Il conviendra d'y mettre et d'y élever des anguilles et des poissons de rivière, afin qu'en y nageant ils donnent à l'eau dormante le mouvement d'une eau courante ".

Les descriptions que font ces divers auteurs semblent confirmer que les deux grands bassins de Gruissan correspondent à des citernes. Enfin, il faut rappeler que ce système de construction (mur bétonné recouvert d'enduit hydraulique) a également été utilisé pour construire l'aqueduc de Béziers : l'auteur qui l'a étudié (Andrieu, 1990) rappelle que cette technique " conduit à un béton de grande qualité pour une consommation réduite de sable et de chaux ".

De plus, Vitruve (VIII, Chap.VI, 14-15) et Pline l'Ancien (Pline, XXVI, 173) conseillent de construire deux citernes " de manière que leurs eaux soient décantées en passant de l'une à l'autre, on aura ainsi à l'usage des eaux beaucoup plus salubres et agréables. "Il serait intéressant de voir si les deux bassins de Gruissan se trouvent à des niveaux différents et avec quelle partie du site ils sont en relation : en effet, outre la parcelle D4-892, des vestiges sont signalés dans la parcelle 865. Des fragments de tegulae, de céramiques, d'amphores et des tesselles ont été ramassés. Il apparaît donc comme probable que les bassins étaient en relation directe avec cette partie sud de l'habitat ${ }^{19}$.

Le nettoyage entrepris sur les bassins a permis d'apporter de nouvelles données et pose plusieurs questions. Il y a très peu de structures de dimensions comparables connus dans notre région. Une comparaison est possible entre les bassins de l'île St-Martin et ceux trouvés à Castillon-du-Gard (30, Gard) au lieu dit La Gramière (Guerre, Buffat 1998). À Castillon ils mesurent environ $21,20 \mathrm{~m}$ de long sur 4,50 m de large pour le premier et $18,3 \mathrm{~m}$ sur $5,25 \mathrm{~m}$ pour le second. Enfin, les techniques de construction sont identiques. À Gruissan, nous ne pouvons pas proposer de datation pour les bassins car ils n'ont pas été fouillés. La chronologie générale du site va du $\mathrm{II}^{\mathrm{e}} \mathrm{s}$. av. J.-C. au Haut Moyen Âge. Nous ne disposons d'aucun renseignement sur la façon dont les bassins de Gruissan étaient alimentés en eau (pluie ? source ?) ni de quelle

(19) Lors de la campagne de fouille, le terrain n'a pas pu être prospecté ; il est grillagé car il sert d'enclos pour des chevaux. manière l'eau était ensuite conduite jusqu'à l'habitat. Or, par leur position géographique, l'eau ne pouvait pas s'écouler sur le site actuellement fouillé (la parcelle 892 , plus au nord est plus haute, l'eau pouvait y être amenée mais non s'y jeter). La seule possibilité qui se présente pour l'instant, est que l'eau devait se déverser dans les parcelles au-dessous du chemin communal (parcelles $\mathrm{n}^{\circ} 863$ et 865). Cette solution semble se confirmer car un habitat est attesté dans ces parcelles. Des fragments de tegulae, de céramiques, d'amphores et des tesselles y ont été trouvés. Il apparaît donc que les bassins sont en relation directe avec cet habitat plutôt qu'avec le site plus au nord. Mais d'autres solutions peuvent être envisagées car des vestiges (murs, sols et mobilier antiques) ont été dégagés sur le côté ouest de la colline. Il paraît également important de comprendre les relations qui ont pu exister entre divers points du site (habitat, bassins, aménagement en grand appareil) mais aussi leur rapport avec l'étang.

\section{UN SITE CLÉ DU LITTORAL NARBONNAIS}

\section{Chronologie PROVISOIRE DES VESTIGES}

De nombreux fragments de céramique campanienne $\mathrm{A}$, de sombrero de copa et d'amphores italiques attestent une fréquentation du site de l'île Saint-Martin consécutive à la fondation de Narbonne, dans la seconde moitié du $\mathrm{II}^{e}$ s. av. notre ère. Pour l'instant, les structures de cette période n'ont pas été découvertes, mais il sera sans doute possible de les appréhender dans la zone 3, c'est-à-dire dans la partie nord du site. En effet cette zone est très arasée et les US de la fin du ${ }^{\text {er }} s$. av. notre ère affleurent. Les niveaux antérieurs au milieu du $I^{\text {er }} s$. n'ayant pas été atteints, nous considérerons provisoirement la phase 1 , datée du milieu du $\mathrm{I}^{\text {er }} s$. av. notre ère comme la phase la plus ancienne mise en évidence.

\section{Phase 1 - Structures primitives (vers 50 avant notre ère)}

Une première phase architecturale a pu être appréhendée : la position stratigraphique des structures (sous les niveaux de sols de la phase 2) et leur orientation non conforme à l'organisation générale nord/sud du site confirmant leur ancienneté. Il s'agit de deux murs parallèleș (MR 18 et 19) et d'un mur circulaire (MR 15). Contre le mur 19, côté est, un foyer composé d'une tegula fortement rubéfiée mesure $62 \mathrm{~cm}$ sur $47 \mathrm{~cm}$. 
Le mur 15 correspond à une structure circulaire dont la fonction reste inconnue. La fouille effectuée à l'intérieur a montré qu'il s'agit déjà d'une fondation conservée sur $0,50 \mathrm{~m}$ d'épaisseur environ. Le comblement, composé de niveaux de pierraille et d'argile, n'apporte pas d'éléments pour la compréhension de cette structure.

Le mobilier recueilli n'est pas abondant car les niveaux de cette phase ont été peu fouillés. On trouve essentiellement des fragments d'amphores italiques, de parois fines et de campaniennes qui nous situent vers le milieu du $I^{\text {er }}$ siècle avant notre ère.

\section{Phase 2 - Nouvelle phase de construction (deuxième moitié du $\mathrm{I}^{\text {er }} s$. av. notre ère)}

La plupart des sols dégagés sur la totalité de la zone 3 et en partie sur la zone 4 recouvrent les structures précédentes. Ils se composent différemment selon les secteurs : mortier, terre mélangé à du mortier ou pierres calcaires en décomposition. Ces dernières donnent un aspect très jaune et sableux et se retrouvent en partie dans le secteur 1 et autour de l'aménagement en grand appareil qui caractérise cette phase.

La fouille n'a pas entamé le sol à l'intérieur cette imposante structure. Nous avons cependant procédé à un sondage à l'extérieur. La fouille des différentes couches n'a été que ponctuelle et a révélé du matériel qui semble correspondre à la seconde moitié du $\mathrm{I}^{\mathrm{er}} \mathrm{s}$. av. notre ère. On notera une rupture de niveau matérialisée par les murs 7 et 6 . En effet les sols se retrouvent à $0,40 \mathrm{~m}$ d'écart de part et d'autre de cet axe ouest/est. Pour la construction en grand appareil cette différence correspond aux sols des parties internes et externes.

\section{Phase 3 - Construction des " annexes " (époque augustéenne)}

- Phase 3A-Destruction : Un niveau de destruction recouvre la totalité de la zone 3 et une partie des zones 2 et 4. Cette couche, de 0,40 m d'épaisseur environ, se caractérise par sa structure argileuse et de nombreuses inclusions de couleurs différentes. On peut distinguer les fragments d'adobes provenant de la destruction de structures en matériaux légers; le matériel découvert est homogène, les quelques fragments de sigillées italiques permettant de dater l'ensemble de l'époque augustéenne.

- Phase 3B - Nouvelle phase de construction : les niveaux de destruction sont coupés par les tranchées de fondation des murs 6 . Les murs 6 et 10 s'appuient sur l'aménagement en grand appareil puisqu'ils viennent tout deux déborder sur les premières assises, ce qui indique que les élévations de l'édifice ont servi de support à de nouveaux bâtiments. Les murs en grand appareil (murs 8 et 20) vont alors être cachés en partie par cette nouvelle construction, confirmant ainsi sa postériorité.

Les sols en relation avec ces structures ne sont pas conservés, ce qui nous prive d'éléments de datation pour cette nouvelle phase. Cette dernière succède à la phase de démolition (phase 3), et correspond à une nouvelle phase de construction. Elle se caractérise par de nouvelles structures en dur s'accolant à l'édifice.

Il est possible qu'au même moment l'hypocauste soit créé. Notons en effet que les fragments de pilettes pourraient appartenir, par leurs dimensions, au début du $\mathrm{I}^{\text {er }}$ s. de notre ère (information orale G. Fédière).

\section{Phase 4 - Fonctionnement}

(Haut-Empire et Antiquité tardive)

La phase $4 \mathrm{~A}$ correspondant au Haut-Empire est peu représentée. Seule la fosse 3023, contenant des fragments de sigillées sud-gauloise, témoigne de ce moment de l'occupation du site. L'absence de ces niveaux s'explique par des aménagements en terrasse et l'arasement du site.

On atteint en effet directement dans la zone 3 des niveaux $\mathrm{du}^{\mathrm{er}} \mathrm{s}$. av. notre ère; au sud de la zone 4 ainsi que dans la zone 2, la fouille s'est concentrée sur des vestiges abandonnés durant l'Antiquité tardive.

La phase $4 \mathrm{~B}$ est difficile à appréhender. Les niveaux sont mieux conservés au sud : les secteurs 7 et 9 ont permis de dégager des structures appartenant à la phase 4. Il s'agit des niveaux de l'hypocauste et du mur en abside (MR 11). Reste à vérifier si le mur 3, supportant la canalisation en tegulae, a fonctionné avec cet ensemble qui peut appartenir à une zone thermale. Les datations s'échelonnnent entre le $\mathrm{III}^{\mathrm{e}}$ et le $\mathrm{V}^{\mathrm{e}} \mathrm{s}$. de notre ère.

\section{Phase 5 - Restructuration (Antiquité tardive ?)}

Le démantèlement du monument, matérialisé par la présence de blocs cassés à même le sol, a lieu à une époque indéterminée. La récupération de blocs pour les piliers de la pièce du secteur 3 témoigne d'un réemploi des vestiges et d'une restructuration des " annexes ". C'est sans doute au même moment que l'on reconstruit sur les blocs arra- 
chés avec des matériaux légers (des briques crues sont encore en place sur le mur 20).

\section{Phase 6 - Destruction ( $V^{e}-V^{e}$ s. de notre ère)}

Le mur à pans de bois du secteur 1 constitue l'un des éléments les mieux conservés du site. La surface couverte par cette démolition et son état de conservation en font une découverte majeure pour l'étude des constructions en bois et en terre d'époque romaine. Outre l'analyse des modules des briques crues, leur agencement, des éléments d'accrochage en fer ont également été dégagés et devront être étudiés. L'abandon de ces structures durant l'Antiquité tardive permet de connaître les dernières phases d'activité d'un site qui semble profondément remodelé depuis sa création.

\section{Phase 7 - Occupation médiévale (IX' $-\mathrm{XI}^{\mathrm{e}} \mathrm{s}_{\text {. }}$ )}

L'occupation médiévale a fortement perturbé les niveaux antiques, à l'image du silo 3025 et de la fosse 2004 qui sont profonds $(0,75 \mathrm{~m}$ pour l'une, $1 \mathrm{~m}$ pour l'autre). Leur comblement est riche en mobilier mêlé à de la cendre. On observe de nombreux fragments de vases en céramique grise dont les recollages montrent qu'ils ont été jetés quasiment complets. Il s'agit essentiellement d'urnes à bord simple très déversé et portant des traces de feu. La faune est aussi bien représentée. Des restes de bovidés et d'équidés sont nombreux dans la fosse 2004, tout comme des fragments de coquillages, en particulier de moules.

La durée d'occupation du site a pu être revue, la présence d'urne à bandeau de type Cathma 6a montre un abandon au cours du VI $s$. ap. notre ère. La découverte de fosses comblées avec des céramiques communes à bec ponté atteste une fréquentation du site durant le Moyen Âge.

\section{ORGANISATION GÉNÉRALE}

\section{Des aménagements en terrasse}

Un des apports de cette fouille a été la mise en évidence d'une stratigraphie complexe due à des aménagements en terrasse. $\mathrm{Du}$ point de vue chronologique, les niveaux archéologiques situés au nord de la parcelle correspondent au I ${ }^{\text {er }}$ s. av. notre ère, tandis que vers le sud, les couches de l'Antiquité tardive affleurent. La majeure partie de la zone 3, jusqu'au mur 6 , dispose d'un état de conservation égal, puisque le niveau de destruction se retrouve de façon homogène $(0,30 \mathrm{~m}$ au-dessus du point 0$)$. Les murs $14 \mathrm{ou}$ 16 doivent servir de murs de terrasse puisque des niveaux de l'Antiquité tardive se retrouvent à $0,75 \mathrm{~m}$ en-dessous du niveau 0 , dans le secteur 7 .

L'approche de l'organisation générale des vestiges est très partielle, si l'on considère l'étendue de la surface explorée par rapport à la superficie du site. Les structures les plus anciennes (phase 1), sont orientées nord-est/sud-ouest, c'est-à-dire dans le sens de la pente naturelle. La construction en grand appareil et toutes les structures qui se succèdent jusqu'à l'Antiquité tardive ont une orientation nord/sud-est/ouest. Le démantèlement du monument et sa réutilisation avec des matériaux en bois et en terre laissent supposer que seuls sont restés les blocs de base de l'édifice, trop imposants pour être prélevés.

\section{Un édifice public?}

La question de la présence d'un édifice de nature indéterminée est soulevée par l'importance des blocs utilisés en position primaire. La technique de construction montre une maîtrise dans la mise en oeuvre du grand appareil mais aussi quelques maladresses (redécoupage des pierres, agencement des blocs sans programme préétabli). Nous sommes donc en présence d'une construction relativement rustique, à caractère monumental. Le recours au grand appareil et certains détails (encoches de positionnement, bossages rustiques) plaideraient pour une datation antérieure au changement d'ère, sans doute vers - 50/- 30 . Cette proposition est confirmée par les niveaux au contact de la construction, fouillés au nord du mur 7 qui forme le seul côté entièrement dégagé, long de 7,60 m.

L'absence d'éléments architecturaux susceptibles d'appartenir à la partie haute du bâtiment nous prive de possibilités de restitution et d'identification. Cette construction de type monumental laisse penser à un édifice public. Dans ce cas, on pourrait supposer, vu l'isolement et sa situation face à l'entrée de l'ancien golfe narbonnais, à un sanctuaire. Cependant aucune découverte comme des ex-voto ne vient valider cette hypothèse. Sa position géographique est le seul élément permettant d'avancer l'idée d'une tour-phare. Or aucune construction de ce type n'est attestée pour nous permettre des comparaisons. On peut aussi penser que l'aménagement en grand appareil et ses annexes faisaient partie d'un établissement privé, de grandes dimensions. Le site de la Fount de Rome, près de l'Oustalet, commune de Fleury d'Aude, prouve le caractère monumental de certains domaines du littoral, proposant tout un système de terrasses soutenues par de puissants murs en petit appareil, 
munis de contreforts. Sur ce dernier site, toutefois, l'utilisation du grand appareil n'est pas attestée.

On le constate, c'est par la poursuite des fouilles sur ce grand site, et par le dégagement complet de la structure centrale en grand appareil et de ses abords que nous pourrons obtenir des certitudes.

\section{Les structures périphériques}

Exception faite du secteur 1, c'est-à-dire de l'aménagement en grand appareil, l'épaisseur des maçonneries oscille toujours entre 0,50 et $0,60 \mathrm{~m}$. Il faut tenir compte du fait que les structures maçonnées visibles sont arasées et que ce que l'on peut en observer correspond bien souvent aux fondations et non à l'élévation proprement dite. Il faut donc être très prudent si l'on souhaite extrapoler des données concernant l'élévation des murs à partir des seuls vestiges visibles.

Au vu des reprises de construction et de l'adjonction de murs de refend, il est probable que les fondations des différentes maçonneries se situent à des hauteurs différentes :

Cela expliquerait le fait que le mur 1 présente en grande partie un appareil soigné, correspondant au début de l'élévation proprement dite, alors qu'au même niveau, le mur 3 (postérieur) montre une maçonnerie de mauvaise facture constituant ses fondations (le sol d'occupation contemporain aurait disparu lors des charruages répétés). Les murs 6 , 2, 9 ct 1 font partic de la même réorganisation car il sont liés entre eux. Cet aménagement est daté entre - 10/30 par les observations faites sur la coupe sud du secteur 4 (les tessons prélevés dans la tranchée de fondation du mur 1 appartiendraient à cette période) et sur les niveaux des zones 2 et 3 . Les éléments de datation sont donc peu nombreux et sujets à caution.

Une petite pièce (secteur 2 ; largeur $1,50 \mathrm{~m}$, longueur indéterminée) est accolée au dispositif en grand appareil.

Nous ne disposons pas pour l'instant des relations avec les murs 12,16 et 11 seulement observés dans la tranchée, sans liaison avec d'autres structures.

On peut dire qu'après l'édification d'un bâtiment (de type public ?) très vite des aménagements périphériques ont été construits. Jusque dans l'Antiquité tardive, le site connaît de nombreux remaniements que nous ne pouvons réellement identifier sans une fouille extensive.

\section{INTERPRETATIONS ET DIFFERENTES QUESTIONS SOULEVEES} PAR LES FOUILLES 1999

Par sa durée d'occupation, sa position géographique et la particularité de ses structures, le site de Saint-Martin permet d'aborder différentes questions régionales.

\section{Un antique établissement littoral}

La création d'un établissement de la fin du $\mathrm{II}^{\mathrm{e}}$-début du $\mathrm{I}^{\text {er }}$ s. av. notre ère ${ }^{20}$, peut-être voué à l'exploitation des ressources d'un vaste terroir agricole, pose des problèmes par manque d'éléments de comparaisons, peu d'habitats antiques littoraux ayant été fouillés ${ }^{21}$. Concernant la première phase reconnue, les éléments architecturaux se caractérisent par la présence d'une structure circulaire (MR 15) en correspondance avec deux murs parallèles et une plaque-foyer sur tegulae. Il est pour l'instant difficile d'expliquer l'existence de bâtiments aux orientations distinctes de celles des constructions plus récentes. Peut-on considérer ces modifications architecturales comme l'indice d'un changement de statut?

C'est bien entendu la présence d'un édifice imposant qui fait la spécificité du site. Par sa position assez centrale au vu de son étendue supposée, il s'agit d'une construction majeure dans l'organisation architecturale, puisqu'elle donnera une nouvelle orientation aux structures. C'est visiblement durant l'époque augustéenne qu'elle sert d'appui à de nouvelles constructions. On est donc en présence de modifications importantes qui ont lieu dans un intervalle de temps réduit. La mise au jour d'une partie thermale pourrait confirmer que ce secteur correspond à une pars urbana. Lisolement du lieu restreint l'interprétation : lieu de culte, bâtiment privé à caractère monumental ? Nous ne disposons pas encore d'assez d'éléments pour valider l'hypothèse d'un monument public, aucun édifice rural n'étant connu dans la

(20) Il faut malheureusement constater, bien que la question des établissements créés en Narbonnais au cours des II II $^{\mathrm{er}} \mathrm{s}$. av. J.-C. soir appréhendée par les données de prospection, qu'aucun site de cette époque n'a été fouillé. Concernant Saint-Martin, les aménagements en terrasse et la mise en culture font que les niveaux anciens sont affleurants dans la partie nord de la parcelle. L'épaisseur de la couche archéologique conservée dans la partie sud ne permettra pas de saisir les niveaux anciens avant plusieurs années de fouilles.

(21) Sur le littoral narbonnais, signalons le proche site des Carrières à Peyriac de Mer : il a fait l'objet de fouilles révélant l'existence d'une " cave " attaché à un établissement à occupation courte (Solier 1982 et 1987). Voir aussi la Fount de Rome à l'Oustalet (Fleury d'Aude) et les Arènes à Bages. 
région narbonnaise. Faut-il rattacher cette construction au système portuaire ? Et dans ce cas quelle fonction lui attribuer ? On peut alors proposer une comparaison avec la structure quadrangulaire de $10 \mathrm{~m} \times 9,50 \mathrm{~m}$, recouverte de mortier hydraulique, de Tintaine-le-Haut (Solier 1981, p.11). Selon Y. Solier, "l'épaisseur des parois et la présence de contreforts trahissent un édifice élevé, dont il serait intéressant de préciser la destination ". Dans le cas de SaintMartin, nous avons également affaire à un bâtiment atypique sur un site considéré comme un des ports de Narbonne antique. La fonction à donner à ce monument reste donc ouverte : tour-phare, édifice cultuel, mausolée?

Il reste cependant à obtenir une idée plus globale de l'étendue du site pour le caractériser. Les nombreux fragments de dolia ainsi que de tuiles surcuites (à l'extrémité nord-est) observés dans la parcelle voisine montrent qu'il s'agit d'un secteur artisanal et agricole aux activités diversifiées. Il faur remarquer la présence de trois fragments de tegulae découverts en 1999 et portant les estampilles (T.FADI).LICINI (les trois dernières lettres liées) ${ }^{22}$. Sur une des tegulae probables, la "couverte " de la partie de l'avers présente des défectuosités dues à la fabrication, à la cuisson ou à une autre raison, peut-elle être considérée comme un raté de cuisson, bien que ce matériau ait été apparemment vendable? On ne peut pour l'instant relier cette production à la dizaine de tuiles estampillées au nom de la gens FADIA, trouvées sur le même site par $\mathrm{G}$. Fédière lors de recherches en surface. Une carte de répartition de cette marque permettrait d'avoir une idée plus précise de sa zone de production. Notons qu'un membre de la gens FADIA, Sextius Fadius Secundus Musa est considéré comme naviculaire, à cause des tituli sur amphores à son nom trouvées au Monte Testaccio (Gayraud 1981, p. 342 et 532).

Mais la véritable originalité du site de Saint-Martin réside dans sa position géographique : à la croisée de la terre, de la lagune et de la mer, dans une zone propice au développement économique, il dispose ainsi d'atouts indéniables susceptibles d'en faire un site de référence du littoral narbonnais ${ }^{23}$.

\section{Quelle relation avec le système portuaire narbonnais?}

Le site de Saint-Martin constitue-t-il un avant-port de Narbonne ? C'est ce que tendent à accepter la plupart des

(22) Lecture et observations de G. Fédière que nous tenons à remercier.

(23) Ajoutons à cela la proximité de la cité de Narbonne, capitale de province, dont le rôle de carrefour économique n'est plus à démontrer. chercheurs ayant travaillé sur cette question. Ainsi, M. Gayraud admet une fréquentation du port de Saint-Martin depuis la période républicaine jusqu'au Haut-Empire. C'est au Haut-Empire en effet que, suite à l'abandon du port de La Nautique, le port de Saint-Martin aurait pris selon lui une nouvelle impulsion :

" Ainsi au III et au IV s. se dessine une nouvelle carte des ports de Narbonne. Le débarcadère de Saint-Martin sur l'étang de l'Ayrolle, qui avait végété depuis le ler s. av. J.-C., se développe. Proche du grau de la Vieille Nouvelle et même de celui du Grazel qui entre en activité au IVe s., nullement gêné par l'Ardillon, il reçoit alors une grande partie du trafic détourné de la Nautique. La crique est bordée de ruines importantes. Au lieu-dit le Vieux Château s'étend un long bâtiment de $35 \mathrm{~m}$ sur $20 \mathrm{~m}$ dont les murs sont en blocage recouvert de briques, que l'on pourrait dater, peut-être du IVe s. Le port, à l'ouest de cet habitat, en face du tènement de l'Éve̊que, a été repéré par la photographie aérienne qui montre des traces de bassin et de digues " (Gayraud 1981, p. 527).

A la recherche d'un port ayant succédé à la Nautique, Y. Solier envisage le port de l'île Saint-Martin dans la crique sud de l'île :

" abritée des vents du nord et tournée vers le débouché des graus de Vieille Nouvelle et de La Nouvelle dans l'étang, elle offre des céramiques éparpillées sur la plage et les ruines d'un habitat (mur en petit appareil régulier et vestiges d'une grande citerne appelée le Vieux Château). De plus, la photographie aérienne montre à l'emplacement de la crique des traces sans rapport avec la topographie actuelle délimitant un bassin. II est très vraisemblable que ce site a servi de cadre à une installation portuaire, mais nous ne saurions affirmer, étant donné la superficie relativement réduite de l'habitat et la faible quantité de céramiques qu'on y découvre actuellement s'il s'agit réellement d'un avant-port ou d'un débarcadère privé. Le port commercial éventuel devait recevoir principalement les navires venus de la péninsule ibérique, qui pouvaient entrer directement dans l'étang par les graus de La Nouvelle. " (Solier 1981, p. 260).

Toutes ces affirmations reposent sur des hypothèses liées à des impressions de terrain ${ }^{24}$, et à la position géographique

(24) Un autre fait mérite d'être signalé, outre les données de prospection qui attestent une céramique abondante sur la plage : la découverte d'un clou riveté récolté par $\mathrm{G}$. Fédière (clous à courte pointe acérée, à tête plate munie au revers de protubérances régulièrement disposées qui connaissent un usage spécifique dans le cadre de la protection des coques des bateaux par des plaques de plomb). 
de cette zone proche du grau de la Vieille Nouvelle dont Y. Solier souligne la fréquentation maritime durant toute l'Antiquité. Si un port a existé en relation avec ces deux grands centres d'habitats que sont l'Évêque et SaintMartin-le-Bas de part et d'autre de la crique, il devait s'agir d'un port privé bien plus que d'un port de commerce.

\section{L'exploitation des ressources naturelles maritimes}

La proximité de la mer et des étangs fait du site archéologique de Saint-Martin un espace privilégié pour l'exploitation des ressources maritimes, destinées à la consommation locale et peut-être à la commercialisation. Il faut en effet souligner le réel potentiel de cette région du littoral narbonnais, très proche de la mer, riche en salines, en poissons et en coquillages marins.

Dans le domaine alimentaire, le sel ${ }^{25}$ occupe dans la région narbonnaise une place plutôt ambiguë : les vestiges archéologiques attestant une exploitation ou une consommation de sel de type antique sont fort rares ${ }^{26}$. Néanmoins, plusieurs éléments peuvent non seulement attester la consommation, mais aussi la production importante de sel dans la région durant l'Antiquité ${ }^{27}$. Le seul véritable vestige attestant l'exploitation antique du sel dans la région correspond à une épitaphe d'un saunier (salinator) trouvée aux environs de la campagne d'Estarac, commune de Bages. Sidoine Apollinaire mentionne bien des salines entre les îles et les étangs de Narbonne, mais leur localisation demeure difficile à préciser.

L'existence de salines à Saint-Martin n'est pas attestée avant le XIX ${ }^{\mathrm{e}}$ siècle ; elles étaient pourtant déjà nombreuses dans la région dès le VIII' ${ }^{e}$. Qui plus est, le site se trouve en bordure de la lagune, non loin du grau de la Vieille Nouvelle : les graus sont des lieux propices, riches en éléments nutritifs et à fort courant, donc favorables au passage des bancs de poissons (cf. Stenberg 1989). Les bassins ont été considérés comme liés au conditionnement des produits de la pêche tels les salaisons ou le garum (Dellong 1999). Cette hypothèse n'est pas à exclure même si le type

(25) $\mathrm{Ce}$ « sel produit constant des marais salants du littoral, nécessaire à la nourriture des hommes et du bétail, aux usages industriels (tannage) et aux salaisons de poisson qui en dépendent ", (Benoit, 1959).

(26) Peut-être faut-il lier cette rareté de vestiges à l'absence, dans une exploitation saline, d'infrastructures durables.

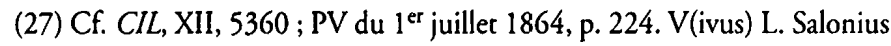
L.P.L(ibertus) / Buccio sibi et / (obito) L. Salonio L.P.L(iberto) / Hilaro salinatori. de construction dégagée, de manière partielle il est vrai, s'apparente plus, comme nous l'avons vu, à des citernes d'eau douce. On explique pourtant mal leur emplacement topographique vu leur distance par rapport aux autres vestiges mis au jour. En vérité, l'état d'avancement des investigations archéologiques ne permet ni de confirmer, ni $\mathrm{d}^{\prime}$ infirmer cette hypothèse ${ }^{28}$.

Les coquillages retrouvés en cours de fouilles sont là pour témoigner d'une forme d'exploitation de la lagune. Les problématiques de recherches nous avaient incités à procéder à une étude préliminaire des coquillages marins présents sur le site 29 .

Vues les conditions de l'étude, il n'a pas été possible d'isoler dans chaque US, le " nombre minimum d'individus " (NMI). Aussi avons-nous considéré conjointement le nombre de fragments de coquillages observés ${ }^{30}$ ainsi que le NMI provisoire. La prise en compte des NMI n'a été réalisée que lorsque nous avions affaire à des ensembles clos significatifs : tel a été le cas dans l'US 2004 et l'US 2017, deux fosses datées respectivement du Moyen Âge et de l'Antiquité. On remarque l'importante quantité de moules concassées mises au jour dans les niveaux du $\mathrm{VI}^{\mathrm{e}}$ s. et du Moyen Âge.

(28) Une chose est sûre : la consommation de poissons est attestée sur le site par la présence d'écailles de poissons, d'ossements caractéristiques de muges, raies...

(29) Les intérêts d'une telle étude ne sont plus à démontrer (Poitevin, 1992, p. 126) : elle permet entre autre, de mieux connaître le biotope dans lequel ont vécu les espèces en décelant notamment un certain nombre de critères concernant la nature du sol (sable, vase ou rocher), la profondeur relative des fonds marins, la présence de courants plus ou moins violents ou le degré de salinité du milieu dans lequel ont été prélevés les coquillages. Il faut aussi, au préalable, se demander si les coquillages récoltés sont tous issus de la consommation humaine. Plusieurs cas de figure peuvent en effet se présenter : il peuvent être le fait d'un ramassage volontaire destinés soit à la consommation alimentaire, soit à une toute autre utilisation (utilisation ou réutilisation après consommation dans la construction par exemple...) soit involontaire (ils ont pu, par exemple, être déposés là avec un filet sur lequel ils s'étaient accrochés, ou ramenés avec une grappe de moule ou un naissain d'huîtres). Se pose aussi la question du stockage des coquillages après consommation : "Sauf dans le cas des moules assez facilement concassées, les coquilles séparées, difficilement réemboîtables, restent coupantes et mal odorantes, et, par quelques restes de chair conservés au point d'ancrage du muscle adducteur, vite en putréfaction, attirent insectes et petits carnivores nuisibles. La question du stockage des coquillages, après ingestion, se pose donc rapidement au consommateur. " Poitevin 1992, p. 125. Quant aux méthodes d'analyse des restes conchylicoles, elles ont été pratiquées et exposées par F. Brien Poitevin en 1992 (cf. Poitevin, 1992, p. 126).

(30) Soulignons d'ores et déjà que les coquillages pris dans le mortier n'ont pas été pris en considération. 
Parmi les restes fauniques récoltés, les coquillages représentent une large part de la consommation puisque sur un total de 2928 fragments de restes fauniques, 1605 correspondent à des coquillages ${ }^{31}$ (contre 1323 ossements), ce qui tend à souligner l'importance des produits de la lagune dans l'alimentation des habitants. Dans l'ensemble, les espèces de coquillages rencontrées sur le site de SaintMartin sont peu diversifiées, 14 types étant représentés.

L'analyse globale des taxons suggère un certain nombre de caractéristiques : l'abondance d'un premier groupe caractérisé par l'association moules-huîtres et petites coques (toutes périodes confondues), l'existence de coquillages intermédiaires (vraisemblablement consommés) parfois en quantité non négligeable, des coquillages moins abondants et qui pour certains peuvent ne pas provenir d'une consommation alimentaire (fig. 34).

Assiste-t-on à des différences notables en fonction des périodes reconnues? Y a-t-il des associations de coquillages à des périodes données ? Correspondent-elles à des changements de goût liés à des modes alimentaires ou témoignent-elles d'un changement du milieu ?

Au terme du mois de juin 1999, la fouille du site de Saint-Martin a permis de dégager plusieurs ensembles clos, fosses ou silos, dans lesquels avaient été jetés pèle-mêle des déchets. Ces faits permettent d'avoir une vue d'ensemble des produits consommés sur le site ou à proximité lors des différentes périodes de son occupation :

\section{Une fosseldépotoir du Haut Moyen Âge FS 2004}

Cette unité stratigraphique correspond à un vaste dépotoir archéologiquement homogène et non altéré dans ses couches superficielles, constitué de coquillages et d'ossements, comblé semble-t- il rapidement aux alentours des $\mid X^{e}-X^{e} s$.

Trois groupes distincts de coquillages sont ici perceptibles : le premier groupe associe la moule, l'huitre et la petite coque avec une nette supériorité des moules. Un groupe intermédiaire comprenant des coquillages vraisemblablement consommés associant bivalves (coquille St-Jacques, amande de mer) et mollusques (nasse, cérithe). S'agit-il d'une consommation d'appoint ? Un dernier groupe est constitué de coquillages rares : murex, grosse coque (1 seul exemplaire).

Les cérithes ont-ils été consommés ? Le cas du Cerithium vulgatum est particulier. II s'agit d'un mollusque vivant dans les

(31) Sur ces 1605 fragments, 137 présentaient des traces de mortier. algues et dont la coquille est très souvent récupérée par le pagure ou bernard-I'ermite. Selon F. Poitevin, le bernard-l'ermite a un caractère alimentaire certain " même s'il n'est plus consommé de nos jours, avec une fine saveur de crabe. Mais il est aussi un excellent appât pour les dorades, sars ou labres (...) Il est difficile de trancher sur la cause de son arrivée sur un site : alimentaire ou appât (...) ", Poitevin 1992, p. 129. II pourrait aussi s'agir de triages de pêche.

Cette impression de consommation strictement alimentaire des coquillages de l'US 2004 se confirme lorsqu'on observe les dimensions des coquilles (fig. 35) : elles suggèrent que les coquillages ont été choisis pour leurs dimensions ${ }^{32}$ " normales ".

\section{Un dépotoir d'huîtres du Bas-Empire (FS 2017)}

L'US 2017 correspond, elle aussi, à une fosse comblée, si l'on en croit le mobilier retrouvé, au IVe-Ve $s$. de notre ère. Son comblement a été vraisemblablement rapide avec des déchets culinaires quasi-exclusivement constitués de coquillages et de céramiques.

Cette fosse se signale par le manque de diversité des taxons rencontrés (fig. 36 et 37), puisque seulement 6 espèces sont représentées avec une majorité écrasante d'huîtres ${ }^{33}$ (243fr.). Parallèlement à cette supériorité numérique de l'huître, on note l'absence totale de moules. L'association huître-petite coque-amande de mer est certaine. De nombreux échantillons mesurés soulignent un ramassage sélectif.

Deux fosses, deux dépotoirs dans lesquels ont été jetés rebuts culinaires et céramique brisée mais à des époques radicalement différentes. Ainsi, au Moyen Âge on note l'association moule-huître-petite coque, la part des moules étant largement majoritaire. II ne fait de plus aucun doute que les coquillages aient été consommés.

$\mathrm{Au}$ Ve s. la situation paraît différente puisque I'US 2017 est marquée par l'abondance des coquilles d'huîtres.

Comment expliquer un telle évolution depuis le $V^{e} s$. jusqu'au Moyen Âge ? A-t-on affaire à un changement de goût alimentaire ou à une fluctuation du biotope marin ? Les espèces rencontrées tant dans I'US 2004 que dans I'US 2017 se retrouvent uniformément. Cette constance des taxons durant près d'un millénaire suggère donc une régularité du milieu marin probablement liée à la proximité d'un milieu de transition entre la pleine mer et les étangs. Elle témoigne en tout cas d'une exploitation continue de la lagune.

(32) Ce qui souligne au passage la préférence alimentaire pour l'abondance de la chair.

(33) Certaines étaient encore en naissain lorsqu'elles ont été ramassées, ce qui souligne leur abondance à cetre époque dans la lagune toute proche. 


\begin{tabular}{|c|c|c|c|c|c|c|c|}
\hline Bivalves & & US (1): & 2004 & $2017 b$ & 2017 & & $\mathrm{G} / \mathrm{D}$ total \\
\hline Cardium paucicostatum & Petite coque & G & 15 & 5 & 7 & $\mathrm{G} / \mathrm{D}$ & 143 \\
\hline (Sauv 1879) & & $\mathrm{D}$ & & 10 & 5 & & \\
\hline Chlamys varialProteopecten & Peigne & G & - & 1 & 1 & $\mathrm{G} / \mathrm{D}$ & 3 \\
\hline glaber (Linné 1758) & & D & - & - & - & & \\
\hline \multirow[t]{2}{*}{ Ensis ensis (Linné 1758) } & Couteau & G & - & - & - & G/D & 1 \\
\hline & & $\mathrm{D}$ & - & - & - & & \\
\hline Glycimeris glycimeris & Amande de mer & G & 23 & 3 & - & $\mathrm{G} / \mathrm{D}$ & 63 \\
\hline (Linné 1758) & & $\mathrm{D}$ & - & 2 & - & & \\
\hline Cerastoderma edule & Grosse coque & G & 1 & - & - & G/D & 34 \\
\hline $\begin{array}{l}\text { (Linné 1758)/Acanthocardia } \\
\text { aculeta (Linné 1758) (2) }\end{array}$ & & $\mathrm{D}$ & - & - & - & & \\
\hline \multirow[t]{2}{*}{ Patella depressa } & Patelle & G & & 1 & - & $-G / D$ & 5 \\
\hline & & $\mathrm{D}$ & - & - & - & & \\
\hline Pecten jacobaeus & Coquille & G & 3 & 1 & - & $\mathrm{G} / \mathrm{D}$ & 18 \\
\hline (Linné 1758) & St-Jacques & $\mathrm{D}$ & 8 & - & - & & \\
\hline Tellina pulchella & Telline & G & - & - & - & $\mathrm{G} / \mathrm{D}$ & 2 \\
\hline (Lamarck 1818) & & $\mathrm{D}$ & - & - & - & & \\
\hline \multirow[t]{2}{*}{ Ostrea edulis (Linné 1758) } & Huître & G & 44 & 109 & 13 & $\mathrm{G} / \mathrm{D}$ & 270 \\
\hline & & $\mathrm{D}$ & 41 & 113 & 10 & & \\
\hline Mytillus galloprovincialis & Moule & G & 80 & - & - & $\mathrm{G} / \mathrm{D}$ & 268 \\
\hline (Lamarck 1819) & & $\mathrm{D}$ & 100 & - & - & & \\
\hline Total valves & & & & & 599 & & 807 \\
\hline
\end{tabular}

Mollusques

Cerithium (thercium)

vulgatum (Brugière 1789)

Onecevra (ocenebra)

ereinacea (Linné 1758)

Murex bradaris (Linné 1758)

Nassarius incrassata

(Storn 1867)

Total

\section{Cérithe}

7

Perce huître

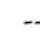

Murex

$$
-1
$$

Nasse
4

3

Fig. 34. Inventaire et détermination des restes conchyliologiques.

Certaines espèces observées témoignent de biotopes particuliers qu'il convient ici de décrire plus précisément : d'une part des fonds de faible profondeur, la mer libre d'autre part, mais aussi un biotope intermédiaire caractérisé par l'apport d'eau douce. Les fonds de faible profondeur pourraient ainsi être définis par la masse des moules et la présence de coques (cf. US 2017) : les moules vivent en grappe à faible profondeur sur des points d'ancrage et peuvent rester quelques heures sur des fonds sableux ou sablonovaseux. Quant à la coque, elle affectionne particulièrement les fonds détritiques, vivant à faible profondeur dans des eaux calmes. Il serait intéressant ici de distinguer les autres variantes de cette espèce, notamment la cerastoderma edule variante lamarki (Reeve) à coquille colorée qui témoigne, comme le souligne F. Poitevin, de la déssalure du biotope. Ces fonds de faible profondeur sont encore aujourd'hui ceux de l'étang de Campignol.

La mer libre est aussi représentée par les amandes de mer et la grosse coque. Lamande vit dans des sables gros- 


\begin{tabular}{lccc}
\hline Classes (en mm) & Moules & Coquilles St-Jacques & Huîtres \\
\hline $0-300$ & 1 & 4 & - \\
$300-500$ & 10 & 1 & 7 \\
$500-700$ & 51 & 1 & 20 \\
$700-900$ & 18 & 1 & 15 \\
$900-1100$ & 3 & - & 2 \\
\hline
\end{tabular}

Fig. 35. US 2004. Hauteur des valves (sup. et inf.).

siers tandis que la grosse coque préfere le sable fin. Ces coquillages n'ont pu être ramassés qu'à proximité d'un cordon littoral, côté mer et non côté étang. Un autre milieu est perceptible, milieu de transition, caractérisé par l'apport d'eau douce. Il s'agit de la biocénose à algues photophiles pouvant avoir un degré de dessalure dû à la résurgence d'eaux douces (on pense bien évidemment ici au débouché de l'Aude) : c'est la moulière, telle que l'on peut encore l'observer dans les étangs à proximité de l'île de l'Aute, île proche du débouché de la Berre.

Les huîtres aussi vivent sur des fonds détritiques près des estuaires et des fleuves côtiers ; elles se fixent sur un substrat rocheux, de galets, coquilles, épaves et autres débris tapissant le fond. Notons enfin que la présence de peignes induit celle d'étangs et de littoraux saumâtres tandis que le murex vit en haute mer ou dans des graus (proximité du grau de la Vieille Nouvelle).

Un certain nombre de jalons sont donc ici clairement posés : l'enjeu est de taille puisqu'il s'agit à terme, tout en distinguant des biotopes différents, d'établir une chronologie de leurs changements. Une telle perspective entraîne bien évidemment des questions : proximité d'un débouché potentiel du fleuve Aude à une certaine période, datation de la formation du cordon littoral, présence d'un grau. Nous ne pouvons malheureusement pas établir de chronologie, compte tenu du fait que nous ne disposons pas d'assez d'échantillons. Seule la suite des fouilles et la pratique d'analyses plus fines liées tant à des analyses géologiques qu'ichtyologiques, permettraient de mettre clairement en évidence des évolutions du milieu marin. Des tendances ont pu être soulignées et des évolutions simplement suggérées : l'importance des coquillages dans la part d'alimentation des habitants, l'évolution des goûts alimentaires, l'existence de biotopes variés mais constants au fil des périodes

\begin{tabular}{|c|c|c|c|c|c|c|}
\hline Bivalves & & US : & 2004 & $2017 b$ & $2017 a$ & 2017 \\
\hline \multirow{2}{*}{ Cardium paucicostatum (Sau 1839) } & \multirow[t]{2}{*}{ Petite coque } & NMI a & 15 & 5 & 7 & 12 \\
\hline & & NMI b & 17,5 & 6,25 & 7,75 & 14 \\
\hline \multirow{2}{*}{$\begin{array}{l}\text { Chlamys varia / Proteopecten glaber } \\
\text { (L. 1766) }\end{array}$} & \multirow[t]{2}{*}{ Peigne } & NMI a & - & 1 & 1 & 2 \\
\hline & & NMI b & - & - & - & - \\
\hline \multirow[t]{2}{*}{ Ensis ensis (Linné 1758) } & \multirow[t]{2}{*}{ Couteau } & NMI a & - & - & - & - \\
\hline & & NMI b & - & - & - & - \\
\hline \multirow[t]{2}{*}{ Glycimeris glycimeris (L. 1767) } & \multirow[t]{2}{*}{ Amande de mer } & NMI a & 23 & 3 & - & 3 \\
\hline & & NMI b & - & 3,5 & - & 3,5 \\
\hline \multirow[t]{2}{*}{ Cerastoderma edule (L 1767) } & \multirow[t]{2}{*}{ Grosse coque } & NMI a & 1 & - & - & - \\
\hline & & NMI b & - & - & - & - \\
\hline \multirow[t]{2}{*}{ Patella depressa } & \multirow[t]{2}{*}{ Patelle } & NMI a & 1 & - & - & - \\
\hline & & NMI b & - & - & - & - \\
\hline \multirow[t]{2}{*}{ Pecten jacobaeus (L. 1758) } & \multirow[t]{2}{*}{ Coquille St-Jacques } & NMI a & 8 & 1 & - & 1 \\
\hline & & NMI b & 8,75 & - & - & - \\
\hline \multirow[t]{2}{*}{ Tellina pulchella } & \multirow[t]{2}{*}{ Telline } & NMI a & - & - & - & - \\
\hline & & NMI b & - & - & - & - \\
\hline \multirow[t]{2}{*}{ Ostrea edulis } & \multirow[t]{2}{*}{ Huître } & NMI a & 44 & 113 & 13 & 126 \\
\hline & & NMI b & 54,25 & 140,25 & 15,5 & 155,75 \\
\hline \multirow[t]{2}{*}{ Mytillus galloprovincialis } & \multirow[t]{2}{*}{ Moule } & NMI a & 100 & - & - & - \\
\hline & & NMI b & 105 & - & - & - \\
\hline
\end{tabular}

NMI $\mathrm{a}=$ nombre maximum de valves

$\mathrm{NMI} b=\mathrm{NMI} \mathrm{a}+($ minimum de valves/2).

Fig. 36. FS 2004/FS 2017. Dénombrement des coquilles marines en nombre minimal d'individus (NMI). 


\begin{tabular}{lcc}
\hline Classes (en mm) & Coques & Huîtres \\
\hline $0-300$ & 10 & - \\
$300-500$ & - & 8 \\
$500-700$ & - & 101 \\
$700-900$ & - & 164 \\
$900-1100$ & - & 9 \\
\hline
\end{tabular}

Fig. 37. US 2017. Hauteurs des valves (sup. et inf.).

concernées, le ramassage sélectif des espèces destinées à la consommation. Il faut pourtant insister sur l'importance d'une étude conchyliologique plus fine qui apportera sans doute des données complémentaires à ces premières réflexions.

\section{CONCLUSION}

Lorganisation et la chronologie du site de Saint-Martin-leBas ont pu être précisées lors de la campagne de fouille 1999. La datation de l'aménagement en grand appareil correspondrait à la seconde moitié du $\mathrm{I}^{\mathrm{er}} \mathrm{s}$. av. notre ère. De nouvelles structures ont également été mises au jour : un ensemble de pièces dont la fonction et les datations restent à définir, un hypocauste appartenant certainement à une partie thermale et un mur à pans de bois de la fin de l'Antiquité exceptionnellement bien conservé. Une fréquentation médiévale est également attestée. Considérant le rapport entre la surface explorée et la superficie du site, l'approche de l'organisation générale des vestiges reste partielle mais plusieurs phases de construction ont déjà été mises en évidence. Les structures les plus anciennes (vers - 50), sont orientées nord-est/sud-ouest, suivant le pendage naturel du terrain. La construction en grand appareil vient modifier totalement l'orientation du site (N/S-E/O). Tous les nouveaux aménagements qui se succèdent jusqu'à l'Antiquité tardive garderont cet axe. Cependant, au sud, des bassins montrent l'extension du site vers l'étang sans respecter cette orientation. D'autres vestiges sont affleurants comme un sol en opus spicatum sous le chemin bordant le domaine de Saint-Martin.

Par sa durée d'occupation, sa position géographique et la particularité de ses aménagements, le site de SaintMartin constitue un ensemble complexe, d'autant que sa fonction a pu changer selon les époques. La création de la fin du II ${ }^{\mathrm{e}}$ ou du début du $\mathrm{I}^{\mathrm{er}} \mathrm{s}$. av. notre ère peut laisser supposer qu'il s'agit d'un établissement colonial visant à exploiter les ressources du terroir et de l'étang. La phase précédant la création en grand appareil témoigne d'une occupation déjà importante : une structure circulaire en correspondance avec deux murs parallèles et une plaquefoyer sont les premiers éléments dont nous disposons. La construction en grand appareil tend à prouver que le site de l'île Saint-Martin n'est pas, à la fin du ${ }^{\text {er }} s$. av. notre ère qu'un simple établissement littoral.

Dans la parcelle voisine, les nombreux fragments de dolia, et à l'extrémité nord-est, les tuiles surcuites repérées en surface témoignent de l'existence d'un secteur agricole et artisanal. Il semblerait donc que la construction en grand appareil ait servi d'appui au développement d'un établissement occupé jusqu'à l'Antiquité tardive et au Haut Moyen Âge.

\section{ABRÉVIATIONS BIBLIOGRAPHIQUES}

J.-L. ANDRIEU 1990 - Béziers, l'aqueduc romain, Centre de Recherche d'Histoire Ancienne, 93.

C.-A. de CHAZELLES-GAZZAL 1997 - Les maisons de terre de la Gaule méridionale, Monographie Instrumentum 2, Montagnac.

E. DELLONG 1999 - L'Homme et le littoral narbonnais de l'Antiquité au Moyen Age, mémoire de DEA, Université Toulouse Le Mirail.

J. FABRE 1967 - Rapport de fouilles du site de l'Oustalet-Fount de Rome, année 1967 (commune de Fleury), Arch. SRA Montpellier, 13 p.

J.-M. FALGUERA 1999 - Rapport du sondage n 13-99 Réalisé du 15 au 27-06-1999 Port-La-Nautique, $17 \mathrm{p}$.
M. GAYRAUD 1981 - Narbonne antique des origines à la fin du III $^{e}$ s., RAN, supp. 8, Paris.

J. GUERRE, et L. BUFFAT 1998 - La Gramière (Castillon-du-Gard, 30), rapport de diagnustic, SRA, 29 p.

Ch. GRAULLE 1990 - Sondage 1990 sur le site de Saint-Martin, rapport, $5 \mathrm{p}$.

E. GRIFFE 1974 - Les anciens pays de l'Aude de l'Antiquité et du Moyen Âge, Carcassonne.

M. GUY 1955 - Les ports antiques de Narbonne, R.E.Lig., 21, 3-4, p. $213-240$. 
M. GUY 1987 - Chronologie relative et explication des formes d'anciens rivages d'après leurs images aériennes, Colloques internationaux du CNRS, Déplacements des lignes de rivage en Méditerranée, éditions du CNRS, Paris, p. 45-58.

G. LUGLI 1957 - Tecnica edilizia romana, Rome.

S. MAUNÉ 1988 - Les campagnes de la cité de Béziers dans l'Antiquité (partie nord-orientale), $\mathrm{II}^{\mathrm{c}}$ s. av. J.-C., $\mathrm{VI}^{\mathrm{c}}$ s. ap. J.-C., Montagnac.

Y. SOLIER 1981 - Les épaves de Gruissan, Archaéonautica, 3, p. 8-264

D. PAYA 1988 - Sondage 1988 sur le site de Saint-Martin, rapport, $5 \mathrm{p}$.

Ch. PELLECUER 1995 - La villa des Près-Bas (Loupian, Hérault). Domaine et production agricole dans le territoire de la cité antique de Béziers, in Actes du colloque européen "Cité et territoire ", Béziers 14-16 octobre 1994, Paris, pp 187-194.

V. PERRET 1956 - Le capitole de Narbonne, Gallia, t. 14, p. 1-22.

F. POITEVIN 1992 - Collecte, consommation et réutilisation des coquillages sur le site de Lattes, Lattara 6.
M. PY 1993 - Dicocer, Dictionnaire des céramiques antiques en Méditerranée nord occidentale (Provence, Languedoc, Ampurdan), Lattara 6, Lattes.

M. PY 1995 - Recherches sur l'économie vivrière des Lattarenses, Lattara 5.

C. RAYNAUD 1991 - Amphores et céramiques communes, in Solier (dir.), La basilique paléochrétienne du Clos de la Lombarde, (suppl. 23 à $R A N$ ), Paris, p. 215-234.

Y. SOLIER 1973 - Notes sur les galeries souterraines de Narbonne, in Les cryptoportiques dans l'architecture romaine, MEFRA, 14.

Y. SOLIER 1982 - Fouille de sauvetage à Peyriac de Mer (Aude), lieudit " les Carrières ", 21 p. dact.

Y. SOLIER, J.-M. MASCLA, H. BARBOUTEAU 1987 — La fouille de sauvetage 1987 au lieu-dit « les Carrières » à Peyriac de Mer (11), 21 p. dact.

M. STENBERG 1989 - La consommation du poisson à Lattes (Hérault) III ${ }^{e}-I^{\text {er }}$ s. av. n. è. Méthodes de prélèvement et premiers résultats, Lattara 2, p. 101-120. 